\title{
Sawflies of the Bakony Mountains and the Balaton Uplands (Hymenoptera: Symphyta)
}

\author{
ATtILA HARIS \\ H-1076 Budapest, Garay street 19 2/20, Hungary \\ e-mail: attilaharis@yahoo.com
}

\begin{abstract}
Haris, A.: Sawflies of the Bakony Mountains and the Balaton Uplands (Hymenoptera: Symphyta). Abstract: 358 species are listed from the Bakony Mountains and the Balaton Uplands. Monostegia analis (Konow, 1887) and Pristiphora cincta Newman, 1837 are new records for the Hungarian fauna. Megalodontes laticeps Konow, 1897, Gilpinia laricis (Jurine, 1807), Tenthredo arcuata Förster, 1771, Apethymus cerris (Kollar, 1850), Monostegia cingulata (Konow, 1891), Empria alector Benson, 1938, Cephalcia alpina (Klug, 1808), Nematinus luteus (Panzer, 1805), Nematus brevivalvis Thomson, 1871, Pachynematus montanus (Zaddach, 1883), Pamphilius aurantiacus (Giraud, 1857) are cancelled from the fauna-list of the Bakony Mountains.
\end{abstract}

Keywords: Hymenoptera, Symphyta, Hungary, Bakony, new records

\section{Introduction}

The Bakony is a limestone cliff mountains with an area of about $4000 \mathrm{~km}^{2}$, the westernmost and largest member of the Transdanubian Mountains (Fig. 1).

The Bakony is divided by the west-eastern fracture line between Devecser and Várpalota into two parts: the North Bakony and the South Bakony (Fig. 3 and 4). In broader sense, the Keszthely Plateau (Figs. 7 and 8) and the Balaton Uplands (Figs. 2, 5, 6 and 10) are also part of the Bakony Mts.

The Bakony is dominantly made up of Triassic and Jurassic marine sediments (limestone, dolomite, marl). In its southern areas, volcanic basalt also appears. The present form of the mountains likely formed during the Tertiary period, some 45 million years ago. Its highest peak is the Köris hill with $709 \mathrm{~m}$ altitude above the sea level. There are also 15 strictly protected caves in this region.

The mountain range is perpendicular to the most common, northwestern wind direction. As a result of this, most of the precipitation occurs in the northwestern Bakony area (up to $800 \mathrm{~mm}$ per year in some areas), while the southeast, especially the Veszprém Plateau, is dry (with less than $600 \mathrm{~mm}$ yearly precipitation). The annual average temperature is $8.5^{\circ} \mathrm{C}$ in North Bakony and close to $10^{\circ} \mathrm{C}$ in South Bakony. The slopes overlooking Lake Balaton have Mediterranean influences, making the summer even warmer and the winter even milder.

Almost $84 \%$ of the Bakony Mountains are covered with forests. The area of these forests approximately 140,000 hectares. The main species of hornbeam and beech forests are European ash, sycamore maple and Norway maple, large-leaved linden and small-leaved linden and wild cherry. In the higher elevations we can see Scotch elm, 
sycamore maple and European ash. The pine forests, planted in the last 100 years, are also significant part of the vegetation. Next to Fenyő"o, the pine forest is native. Here, there is a special micro-landscape with low nutrient sandy soil maintaining this special habitat. This is the only one natural pine vegetation in the lower regions of the Carpathian Basin.

\section{Material and methods}

The studied material are deposited in 3 collections. The largest is the Bakony Natural History Museum in Zirc. From this collection, 1938 specimens of 197 species are identified by the author in 2019 and further 5137 specimens of 280 species were checked and reidentified. Further 800 specimens are deposited in the Rippl-Rónai Museum in Kaposvár and approximately 600 specimens in Budapest (Hungarian Natural History Museum).

For identification, ZHELOCHOVTSEV's (1988) work on the sawflies of the European part of the former USSR was consulted. We also used some recent revisions and works to make the identifications even more precise (ACHTERBERG and AARTSEN 1986, BLANK \& Ritzau 1998, Haris 2001, 2006, Haris and Gyurkovics 2014, Koch 1988a and b, Prous 2012, Prous et al. 2017, TAeger 1987, 1988, 2002 and TAeger 2015).

Whenever it was necessarry (subfamily Nematinae and genus Dolerus), male genitals were dissected and studied.

For the discussion of distribution of sawflies, we consulted the book of RoLLER and HARIS (2008) titled Sawflies of the Carpathian Basin, History and Current Research augmented by other faunistic records from the Carpathian Basin (AMBRUs 1979, RoLLER 1999, 2000, Roller et al. 2006, HARIS 2001, 2009, 2010, 2011, 2012, 2018, 2019; HARIS and Gyurkovics 2012, BaLÁzs and Haris 2019).

The places of captures of each species were checked and revised. We completed the missing data, where the relevant locations were not given, but the ones of the meadows, hills or valleys were published only. On the other hand, several indefinite locations can't be given precisely. These locations are discussed below:

Cuha valley (Cuha-völgy). In several cases, the collectors labelled the insects only as Bakony: Cuha valley neglecting to give the exact location. In these cases, we should consider the following: Cuha valley is the valley of the Cuha brook. Its total length is 81 $\mathrm{km}$, the brook flows through the area of the following municipialities: Eplény, Olaszfalu, Zirc, Porva, Bakonyszentlászló, Réde and Bakonybánk.

Gerence-valley (Gerence-völgy). Similar to the case above, it is also an indefinite record resulted by improper labelling of the collectors in the 60's and 70's. Gerence valley is the valley of the Gerence brook. The lenght of this brook is $57 \mathrm{~km}$ and flows through the following municipialities: Bakonybél, Hárskút, Pénzesgyőr, Takácsi and Bakonykoppány.

For the host plants record, the Liston Compendium of European sawflies was the most used monograph (LISTON 1995) augmented with other papers like CHEVIN and HAMON 2010, MACEK 2012, SchedL 1972, 1973, 1975, 1976, 1980, 1983, 1987, 2003.

The higher classification of sawflies applied in this work follows the Hymenoptera part of Fauna Europaea (ACHTERBERG 2013).

Most of the specimens were collected by Sándor Tóth and Jenö Papp. Other collectors were Levente Ábrahám, Attila Haris, Előd Kondorosy, Mária Csiby, Ágota Kasper, Lajos Zombori, Béla Kalivoda, Csaba Kutasi, László Móczár, József Erdős, Zsuzsanna 
Szurgyi, József Bali, Beáta Harmat, Attila Kohanóczy, László Rézbányai, Attila Podlussány and Mrs. Havasi.

Till present, the most important papers on the sawflies fauna of the Bakony Mts. and Balaton Upland is the 4 papers series of Zombori (1973, 1979, 1980 and 1982b), titled: Sawfly collection of the Bakony Natural History Museum I.- IV. In this series, he listed the data of 269 species, and colour variations. The early papers, containing 1-3 records from the Bakony Mts. and the first checklist of sawflies of the Kingdom of Hungary are discussed in details in ZoMBORI 1978b. Beyond the 4 papers monograph of Zombori the following papers contain significant amount of data (100-500 data per each) from the Bakony Mountains and the Balaton Upland: "The sawfly-collection of Somogy County Museum" (HARIs 2001); the "Revisional list of the Hungarian Nematinae" (HARIs 2001); the "Sawflies of the Keszthely Hills and its surroundings" (HARIS 2019); "The genus Tenthredopsis Costa, 1859 in Hungary" (HARIS and GyURKovics 2019) and the monograph, titled "Sawflies of the Carpathian Basin, History and Current Research" (RoLLER and HARIS 2008).

In the faunistic list below, we publish all occurrences of each species in the Bakony Mts. and the Balaton Uplands. Only the checked and revised data are published. In bracket, we indicate the source of these data. At the end of each entry, new records take place. Finally, we provide the frequency of each species and the host plants. For the discussion of the frequency, we use the following categories:

"rare species": less or max 10 specimens were captured in Hungary in the last 160 years.

"sporadic species": 11-30 specimens were captured in the last 160 years.

"frequent species": more than 30 specimens were captured and finally

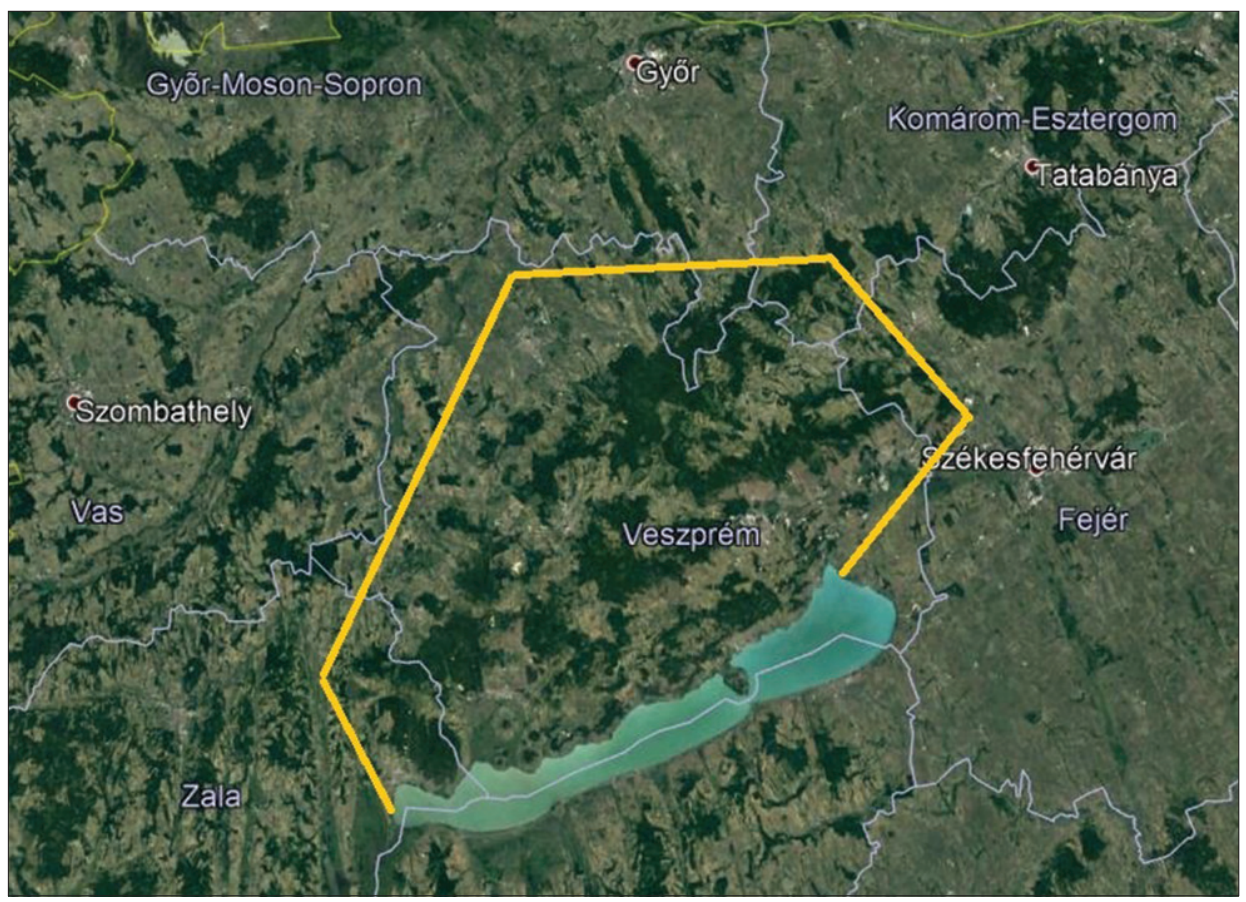

Fig. 1: Map of the investigated area 
"common species": the 20 most frequent species, mostly insect pests, high amount (hundreds) of specimens were collected. These species are common everywhere.

Translations: For better understanding of the geographical names, we provide the following translations from Hungarian to English: tó - lake, mező - field, rét - meadow, hegy - hill, domb - hill, patak - brook, völgy - valley. These words are frequently parts of the Hungarian geographical names.

\section{Results and discussion}

\section{List of the species}

\section{Xyelidae}

Xyela (Xyela) graeca J.P.E.F. Stein, 1876: Cserszegtomaj: Büdöskúti út (HARIS 2019). Sporadic. Larva on Pinus nigra.

Xyela (Xyela) curva Benson, 1938: Szentkirályszabadja: Kö-hegy. Larva feeds on Pinus mugo, P. cembra and P. nigra. Sporadic.

\section{Pamphiliidae}

Acantholyda (Acantholyda) erythrocephala (Linné, 1758): Bakonybél (ZoMBORI 1973). Sporadic. Larva on Pinus spp.

Acantholyda (Itycorsia) hieroglyphica (Christ, 1791): Várpalota. Sporadic. Host plants: Pinus spp.

Cephalcia abietis (Linné, 1758): Bakony (MóczÁr and Zombori 1973), [Kardosrét] Cuha-völgy (Zombori 1973). Sporadic. Host plant: Picea abies.

Cephalcia arvensis Panzer, 1803: Cserszegtomaj: Várvölgyi út: Pörkölt-hegy (HaRIS 2019), [Csesznek:] Gézaháza. Sporadic. Host plant: Picea spp.

Neurotoma fausta (Klug, 1808): Bakony (MócZÁR and ZoMBORI 1973), [Isztimér:] Menyeke (Zombori 1973). Sporadic. Host plant unknown.

Neurotoma mandibularis (Zaddach, 1866): Balatonfüred. Rare. Larva on Quercus.

Neurotoma nemoralis (Linné, 1758): Herend, Pápa, Veszprémfajsz (ZoMBORI 1973), Balatongyörök: Bélap-völgy, Cserszegtomaj: Büdöskúti út, Cserszegtomaj: Dobogó (Haris 2019). Frequent. Larva on Prunus mahaleb, P. armeniaca, P. spinosa and $P$. cerasus.

Pamphilius alternans (A. Costa, 1860): [Csesznek:] Gézaháza (ZomBori 1973) Balatonalmádi, Balatonfüred: Nagymező, Tihany: Kiserdő-tető. Sporadic. Host plant unknown.

Pamphilius ignymontiensis Lacourt, 1973: [Királyszállás:] Barok-völgy, Tés. Rare. Known host plants: Acer platanoides and A. campestre.

Pamphilius betulae (Linné, 1758): Várpalota (ZomBori 1973). Sporadic. Host plant: Populus tremula.

Pamphilius hortorum (Klug, 1808): Fenyőfö: Pisztrángos-tó. Sporadic. Larva on Rubus idaeus.

Pamphilius jucundus (Eversmann, 1847): Balatongyörök: Bélap-völgy (HaRIS 2019), Tihany: Kiserdő-tető. Rare. Host plant unknown.

Pamphilius marginatus (Serville, 1823): Eplény: Malomréti-völgy. Rare. Larva on Corylus avellana and on Carpinus betulus.

Pamphilius pallipes (Zetterstedt, 1838): Ugod. Rare. Larva on Betula. 


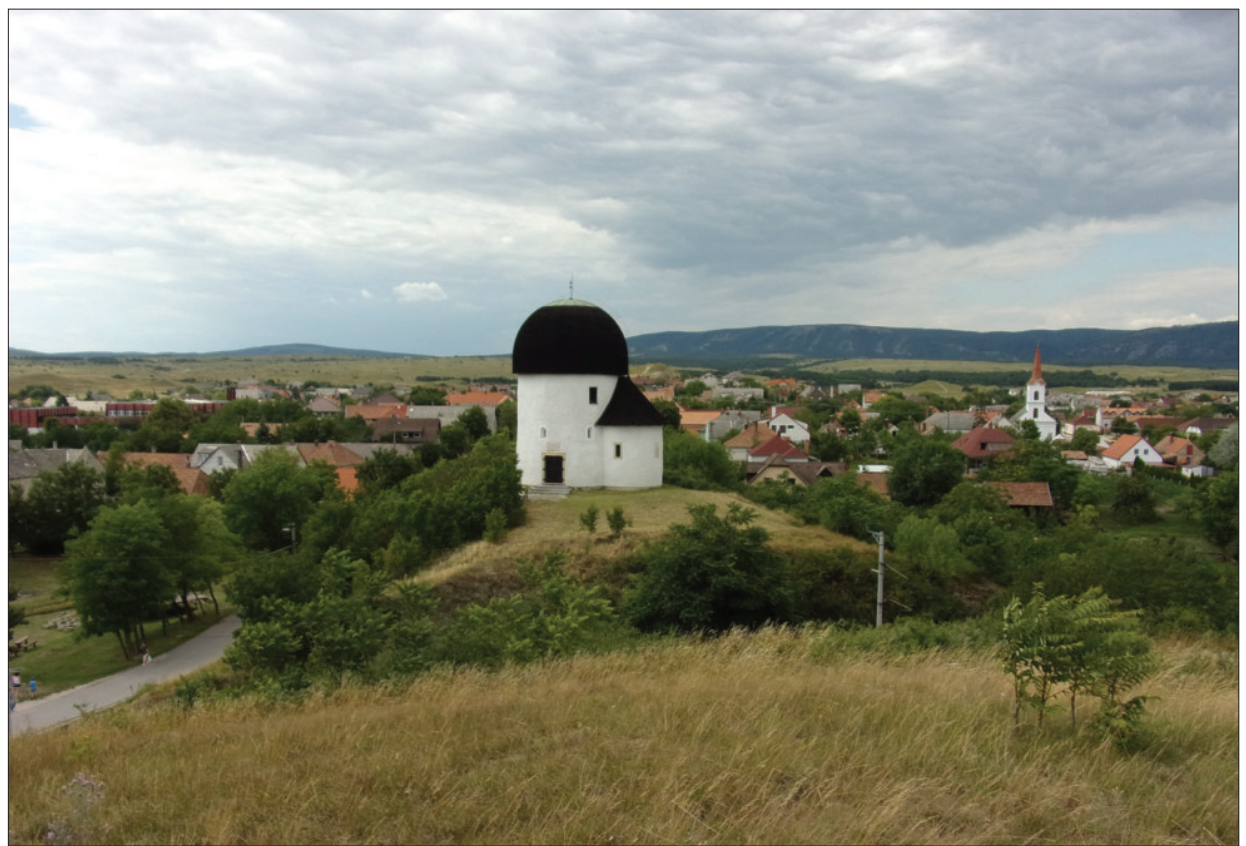

Fig. 2: Landscape from Öskü with the medievale rotunda (photo: Attila Haris)

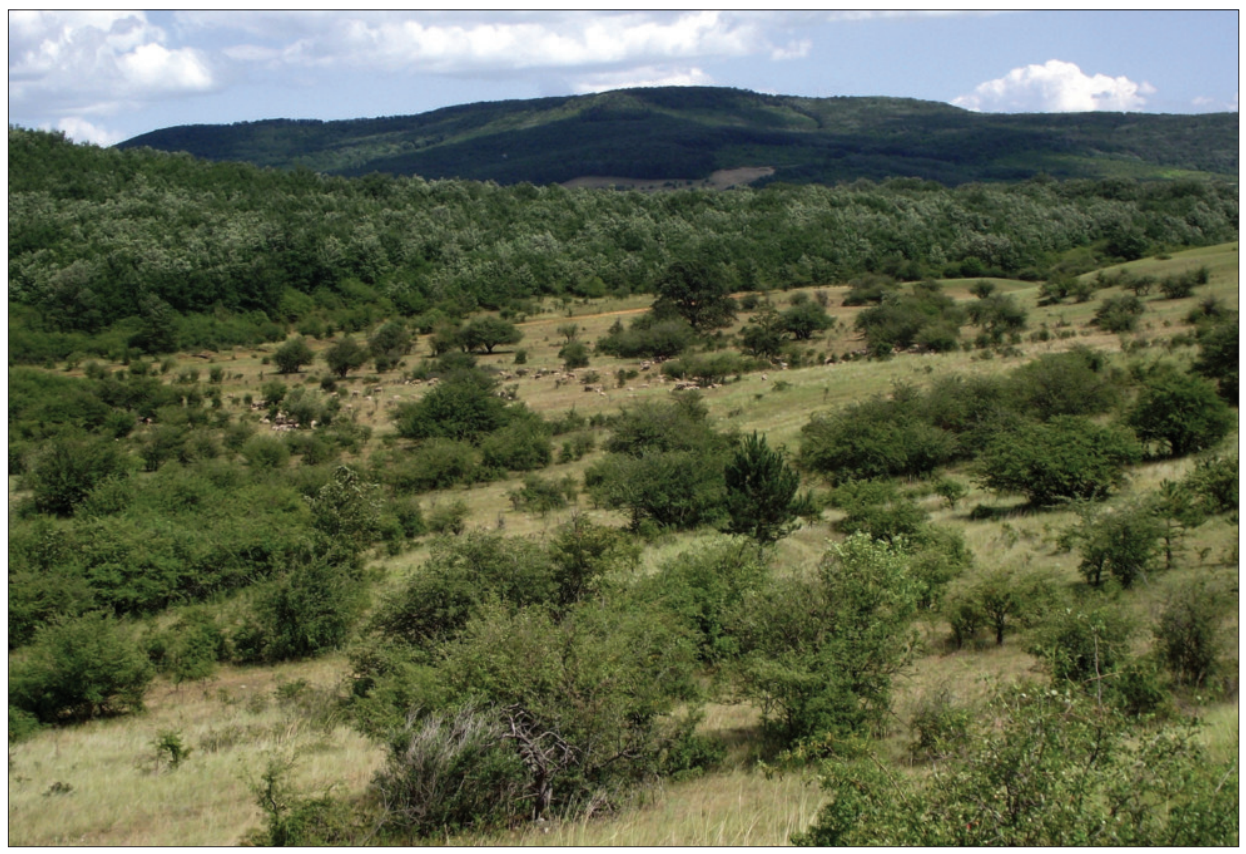

Fig. 3: Tücsöknyerítő Hills and Sátorma (photo: András Zámbó) 


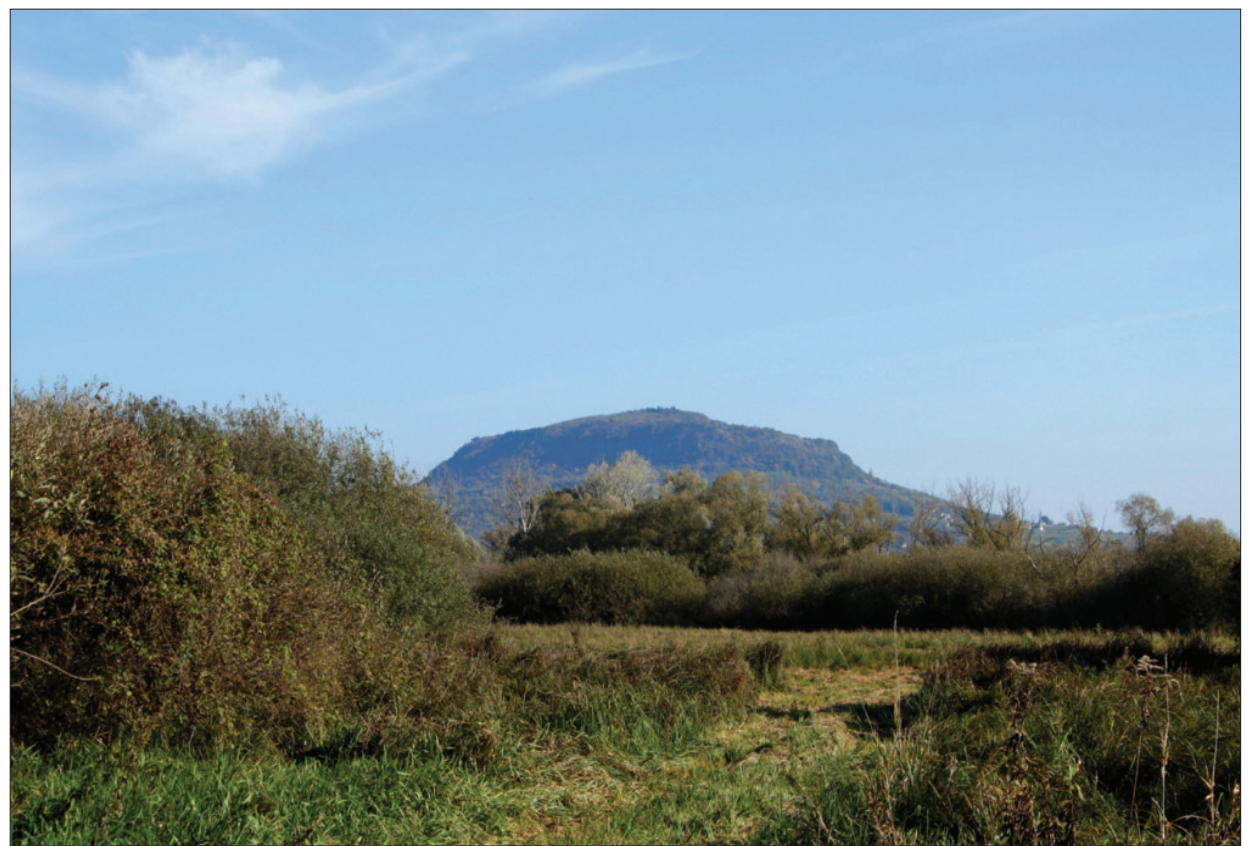

Fig. 4: Kongó: landscape between Nemesvita and Szigliget (photo: András Zámbó)

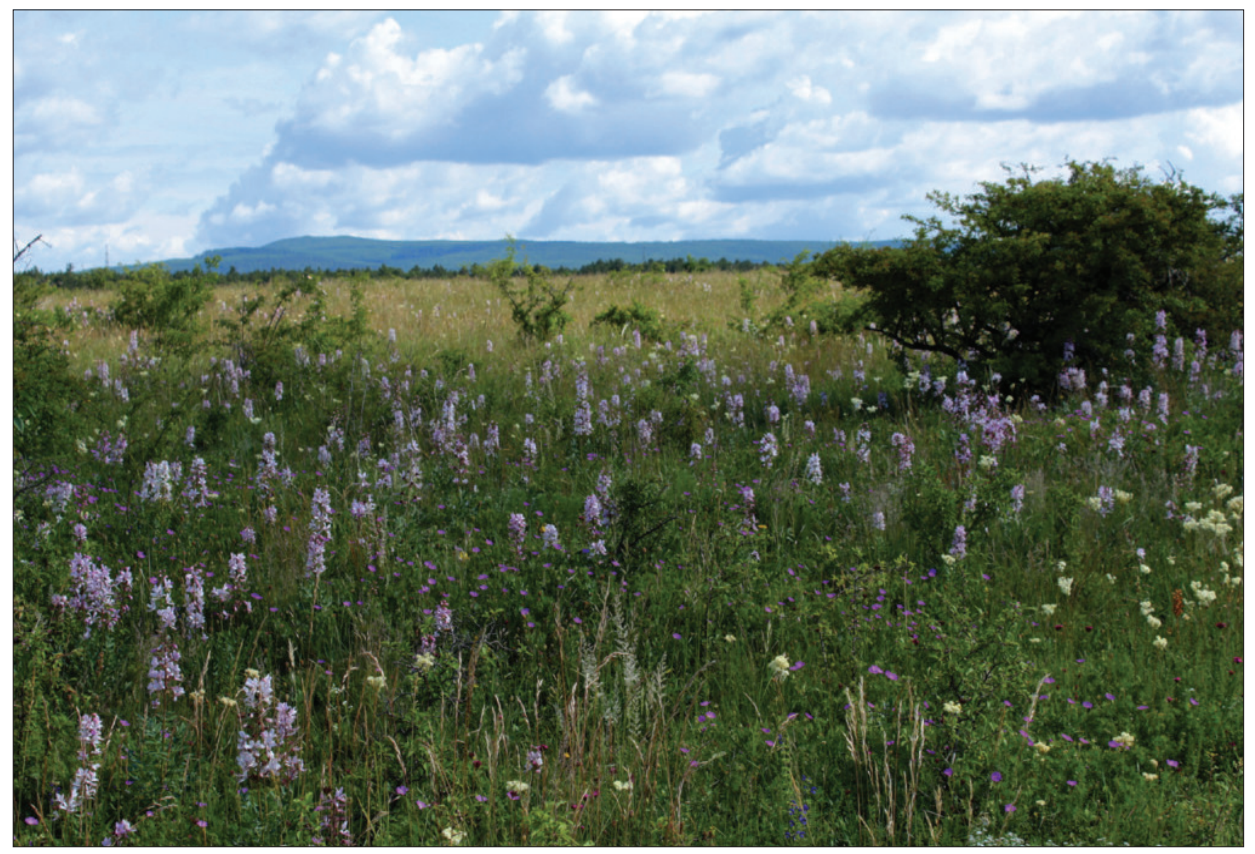

Fig. 5: Meadow at Tapolca (photo: András Zámbó) 
Pamphilius sylvaticus (Linné, 1758): [Királyszállás:] Barok-völgy, Cuha-völgy, [Hárskút:] Esztergáli-völgy, Gyulafirátót, Nemesvámos, Németbánya, Somlóvásárhely, Zirc (Zombori 1973), Porva: Pálihálás (Roller and Haris 2008), Csehbánya: KözépsőHajag, Tihany: Kiserdő-tetö, Tihany: Ranger's house. One of the most frequent sawfly species. Host plants: Sorbus aucupariae, Malus spp., Prunus spp. and Crataegus spp.

Pamphilius vafer (Linné, 1767): Cuha-völgy (Zombori 1973). Sporadic. On Alnus glutinosa and A. incana.

Pseudocephaleia praeteritorum (Semenov, 1934): Vászoly (SHINOHARA and Zombori 1997). Rare. Host plant unknown.

\section{Megalodontesidae}

Megalodontes cephalotes (Fabricius, 1781): Nyirád: Felsőnyirádi-erdő. (ZomborI 1973), Tapolca (HARIs 1998). Frequent. Host plant: Peucedanum cervania.

Megalodontes fabricii (Leach, 1817): Pétfürdő (ZombORI 1973), Hidegkút (Roller and HARIs 2008), Tihany: Gejzír-mező, Tihany: Csúcs-hegy, Tihany: Külső-tó, Tihany: Sajkod. Sporadic. Host plant unknown.

Megalodontes plagiocephalus (Fabricius, 1804): Bakonyszentlászló, Isztimér: Mellár, Szentkirályszabadja, Tihany, Uzsa, Veszprémfajsz (Zombori 1973), Ábrahámhegy, Cserszegtomaj, (Roller and HARIs 2008), Balatongyörök: Bélap-völgy, Cserszegtomaj: Dobogó (HARIs 2019) Balatonalmádi, Balatongyörök: Bélap-völgy, Cserszegtomaj: Gyötrös-tető, Hidegkút, Litér: Mogyorós-domb, Pápa, Sóly: falu É-i szegélye, Szentbékkálla: Fekete-hegy, Tihany: Gejzír-mező, Tihany: Kiserdő-tető, Tihany: Akasztó-domb, Veszprém: Csatár-hegy. One of the most frequent Megalodontesidae species. Known host plant: Peucedanum alsaticum.

Megalodontes thor Taeger, 2002: Tihany: Gejzír-mező. Sporadic. Host plant unknown.

\section{Blasticotomidae}

Blasticotoma filiceti Klug, 1834: Fenyőfő: Kisszépalma (Zombori 1973). Rare. Host ferns are Athyrium filix-femina, Matteuccia struthiopteris, Dryopteris spp., Polystichium spp., and Pteridium aquilinum.

\section{Argidae}

Aprosthema humeratum (Konow, 1892): Veszprém (RoLler and HaRIS 2008). Rare. Host plant unknown.

Aprosthema instratum (Zaddach, 1895): Balatonudvari (ROLLER and HARIS 2008).

Rare. Host plant unknown.

Aprosthema intermedium (Zaddach, 1864): Balatonudvari (ROLLER and HARIS 2008).

Rare. Host plant unknown.

Aprosthema konowi (Mocsáry, 1891): Balatronudvari, Hidegkút (RoLler and HARIS 2008). Rare. Host plant unknown.

Aprosthema melanurum (Klug, 1814): Tihany: Kis-erdö. Sporadic. Host plants: Lathyrus pratensis and Vicia cracca.

Arge berberidis Schrank, 1802: Ábrahámhegy, Dörgicse, Gyenesdiás, Káptalanfüred, Nemesvámos, Vállus, Veszprém (ZomBori 1973), Balatonalmádi, Balatonszepezd, Tihany, (Roller and Haris 2008), Balatongyörök: Bélap-völgy, Cserszegtomaj: Dobogó (HARIs 2019), Balatonfüred: Száka-hegy, Csopak: Nosztori-völgy, Porva: Generál-erdő, Szentgál: Mecsek-hegy, Tihany: Gejzír-mező. Frequent. Larva on Berberis and Mahonia spp. 
Arge cyanocrocea (Förster, 1771): Ajka, Csatka, Csesznek, Csetény, Csőszpuszta, Fenyőfo, [Csesznek:] Gézaháza, Halimba, Kapolcs, Pétfürdő, Somlóvásárhely, Tapolca, Úrkút, Zalaszántó. (Zombori 1973), Keszthelyi-hgs. (Roller and Haris 2008), Balatongyörök: Bélap-völgy, Cserszegtomaj: Dobogó, Csehbánya: Középső-Hajag, Cserszegtomaj: Várvölgyi út: Pörkölt-hegy. (HARIs 2019) [Zirc:] Akli: Gerence-völgy, Bakonyszombathely: Feketevíz-patak, Balatonkenese: Tátorjános, Bánd: Vár-hegy, Csopak: Nosztori-völgy, Eplény: Malomréti-völgy, Fenyőfő: Ösfenyves, [Csesznek:] Gézaháza, Hajmáspuszta, Hárskút, Hétházpuszta, Királyszállás: Barok-völgy, PorvaCsesznek, Tapolca: Szent György-hegy, Tihany, Tihany: Gejzír-mező, Tapolca: Fenyősdomb, Tihany: Kiserdő-tető, Tihany: Külső-tó, Tihany: Ranger's house, Ugod: Séd, Vinye: Köpince-forrás. Common species. Known host plants: Rubus idaeus and Sanguisorba officinalis.

Arge enodis (Linné, 1767): Bakonybél, Balinka, Bodajk, Csatka, Csehbánya, Kúp, Városlőd, Veszprém. (Zombori 1973) Alsóörs: railway station, Balatonfüzfö: at Lake Balaton, Cuha-völgy, Olaszfalu: Felsőpere, Tapolca: Kalapács-ér, Tihany: Bozsai-öböl, Várvölgy. Frequent. Host plants: Salix spp.

Arge frivaldszkyi (Tischbein, 1852): Tihany: Külsö-tó. Rare. Host plant unknown.

Arge gracilicornis (Klug, 1814): [Királyszállás:] Barok-völgy, Csesznek, Úrkút, Zalaszántó (Zombori 1973), Zalaszántó: Tátika-erdő (HARIs 2019). Frequent. Larva on Rubus idaeus.

Arge melanochra (Gmelin, 1790): Bakonybél, Bakonykoppány, Bakonypölöske, Bakonyszombathely, Bodajk, Csatka, Csetény, Felsőörs, Halimba, Herend, Isztimér, [Ajka:] Jókai-bánya, [Fenyőfő:] Kisszépalma, Márkó, Pétfürdő, Porva, [Ugod:] Somberek, Sümeg, Tapolca, Tés, Tihany, Uzsa, Úrkút, Vállus, Városlőd, Várvölgy, Veszprém, Veszprémfajsz, Zirc (Zombori 1973), Ajka, Sümeg (Roller and Haris 2008), Balatongyörök: Bélap-völgy, Várvölgy: Bándi-mező, Vállus: Láz-tető (HARIs 2019), Ajka: Köleske, Bakonynána: Római-fürdő, Balatonfüred: Nagymező, Balatonkenese: Tátorjános, [Vállus:] Büdöskút, Csopak: Nosztori-völgy, Eplény: Malomréti-völgy, Farkasgyepü, Felsőörs: Királykúti-völgy, Fenyőfő: Ösfenyves, Fenyőfő: Pisztrángos-tó, Hétházpuszta, Kardosrét: Cuha-völgy, [Ugod:] Királykapu, Nagytárkány, Porva: Ménesjárás, Pula, Olaszfalu: Felsőpere, Öcs: Nagy-tó, Szentgál: Mecsek-hegy, Tapolca: Fenyős-domb, Tihany, Tihany: Gejzír-mező, Tihany: Külső-tó, Ugod, Ugod: Szár-hegy, Várvölgy, Vinye: Köpince-forrás, Zirc, [Zirc:] Akli: Gerence-völgy, Zirc: Cigány-domb, Zirc: Három-hegy. The most common Argid sawfly. Host plant: Crataegus oxycantha.

Arge nigripes (Retzius, 1783): Balatongyörök: Bélap-völgy (HARIs 2019), Balatonfüred: Koloska-völgy, Fenyőfő, Hárskút: Esztergáli-völgy, Kiliántelep, Tihany: Gejzír-mező. Fequent. Host plants: Rosa spp.

Arge ochropus (Gmelin, 1790): Bakonynána, Balatonalmádi, Lovas, Monoszló, Pétfürdő, Tapolca, Tihany, Úrkút, Veszprémfajsz, Zalaszántó (ZoMBoRi 1973), Hidegkút, Tihany (RoLler and Haris 2008), Zalaszántó: Tátika-erdő (HARIS 2019), Bánd: Várhegy, Szentgál: Somod, Zirc: Cigány-domb. Pest of Rosa spp. Locally frequent.

Arge pagana (Panzer, 1797): Bakonybél, Balatonalmádi, Balinka, Bodajk, Cuhavölgy, Felsőörs, Fenyőfö, Gyepűkaján, Káptalanfüred, Németbánya, Tihany, [Ugod:] Somberek, Úrkút, Városlőd, Zalaszántó (ZomBori 1973), Balatongyörök: Bece-hegy, Rezi, Szentbékkálla, Vászoly (RoLler and Haris 2008), Cserszegtomaj: Fagyos-kereszt (HARIs 2019), Felsőörs: Királykúti-völgy, Hárskút: Esztergáli-völgy, Németbánya, Tihany: Bozsai-öböl, Tihany: Gejzír-mező, Tihany: Kiserdő-tető, Tihany: Külső-tó, Tihany: Óvár, . Frequent. Host plants: Rosa spp.

Arge rustica (Linné, 1758): Balatonalmádi, Gyenesdiás, [Fenyőfö:] Kisszépalma, Vállus, Veszprémfajsz (Zombori 1973), Balatongyörök: Bélap-völgy (HaRIs 2019), 
Fenyőfő: Ősfenyves, Olaszfalu: Felsőpere, Németbánya: Pisztrángos-tó, Olaszfalu: Malom-völgy. Frequent. Host plant: Quercus spp.

Arge ustulata (Linné, 1758): [Királyszállás:] Barok-völgy, Márkó, Zirc (ZoMBORI 1973), Balatonfüred, Zirc (Roller and HARIS 2008), Eplény: Malomréti-völgy, Csehbánya: Középső-Hajag, Királyszállás: Barok-völgy, Olaszfalu: Malomréti-völgy,

Zirc: Cigány-domb. Frequent. Larva on Betula, Salix and Crataegus.

Spinarge metallica (Klug, 1834): Zirc (MocsáRY 1900). Rare, the solely record from Hungary. Larva on Betula pendula.

Sterictiphora angelicae (Panzer, 1799): Bakonybél, Budapest, Hajmáspuszta, Káptalanfüred, Márkó, Szigliget, Tihany (ZomBori 1973), Mindszentkálla, Pápa, (Roller and Haris 2008), Kiliántelep, Nyirád. Frequent species. Larva on Prunus.

Sterictiphora geminata (Gmelin, 1790): Balatoncsicsó, Porva: Pálihálás (RoLlER and HARIS 2008). Larva on Rosa spp. and Sorbus aucuparia. Sporadic.

Sterictiphora longicornis Chevin, 1982: Balatoncsicsó (Roller and HARIS 2008), Cuha-völgy, [Hárskút:] Esztergáli-völgy, [Bakonyszentlászló:] Hódos-ér, Kardosrét, Pénzesgyőr: Szömörke-völgy, [Devecser] Széki-tó. Note: It was (1981) separated from the similar S. geminata, all available records were checked. Sporadic. Host plant: Carpinus betulus. Adults associated with Prunus spinosa.

\section{Cimbicidae}

Abia aenea (Klug, 1820): Hárskút: Esztergáli-völgy (ZomBORI 1973), Balatongyörök, Isztimér: Tüskés, Tihany: Gejzír-mező. Sporadic. Host plants: Lonicera and Symphoricarpos spp.

Abia candens Konow, 1887: [Zirc:] Aklipuszta (ZomBori 1973), Balatongyörök (Roller and HARIS 2008). Sporadic. Larva on Knautia arvensis.

Abia fasciata (Linné, 1758): [Kardosrét] Cuha-völgy, Várpalota (ZomBori 1973). Sporadic. Host plants: Lonicera xylosteum, L. periclymenum, L. tatarica, Leycesteria spp. and Symphoricarpos spp.

Abia nitens (Linné, 1758): Felsőörs, Várpalota, Veszprém (ZomBORI 1973), Bakonyszentlászló (Roller and Haris 2008), Hegyesd: Szent Péter-dűlő. Less frequent than the next species. Host plants: Scabiosa columbaria and $S$. canescens.

Abia sericea (Linné, 1767): Csatka, Veszprém, Zalaszántó (Zombori 1973), Cserszegtomaj (Roller and HARIS 2008), Zalaszántó: Tátika-erdő (HARIs 2019), Bakonybél: Barátok útja, Budatava, Cuha-völgy, Porva-Csesznek, Zirc: Három-hegy. Frequent. Larva on Succisa, Knautia and Fragaria spp.

Cimbex femoratus (Linné, 1758): Bakonybél, Sáska, Szigliget, Várpalota, (ZoMBORI 1973), Sümeg (Haris 1998), Bakonybél: Köris-hegy, Tapolca. Widely distributed, frequent species. Host plants: Betula pendula and B. pubescens.

Cimbex luteus (Linné, 1758): Bakonybél, Vállus, Várpalota (Zombori 1973) Sporadic. Larva on Populus tremula and Salix spp.

Cimbex quadrimaculatus (O.F. Müller, 1766): Bakonyjákó (Zombori 1973), Balatonalmádi, Balatonfüred: Nagymezö, Veszprém. Frequent insect pest. Larva on Crataegus, Pyrus and Prunus spp.

Corynis crassicornis (Rossi, 1790): Bakony: Northern part of Cuha-völgy, Balatonfüred, Bodajk, Csopak, Öcs, Sümeg, Tapolcafö, Vállus, Városlőd (Zombori 1973), Eplény: Malomréti-völgy, Hegymagas: Szent György-hegy, Öcs: Nagy-tó, Szentgál: Somod, Tapolca, Tihany: Külső-tó. Sporadic. Hosts are Sedum spp. (S. album, S. acre and $S$. sexangulare).

Corynis obscura (Fabricius, 1775): Tapolca (Mocsáry 1900), Hidegkút, Tapolca (Roller and Haris 2008). Larva on Geranium sylvaticum. Sporadic. 
Pseudocavellaria amerinae (Linné, 1758): Bakonybél (Zombori 1973). Host plants: Salix and Populus spp. Frequent.

Trichiosoma latreillii Leach, 1817: Bakonybél, Veszprém (ZOMBORI 1973). Rare. Larva on Betula and Salix.

Trichiosoma vitellina (Linné, 1760): Bakonybél (Zombori 1973). Host plants unknown. Rare.

\section{Diprionidae}

Diprion pini (Linné, 1758): Sümeg (Roller and HaRIS 2008), [Csopak:] Nosztorivölgy. Frequent. Insect pest of Pinus spp.

Gilpina frutetorum (Fabricius, 1793): Zirc (MocsÁRY 1900). Larva on Pinus sylvestris. Rare in Hungary.

Gilpina polytoma (Hartig, 1834): Badacsony (MóczÁR and ZoMBori 1973). Larva on Picea abies and P. obovata. Sporadic.

Monoctenus juniperi (Linné, 1758): Bakony, (MóczÁr and ZoMBori 1973), Fenyőfö. Pinus sylvestris and Juniper vegetation. Host plants: Juniperus communis and J. nana. Sporadic.

Monoctenus obscuratus (Hartig, 1837): Fenyőfö (Zombori 1973). Sporadic. Host plants: Juniperus communis and J. nana.

Neodiprion sertifer (Geoffroy, 1785): Sóly (Havas 1897), Fenyőfő. Larva on Pinus spp. Frequent.

\section{Tenthredinidae \\ Dolerinae}

Dolerus (Poodolerus) aeneus Hartig, 1837: Felsőörs, Fenyőfö (ZoMBori 1979), Keszthelyi-hgs.: Pilikáni út (HARIS 1998), Cserszegtomaj: Dobogó, Cserszegtomaj: Keszthelyi-hgs.: Pilikáni street (Haris 2019), Bakonybél: Gerence-völgye, Eplény: Malomréti-völgy, Zirc: Cigány-domb. Sporadic. Host plants: Graminae.

Dolerus (Poodolerus) anthracinus (Klug, 1818): Pápasalamon (Zombori 1979), Fenyőfö: Halastavak (RoLler and Haris 2008). Sporadic. Host plants: Graminae.

Dolerus (Poodolerus) asper Zaddach, 1859: Balatongyörök: Bélap-völgy (HARIS 2019). Sporadic. Host plants: Graminae and Cyperaceae.

Dolerus (Dolerus) bajulus Serville, 1823: Ácsteszér, Bakonybél, Bakonycsernye, Hajmáspuszta, Gyulafirátót, [Pápa:] Kéttornyúlak, [Bakonybél:] Kőris-hegy, Márkó, Németbánya, Olaszfalu, Pálihálás, [Ugod:] Somberek, Somlóvásárhely, Tüskevár, Ugod, Várvölgy, Veszprém, Zalaszántó (ZOMBori 1979), Bakony: Cuha-völgy, (Roller and HARIS 2008), Zalaszántó: Kovácsi-hegy, Várvölgy (HARIS 2019), Bakonybél: Gerencevölgy, Bakonybél: Fekete-séd, Bakonynána, Balatonalmádi: Budatava, Felsőörs: Királyréti-völgy, Hárskút: Esztergáli-völgy, Hajmáspuszta, Veszprém: Aranyos-völgy. Frequent. Larva on Equisetum palustre.

Dolerus (Dolerus) bimaculatus (Geoffroy, 1785): Bakonybél, Balatonfüred, Gyulafirátót, Herend, Németbánya (ZOMBORI 1979), Lesenceistvánd: patakpart, láprét. Sporadic. Larva on Equisetum spp.

Dolerus (Poodolerus) blanki Liston, 1995: Tapolca. Rare. Hostplant unknown.

Dolerus (Poodolerus) brevicornis Zaddach, 1859: Rezi: Gyöngyösi csárda, Zalaszántó: Alsó-nyíres (HaRIs 2019). Sporadic. Larva on Graminae.

Dolerus (Oncodolerus) eversmanni W.F. Kirby, 1882: Bakony: Cuha-völgy, Bakonybél, Bakonyszücs, Csehbánya, Herend, Márkó, Pénzesgyőr, Somlóvásárhely, Vinyesándormajor (ZOMBORI 1979), Vállus (RoLler and HARIS 2008), Várvölgy: Zsidirét (HARIs 2019), Eplény: Malomréti-völgy, Fenyőfő: Pisztrángos-tó, Lesenceistvánd, 
[Bakonyszentlászló:] Hódos-ér völgye, [Fenyőfö:] Kék-hegy, Zirc. Frequent. Larva on Equisetum arvense and E. palustre.

Dolerus (Achaetoprion) ferrugatus Serville, 1823: Zirc (Zoмвori 1979), Bakonybél (Roller and Haris 2008), Öcs: Nagy-tó. Sporadic. Host plant: Juncus effusus.

Dolerus (Poodolerus) fumosus Stephens, 1835: Eplény: Malomréti-völgy, Királyszállás: Barok-völgy. Sporadic. Hostplant unknown. In interesting way, where Dolerus sanguinicollis Kl. specimens were captured, the males of D. sanguinicollis weren't, but males of Dolerus fumosus Steph. were found. Probably, the males of the two closely related species are reversed, or the females of D. fumosus has red colour variation either.

Dolerus (Dolerus) germanicus ssp. germanicus (Fabricius, 1775): Ajka, [Zirc:] Akli, Ácsteszér, [Ugod:] Somberek, Bakonybél, Bakonykoppány, Balatonfüred, Balinka, Csatka, Csehbánya, Fenyőfö, Gyulafirátót, Hajmáspuszta, Herend, Németbánya, Nyárád, Nyirád, Olaszfalu, Pápa, Pénzesgyőr, Porva, Somlóvásárhely, Tapolcafö, Tihany: Külső tó, Várvölgy, Vinyesándormajor, [Bakonyszücs] Vörös János-séd, Zalaszántó (ZoMBORI 1979), Kapolcs, Keszthely (HARIs 1998), Bakonybél, Bakonyszentlászló, Balatongyörök, Pápa, Vonyarcvashegy, (RoLleR and HARIs 2008), Várvölgy: Zsidi-rét, Vonyarcvashegy: láprét, (HARIs 2019), Aszófö: Köves-földek, Bakonyszűcs: Vörös János-séd, Balatonalmádi: Budatava, Balatonfüred: Balatonpart, Csesznek, Dudar, Eplény: Malomréti-völgy, [Bakonyszentlászló:] Hódosér-völgy, [Ugod:] Királykapu, Lesenceistvánd, Porva, Ugod: Séd, Zirc: Cigány-domb. Common. Larva on Equisetum arvense and $E$. palustre.

Dolerus (Poodolerus) gonager (Fabricius, 1781): Balatonalmádi, Balatonfüred, Eplény, Farkasgyepü, Herend, [Bakonyszentlászló:] Hódos-ér, Márkó, Padragkút, Porva, Pula, Sáska, [Pénzesgyőr:] Szömörke-völgy, Tés, Veszprém, Zirc (ZomboRi 1979), Vállus (ROLLER and HARIs 2008), Balatongyörök: Bélap-völgy, Vállus: Szarvas-kotrás, Vállus: Kis-Láz-völgy (HARIs 2019), Bakonybél: Gerence-völgy, Csesznek: Vár-hegy, Dudar: Ördög-árok, Eplény: Malomréti-völgy, [Csesznek:] Gézaháza: Ördög-árok, Kővágóörs, Kővágóörs: Kornyi-tó, Lesenceistvánd, Pénzesgyőr, Szentbékkálla, Tihany: Csúcs-hegy, Zirc, Zirc: Kőbánya, Zirc: Arborétum, Zirc: Pintér-hegy. Common. Larva on Graminae.

Dolerus (Poodolerus) haematodes (Schrank, 1781): Eplény, Herend, Kapolcs, Márkó, Porva, Várpalota, Zirc (Zombori 1979), Csesznek: Ördög-árok, Dudar: Ördög-árok, [Csesznek:] Gézaháza: Ördög-árok, [Fenyőfö:] Kisszépalma: patak. Frequent. Larva on Juncus, Scirpus, Carex and Gramineae.

Dolerus (Poodolerus) liogaster C. G. Thomson, 1871: Bakonybél, Farkasgyepü, [Bakony:] Gerence-völgy, Herend, [Pénzesgyőr:] Szömörke-völgy, Tés (Zombori 1979), Cserszegtomaj: Várvölgyi út: Pörkölt-hegy (HARIs 2019). Sporadic. Host plants: Graminae.

Dolerus (Achaetoprion) madidus (Klug, 1818): Herend (Zombori 1979), Veszprém (Roller and Haris 2008), Felsőörs: Királykúti-völgy. Sporadic. Host plant: Juncus effusus.

Dolerus (Poodolerus) niger (Linné, 1767): Bakony: Cuha-völgy, Bakonypölöske, Balatonfüred, [Királyszállás:] Barok-völgy, [Csesznek:] Gézaháza, Halimba, Herend, [Nagyvázsony:] Kab-hegy, Márkó, Sáska, [Pénzesgyőr:] Szömörke-völgy (ZoMBORI 1979), Fenyőfő (Haris 1998), Hárskút: Augusztin-tanya, Pénzesgyőr. Sporadic. Host plants: Poaceae.

Dolerus (Poodolerus) nigratus (O.F. Müller, 1776): Bakony: Cuha-völgy, Bakonybél, Eplény, Farkasgyepü, [Bakony:] Gerence-völgy, Gyulafirátót, Hajagos, Herend, [Bakonyszentlászló:] Hódos-ér, [Csesznek: Cuha:] Káró, Németbánya, Pénzesgyőr, 
[Herend:] Rakottyás, Somlóvásárhely, [Pénzesgyőr:] Szömörke-völgy, Várvölgy, Veszprém, Vörösberény, Zirc (Zombori 1979), Sümeg, Tapolca (HaRIs 1998), Fenyőfő (RoLLER and HARIs 2008), Balatongyörök: Bélap-völgy, Cserszegtomaj: Fagyos-kereszt, Rezi: Gyöngyösi csárda, Várvölgy: Bándi-mező, Várvölgy: Zsidi-rét, Zalaszántó: Alsónyíres (HaRIs 2019), Bakonybél: Gerence-völgy, Csesznek: Várbükk, Eplény: Malomrétivölgy, [Csesznek:] Gézaháza: Ördög-árok, Hárskút, [Bakonyszentlászló:] Hódos-ér völgye, Huszárokelőpuszta, Kővágóörs, Lesenceistvánd, Szentbékkálla, Tapolca, Zirc: Cigány-domb, Zirc: Három-hegy, Zirc: Kardosrét, Zirc: Szarvaskút. Common. Larva on Gramineae including cereals.

Dolerus (Poodolerus) nitens Zaddach, 1859: Zalaszántó (ZoMBORI 1979), Várvölgy: Zsidi-rét, Zalaszántó: Kovácsi-hegy (Haris 2019). Sporadic. Larva on Cyperaceae and Graminae.

Dolerus (Achaetoprion) pachycerus Hartig, 1837: Tihany (RolleR and HARIs 2008). Rare. Host plant: Juncus gerardii.

Dolerus (Poodolerus) picipes (Klug, 1818): Bakony: Cuha-völgy, Dörgicse, Eplény, Felsőörs, [Bakony:] Gerence-völgy, [Csesznek:] Gézaháza, [Bakonyszentlászló:] Hódosér, Márkó, Németbánya, Padragkút, Paloznak, Szentgál, [Pénzesgyör:] Szömörke-völgy, Tés, Veszprém, Zirc (ZoMBORI 1979), Balatongyörök, Balatonudvari (RolLER and HARIS 2008), Balatongyörök: Bélap-völgy (Haris 2019), Eplény: Malomréti-völgy, Csehbánya: Középső-Hajag, Dudar, [Fenyőfő:] Kék-hegy, Fenyőfő: Pisztrángos-tó, Fenyőfő: Ösfenyves, Hárskút: Esztergáli-völgy, [Bakonyszentlászló:] Hódosér-völgye, Szentbékkálla, Tapolca: Fenyős-domb, Tihany: Külső-tó Zirc, Zirc: Cigány-domb. Frequent. Larva on Graminae.

Dolerus (Equidolerus) pratensis (Linné, 1758): Bakonybél (ZomBori 1979), Tihany (RoLLER and HARIS 2008), Lesenceistvánd: láprét (marshy meadow). Rare. Host plant: Equisetum heliocharis.

Dolerus (Poodolerus) puncticollis C. G. Thomson, 1871: Bakony: Cuha-völgy, Balatonfüred, Eplény, Fenyőfö, Gyulafirátót, Márkó (ZoMBORI 1979), Balatonalmádi, Balatongyörök, Porva: Pálihálás, Vállus (Roller and HARIS 2008), Balatongyörök: Bélap-völgy, Rezi: Gyöngyösi csárda, Várvölgy: Bándi-mező, Várvölgy: Zsidi-rét (HARIS 2019), Bakonybél: Gerence-völgy, Csesznek: Vár-hegy, Dudar: Ördög-árok, Eplény: Malomréti-völgy, [Bakonyszentlászló:] Hódosér-völgye, Hárskút: Augusztintanya,Királyszállás:Barok-völgy,Kővágóörs:Kornyi-tó,Lesenceistvánd,Lesenceistvánd: patakpart, Lókút, Pénzesgyőr, Szentbékkálla, Tihany: Külső-tó, Zirc, Zirc: Cigánydomb, Vállus. Common. Larva on Graminae including cereals.

Dolerus (Poodolerus) sanguinicollis (Klug, 1818): Bakony: Cuha-völgy, Dudar, [Bakony:] Gerence-völgy, [Csesznek:] Gézaháza, Királyszállás, [Pénzesgyőr:] Szömörkevölgy, (Zombori 1979), Eplény: Malomréti-völgy, Zirc: Szarvaskút. Sporadic.

Dolerus (Achaetoprion) triplicatus (Klug, 1818): Tapolca (HARIS 1998). Sporadic. Larva on Juncus filiformis and J. effusus.

Dolerus (Poodolerus) varispinus Hartig, 1837: Kővágóörs, Porva: Pálihálás (RoLler and Haris 2008), Gyulafirátót: Kálvária-domb. Rare. Host plants: Poaceae.

Dolerus (Dicrodolerus) vestigialis (Klug, 1818): Bakonybél, Bakonyszücs, Balatonfüred, Felsőörs, [Bakony:] Gerence-völgy, Herend, Márkó, Németbánya, [Pénzesgyőr:] Szömörke-völgy, Tapolcafö, Vállus, Városlőd (ZombORI 1979), Bakonybél, Balatonfüred, Porva: Pálihálás (RoLler and HARIs 2008), Balatongyörök: Bélap-völgy, Vonyarcvashegy: Láprét, Vállus: Szentmiklósi-völgy (HaRIs 2019), Csehbánya: KözépsőHajag, Fenyőfő: Pisztrángos-tó, Fenyőfő: halastó, [Bakony:] Gerence-völgy, [Csesznek:] Gézaháza: Ördög-árok, Hajmáspuszta, [Bakonyszentlászló:] Hódosér-völgy, Lesenceistvánd, Németbánya, Olaszfalu, Porva-Csesznek, Zirc: Pintér-hegy, Zirc: 


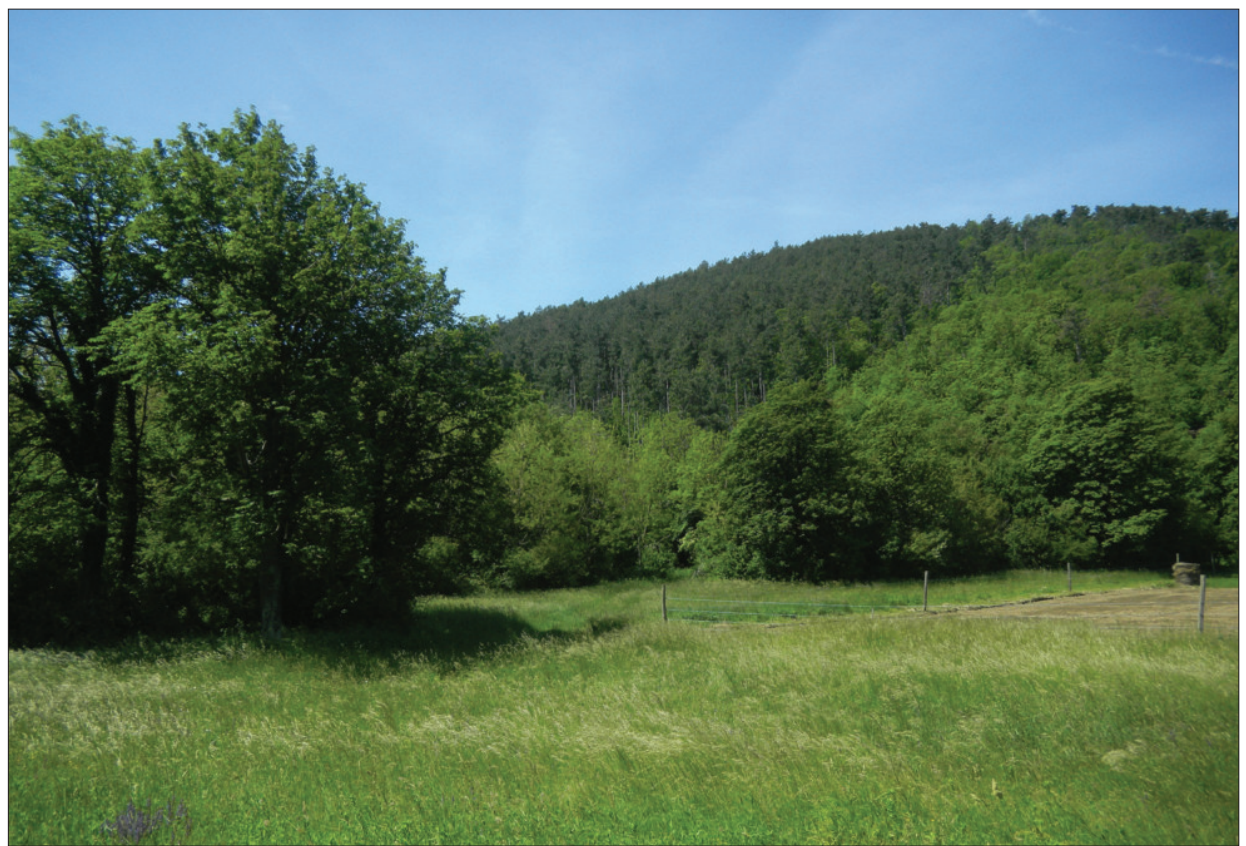

Fig. 6: Bélap völgy (Bélap-valley)

(photo: Attila Haris)

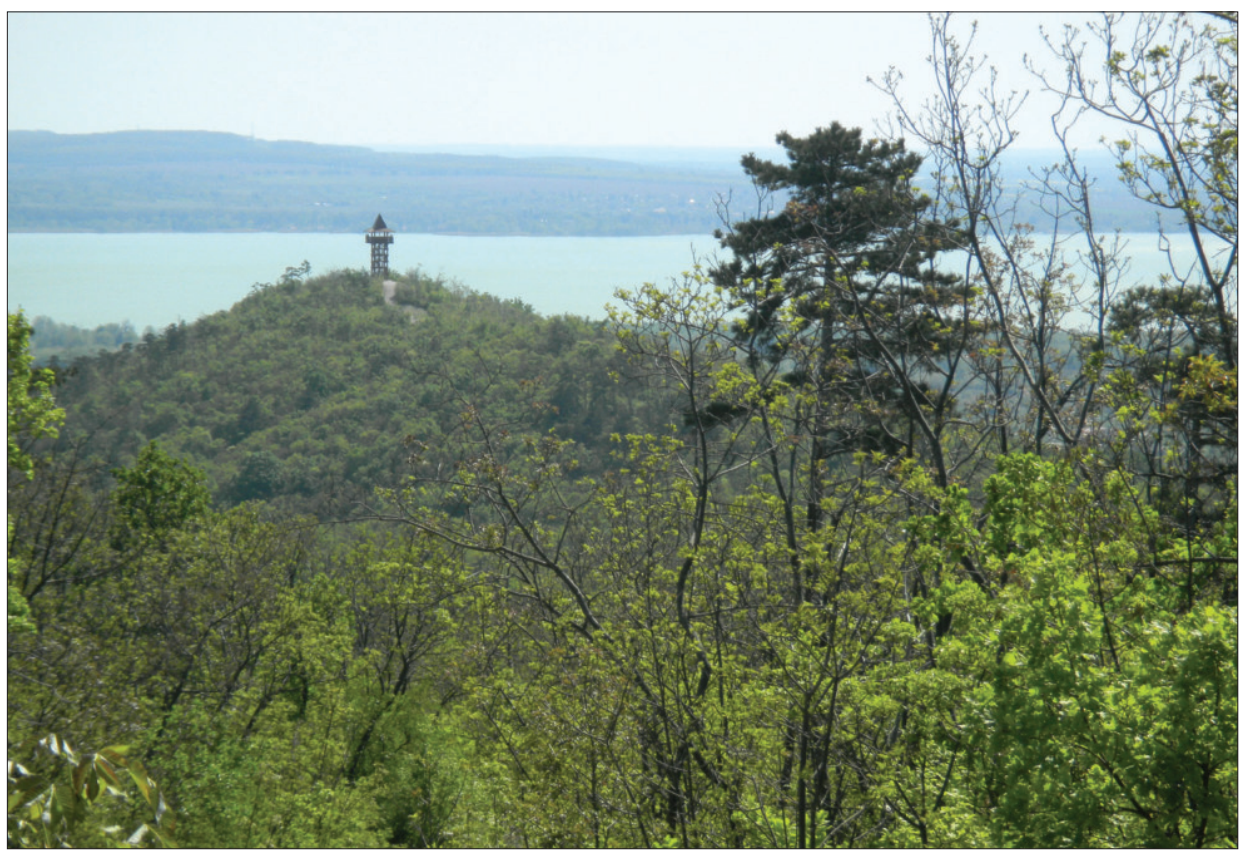

Fig. 7: Keszthelyi-hegység (Keszthely Hills) outlook to Lake Balaton (photo: Attila Haris) 


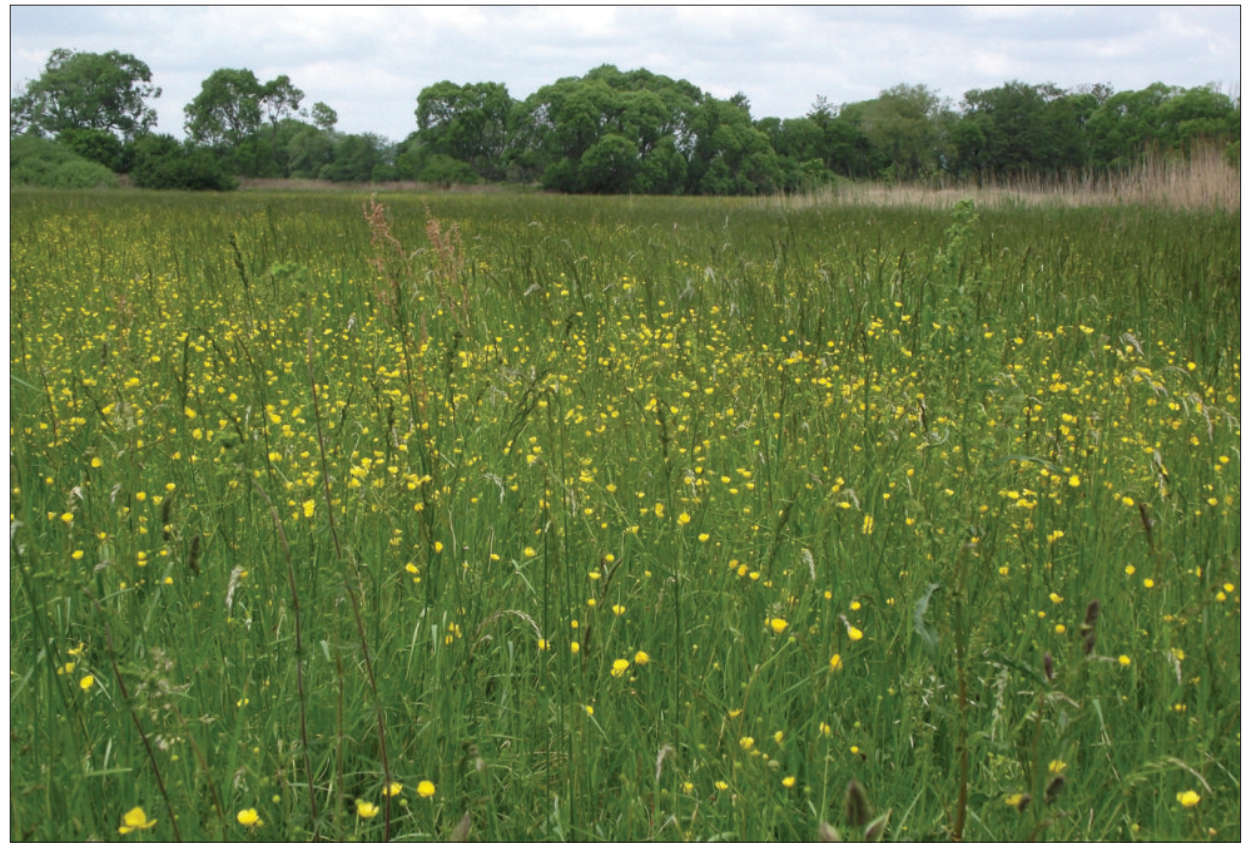

Fig. 8: On the way to Nemesgulács

(photo: András Zámbó)

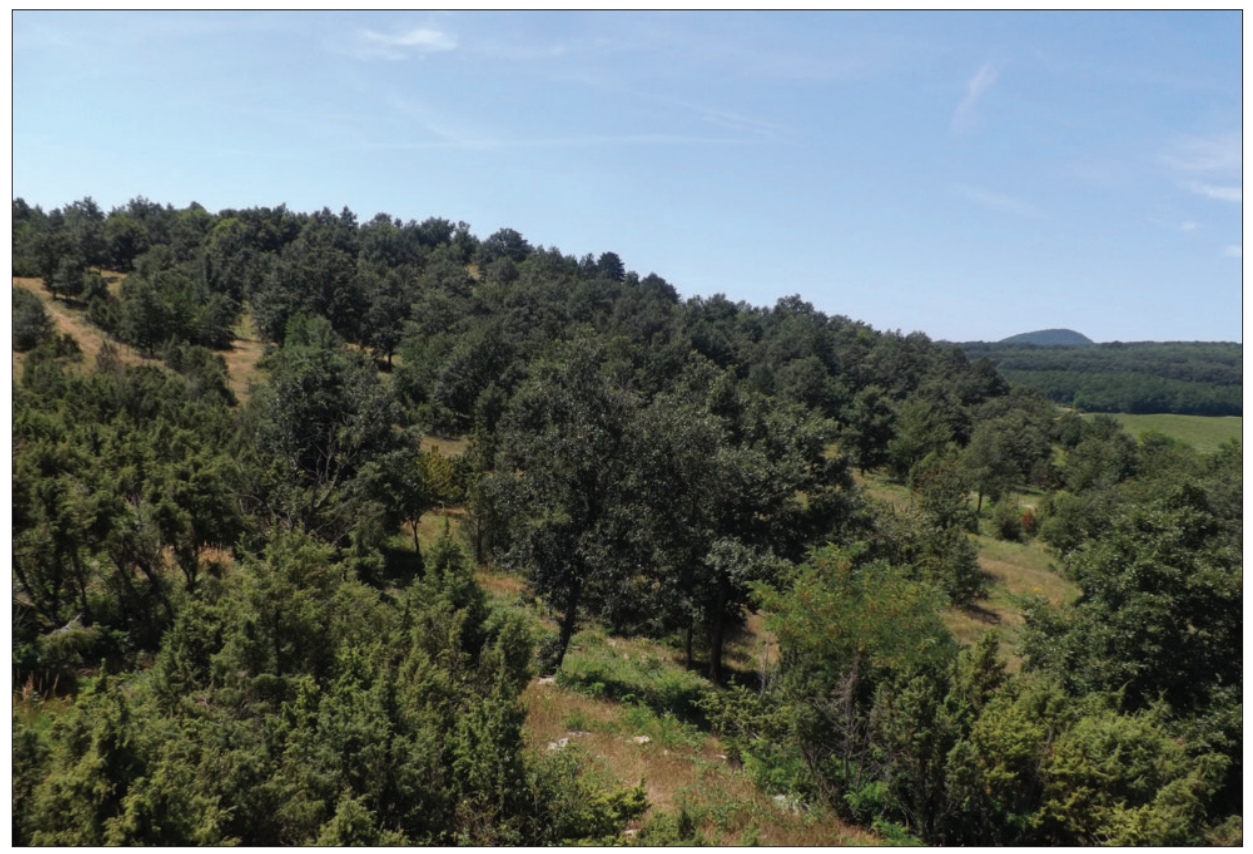

Fig. 9: Csönge-hegy (Csönge Hill) at Salföld (photo: András Zámbó) 
Cigány-domb, Zirc: Szarvaskút. Common. Host plants: Equisetum palustre, E. sylvaticum, E. arvense and E. pratense.

\section{Selandriinae}

Aneugmenus fuerstenbergensis (Konow, 1885): Fenyőfö (Zombori 1979). Rare. Host plant: Pteridium aquilinum.

Aneugmenus padi (Linné, 1760): Fenyőfö (Zombori 1979). Host plants: Asplenium sp. and Pteridium aquilinum. Sporadic in the Carpathian Basin, but rare in Hungary.

Aneugmenus temporalis (C. G. Thomson, 1871): Uzsa (Roller and Haris 2008). Rare. Host plant: Pteridium aquilinum.

Birka (Birka) annulitarsis (C. G. Thomson, 1870): Bakony (ZomBori 1982a). Sporadic. Host plant unknown.

Birka (Birka) cinereipes (Klug, 1816): [Csesznek:] Gézaháza, Kapolcs, Királyszállás, Lesenceistvánd, Öcs, [Pénzesgyőr:] Szömörke-völgy, Tapolcafö, Zirc (ZoMBorI 1979), Balatongyörök: Bélap-völgy, Cserszegtomaj: Dobogó, (HARIs 2019), Bakonyszentlászló, Vinye: Hódos-ér, Bakonyszombathely: Feketevíz-patak, Királyszállás: Barok-völgy, [Bakonybél:] Vörös János-séd, Zirc: Arborétum, Zirc: Pintér-hegy. Sporadic. Host plants: Myosotis spp.

Brachythops flavens (Klug, 1816): Bakony (Zombori 1982a), Bakonyszücs, Balatonfüred, Kapolcs (ZombORI 1979), Köveskál: Kornyi-tó (RoLler and HARIS 2008). Sporadic. Larva on Carex spp.

Nesoselandria morio (Fabricius, 1781): Bakony: Cuha-völgy, Bakonybél, Csatka, Fenyőfö, [Bakony:] Gerence-völgy, Lesenceistvánd, Németbánya, Tapolcafö, Veszprém, [Bakonybél:] Vörös János-séd, (Zombori 1979), Vállus (Roller and Haris 2008), Balatongyörök: Bélap-völgy (HARIs 2019), Csehbánya. Frequent. Host plants: Brachytecium reflexum, Ceratodon purpureus, Chenopodium album, Dicranum scoparium, Fragaria vesca, Hedwigia ciliata, Myosotis arvensis, Plagiomnium cuspidatum, Plagiothecium denticulatum, Polygonum aviculare, Polytrichum commune, Pseudobryum cinclidiodes, Sanionia uncinata, Stellaria media, Veronica chamaedrys and V. officinalis.

Selandria serva (Fabricius, 1793): Bakonybél, Bakonyszombathely, Csetény, Eplény, Felsőörs, [Bakony:] Gerence-völgy, Gyulafirátót, Hajmáspuszta, Kapolcs, [Pápa:] Kéttornyúlak, [Csesznek:] Kő-árok, Németbánya, Öcs, Padragkút, Pannonhalma, Pápa, [Pénzesgyör:] Szömörke-völgy, Tés, Tüskevár, [Bakonybél:] Vörös János-séd, Zirc (Zombori 1979), Badacsony, Hegymagas, Keszthelyi-hgs., Köveskál, Kővágóörs, Salföld, Tihany (Roller and Haris 2008), Csesznek, Tihany: Külső-tó. Frequent. Host plants: Poaceae, Carex spp. and Juncus spp.,

Strongylogaster macula (Klug, 1817): Zirc: Pintér-hegy (Zombori 1977). Rare, larva on Dryopteris spp., Dryopteris carthusiana, D. dilatata, Polystichum spp., Arachnoides miqueliana, Athyrium filix-femina and Pteridium aquilium.

Strongylogaster multifasciata (Geoffroy, 1785): Hárskút (RoLler and HaRIS 2008). Locally fequent. Larva on Dryopteris spp., Polystichum spp., Matteuccia struthiopteris and Pteridium aquilium.

Strongylogaster xanthocera (Stephens, 1835): Fenyőfö (Zombori 1979). Larva on Dryopteris spp., Polystichum spp., Athyrium spp. and Pteridium aquilium. Rare.

\section{Allantinae}

Allantus (Emphytus) calceatus (Klug, 1818): [Pápa:] Kéttornyúlak, Lesenceistvánd (ZoMBORI 1979), Balatongyörök: Bélap-völgy, Várvölgy: Zsidi-rét, (HARIs 2019), Lesenceistvánd, Tihany: Bozsai-öböl. Sporadic. Host plants: Rubus, Sanguisorba, Rosa, Filipendula, Fragaria and Alchemilla spp. 
Allantus (Emphytus) cinctus (Linné, 1758): Bakonybél, Bakonynána, Farkasgyepű, [Csesznek:] Gézaháza, Káptalanfüred, Nagyvázsony, Szentgál, Vörösberény (ZoMBORI 1979), Alsóörs, Balatoncsicsó, Csopak: Nosztori-völgy, Lovas, (Roller and HARIS 2008), Balatongyörök: Bélap-völgy, Balatongyörök: Mogyorós út: Szőlö-hegyek (HARIS 2019), Bakonyszentlászló: fenyves, Csesznek, Fenyőfő, Királyszállás: Barok-völgy, Tihany: tájvédelmi örház, Tihany: Kiserdő-tető Ösfenyves. Frequent. Host plants: Rosa spp.

Allantus (Emphytus) cingulatus (Scopoli, 1763): Bakony: Cuha-völgy, [Csesznek:] Gézaháza, Gyulafirátót, Hajmáskér, Hajmáspuszta, Tés, Tihany, Várvölgy (ZoMBORI 1979), Balatoncsicsó (RoLLER and HARIS 2008) Balatongyörök: Bélap-völgy, Várvölgy: Nagyláz-tető (HARIs 2019), Balatonalmádi, Balatonfüred: Nagymező, Bakonyszentlászló: Vinye: Hódos-ér, Eplény: railway cross, Tihany: tájvédelmi őrház. Frequent. Larva on Fragaria and Rosa spp.

Allantus (Emphytus) didymus (Klug, 1818): [Hárskút:] Esztergáli-völgy, Lovas, Tihany, Veszprém (ZomBori 1979), Balatonalmádi, Balatongyörök, Csobánka, Hegyesd, Uzsa, Veszprém, (Roller and Haris 2008), Balatongyörök: Bélap-völgy (HARIs 2019), Bakonyszombathely: Feketevíz-patak, Balatonkenese: Soós-hegy, Gyepúkaján: Hosszúnyíres, Öskü, Sümeg: around the castle, Tapolca: Fenyős-domb, Vászoly. Sporadic. Larva on Sanguisorba minor; old records from Rubus and Rosa spp. need checking.

Allantus (Emphytus) melanarius (Klug, 1818): Tihany: Akasztó-domb (ZoMBORI 1979), Balatongyörök: Bélap-völgy (HARIs 2019), Hárskút: Esztergáli-völgy. Frequent. Host plant: Cornus sanguinea.

Allantus (Emphytus) laticinctus (Serville, 1823): Bakony (Zombori 1982a). We have only this indefinite record from the Bakony Mountains. The voucher specimen probably lost. Rare. Larva on Rosa spp.

Allantus (Emphytus) rufocinctus (Retzius, 1783): Farkasgyepü, Herend (ZoMBORI 1979), Bakonybél: Gerence-völgy, Balatonalmádi, Királyszállás: Barok-völgy. Larva on Rosa and Rubus spp. Frequent.

Allantus (Allantus) viennensis (Schrank, 1781): Fenyőfö (Zombori 1979), Bakony, (Zombori 1982a), Badacsony (Roller and Haris 2008). Host plants: Rosa spp. Sporadic.

Ametastegia (Protemphytus) carpini (Hartig, 1837): Bakonybél, [Hárskút:] Esztergálivölgy, Németbánya, Veszprém, Vinyesándormajor (ZoMBORI 1979), Balatongyörök: Bélap-völgy (HARIS 2019), Lesenceistvánd, Ugod: Szár-hegy. Frequent. Host plant: Geranium spp.

Ametastegia (Ametastegia) equiseti (Fallén, 1808): Bakony: Cuha-völgy, Balatonalmádi, Balatoncsicsó, Bakonybél, Bakonyszücs, [Királyszállás:] Barok-völgy, [Csesznek:] Kö-árok, Németbánya, Tihany (Zombori 1979), Fenyőfö (Roller and Haris 2008), Csesznek, Eplény: Malomréti-völgy, [Csesznek:] Gézaháza: Ördög-árok, Királyszállás: Barok-völgy, Zirc: Pintér-hegy. Frequent. Larva on Chenopodium album, Lythrum salicaria, Polygonum persicaria and Rumex acetosella.

Ametastegia (Ametastegia) glabrata (Fallén, 1808): Gyulafirátót, Hajmáspuszta, Nyárád, Tüskevár (Zombori 1979), Tihany (Roller and HARIS 2008), Kővágóörs: Kornyi-tó, Tihany: Bozsai-öböl, Tihany: Külsö-tó. Frequent. Larva on Chenopodiaceae, Polygonaceae, Plantago, Salix, Lithrum, Ribes and Rubus spp.

Ametastegia (Protemphytus) pallipes (Spinola, 1808): Bakony: Cuha-völgy, Csesznek, [Hárskút:] Esztergáli-völgy, [Csesznek:] Gézaháza, Iharkút, Lesenceistvánd, Somlóvásárhely, Tapolcafő, Veszprém, [Csesznek:] Zörög-tető (ZoMBORI 1979), Badacsony, Balatoncsicsó, Fenyőfö, Hidegkút (Roller and Haris 2008), Tihany: Gejzír-mező, Zirc: Arborétum. Frequent. Host plants: Viola spp. 
Ametastegia (Protemphytus) tenera (Fallén, 1808): [Csesznek:] Gézaháza (ZomBori 1979), Fenyőfö: Szépalma, Porva:Pálihálás(RollerandHARIs2008), Bakonyszombathely: Feketevíz-patak, Csehbánya: Középső-Hajag, Tihany: Gejzír-mező. Frequent. Larva on Rumex spp.

Apethymus cereus (Klug, 1818): [Fenyőfö:] Kék-hegy Rare. Host plant: Quercus robur.

Athalia ancilla ssp. ancilla Serville, 1823: Bakony: Cuha-völgy, Bakonybél, Bakonypölöske, Balatonakali, Balinka, Bodajk, Borzavár, Csetény, Fenyőfő, [Csesznek:] Gézaháza, Gyulafirátót, Gyulakeszi, Hajmáspuszta, Herend, Márkó, [Gyulafirátót:] Miklád, Nagyvázsony, Nemesvámos, Pápa, Pétfürdő, Porva, Pula, Révfülöp, [Balatonakali:] Ságpuszta, Somlóvásárhely, Szentgál, Szentkirályszabadja, Szigliget, Ugod, Tapolca, Tapolcafö, Tés, Tihany, Várpalota, Veszprém, Zalaszántó, Zirc (ZoMBORI 1979), Balatonakali, Balatonederics, Balatongyörök, Révfülöp, Tihany, Tihany: Cserhegy, Városlőd (RoLler and Haris 2008), Tihany: Külső-tó, Vászoly: Öreg-hegy. Insect pest. Host plants: Diplotaxis tenuifolia, Erysimum cheirnthoides, Raphanus raphanistrum and Sinapsis spp.

Athalia bicolor Serville, 1823: Bakony: Cuha-völgy, Bakonybél, Bakonyszücs, [Királyszállás:] Barok-völgy, Csehánya, Dörgicse, [Bakony:] Gerence-völgy, [Csesznek:] Gézaháza, Gyulafirátót, Hárskút, Iharkút, [Nagyvázsony:] Kab-hegy, [Ugod:] Királykapu, Királyszállás, [Gézaháza] Mogyorós, Németbánya, Öcs, Padragkút, Paloznak, Somló, [Pénzesgyör:] Szömörke-völgy, Sümeg, Tapolcafö, Veszprém, Vinyesándomajor, Vörösberény, Zirc (Zombori 1979), Kapolcs (HaRIs 1998) Keszthelyi-hgs., Vállus, Tihany (RoLler and HARIs 2008), Balatongyörök: Bélap-völgy, Várvölgy: Zsidi-rét (HARIS 2019), Fenyőfő: Pisztrángos-tó, Gyulafirátót, Hárskút: Esztergáli-völgy, Olaszfalu: Malom-völgy, Tihany: Kiserdő-tető, Tihany: Külső-tó, Zirc: Cigány-domb. Frequent. Host plant: Ranunculus spp.

Athalia circularis (Klug, 1815): Bakony: Cuha-völgy, Bakonybél, Bakonyszombathely, Bakonyszücs, Balatonfüred, Balinka, [Királyszállás:] Barok-völgy, Borzavár, Csatka, Csesznek, Csőszpuszta, Felsőörs, Fenyőfö, Gyulafirátót, Hajmáspuszta, Hétházpuszta, Iharkút, Káptalanfüred, Királyszálllás, Monoszló, Nemesvámos, Németbánya, Nyirád, Olaszfalu, Öcs, Padragkút, Pálihálás, [Zirc:] Pintér-hegy, Porva, Porva-Csesznek, Rezi, Sáska, Sümeg, Tapolcafö, Tés, Ugod, Úrkút, Vállus, Várpalota, Vinyesándormajor, Vonyarcvashegy, Zalaszántó, Zirc (Zombori 1979), Kapolcs (Haris 1998) Bakony: Cuha-völgy, Keszthelyi-hgs., Tihany (RoLler and Haris 2008), Várvölgy: Bándi-mező (Haris 2019), Bakonybél: Som-hegy, Fenyőfö: Ösfenyves, Fenyőfö: Pisztrángos-tó, Kővágóörs: Kornyi-tó, Szentgál: Somod, Tihany: Bozsai-öböl, Tihany: Gejzír-mező, Tihany: Külső-tó, Zirc: Arborétum, Zirc: Szarvaskút, . Frequent. Host plants: Arctium lappa, Ajuga reptans, Veronica beccabunga, V. longifolia, V. officinalis, Alliaria petiolata, Glechoma hederacea, Melampyrum, Capsella and Lycopus spp.

Athalia cordata Serville, 1823: Badacsony, Bakonybél, Bakonykoppány, Bakonynána, Bakonyszombathely, Balinka, [Királyszállás:] Barok-völgy, Cserszegtomaj, Dörgicse, [Hárskút:] Esztergáli-völgy, Fenyőfő, [Bakony:] Gerence-völgy, [Csesznek:] Gézaháza, Gyulafirátót, Hajmáskér, Hajmáspuszta, Királyszállás, [Ugod:] Királykapu, Kislőd, Márkó, Nemesvámos, Németbánya, Nyárád, Olaszfalu, Padragkút, Porva, Pula, Szentgál, Tapolcafö, Tés, Tihany, Ugod, Vállus, Várpalota, Veszprém, Vinyesándormajor, Zalaszántó, Zirc (Zombori 1979), Cserszeg, Kapolcs (HARIs 1998), Balatonalmádi, Balatonakali, Balatoncsicsó, Balatongyörök: Bece-hegy, Bakonyszentlászló, Cserszegtomaj, [Gyulakeszi:] Csobánc, Kővágóörs, Tihany, Uzsa, Veszprém, Vállus (Roller and HARIS 2008), Balatongyörök: Bélap-völgy, Balatongyörök: Mogyorós út: Szőlö-hegyek, Cserszegtomaj: Dobogó, Cserszegtomaj: Fagyos-kereszt (HARIS 2019), 
Csesznek: Ördög-árok, Farkasgyepü, Fenyőfö: Pisztrángos-tó, Hárskút: Esztergáli-völgy Szentgál: Somod, Tihany: Külső-tó. Common. Larva on Misopates orontinum, Antirrhinum majus, Ajuga reptans, Teucrium scorodonia and Plantago spp.

Athalia liberta (Klug, 1815): Ajka, Bakony: Cuha-völgy, Bakonybél, Balatonfüred, Balatonkenese, Balinka, [Királyszállás:] Barok-völgy, Bodajk, Budatava, Csesznek, Csopak, Dudar, Fenyőfő, Gyulafirátót, Hajmáspuszta, Hétházpuszta, [Ugod:] Királykapu, Királyszálllás, Németbánya, Olaszfalu, Somlóvásárhely, Szentgál, Pálihálás, Porva, Tés, Ugod, Uzsa, Vállus, Zirc, [Csesznek:] Zörög-tetö (Zombori 1979), Gyenesdiás, Tihany (Roller and Haris 2008), Vállus: Láz-tető (Haris 2019), Bakonybél: Somhegypuszta, Csesznek: Vár-bükk, Fenyőfö: Ösfenyves, Szentgál: Somod, Tihany, Tihany: Bozsaiöböl. Frequent. Feeding on Alliaria petiolata, Arabidopsis thaliana, Cardamine hirsuta and Sisymbrium officinale.

Athalia lugens (Klug, 1815): Bakonybél, Bakonyszombathely, Hajmáspuszta, Iharkút, Ugod, Uzsa (Zombori 1979), Fenyőfő: Pisztrángos-tó, [Fenyőfő:] Kisszépalma, Tihany: Bozsai-öböl. Sporadic. Feeding on various Cruciferae.

Athalia paradoxa Konow, 1886: Tihany (Roller and HaRIs 2008). Rare. Host plant unknown.

Athalia scutellariae Cameron, 1880: Balatonalmádi: Budatava (ZomBoRI 1979). Sporadic. Larva on Scutellaria spp.

Athalia rufoscutellata Mocsáry, 1879: Hárskút, Tihany (Zombori 1979), Tés: Kisfutóné. Sporadic. Host plant unknown.

Athalia rosae (Linné, 1758): Ajka, Badacsony, Bakonybél, Bakonykoppány, Bakonynána, Bakonyszentkirály, Bakonyszombathely, Balatonalmádi, Balatonfüred, Balatonfüzfö, Balatonkenese, Balinka, Csesznek, Csetény, Csőszpuszta, Dudar, Fenyőfó, [Csesznek:] Gézaháza, Gyulafirátót, Hajmáspuszta, [Bakonyszentlászló:] Hódos-ér, Káptalanfüred, Keszthely, [Pápa:] Kéttornyúlak, Márkó, [Gyulafirátót:] Miklád, Nemesvámos, Pálihálás, Porva, [Balatonakali:] Ságpuszta, Szentgál, Szigliget, Somlóvásárhely, Tapolcafö, Tés, Tihany, Városlőd, Vonyarcvashegy, [Bakonybél:] Vörös János-séd, Zirc (Zombori 1979), Cserszeg (HARIs 1998), Balatonederics, Balatonkenese, [Gyulakeszi:] Csobánc, Keszthelyi-hgs., Salföld, Szentbékkálla, Tihany, Uzsa, Veszprém, (Roller and Haris 2008), Balatongyörök: Bélap-völgy, Cserszeg, Cserszegtomaj: Dobogó, Vonyarcvashegy: Láprét, Zalaszántó: Alsó-nyíres (HARIS 2019), Balatonalmádi, Béb, Cserszegtomaj: Csóka-kő, Eplény: Malomréti-völgy, Fenyőfő: Pisztrángos-tó, Kiliántelep, Rezi, Szentgál: Somod, Tapolca: Fenyős-domb, Tihany: Bozsai-öböl, Tihany: Gejzír-mező, Tihany: Kiserdő, Tihany: Külső-tó, Várpalota, Zalaszántó: Hidegkút, Zirc: Három-hegy. Common pest. Host plants: Raphanus sativus, $R$. raphanistrum, Sinapis arvensis, Sisymbrium officinale, Armoracia rusticana, Barbarea sp., Brassica napus, B. juncea, B. rapa, B. oleracea, Tropaeolum majus, Sinapis arvensis, Alliara petiolata and Cardamine spp.

Empria excisa (C. G. Thomson, 1871): [Bakony:] Gerence-völgy (ZoMBORI 1979). Sporadic. Host plant unknown.

Empria hungarica (Konow, 1895): Köveskál (HaRIs 1998). Rare. Host plant unknown.

Empria liturata (Gmelin, 1790): [Zirc:] Akli, Dudar, Gyulafirátót, Lesenceistvánd, Vörösberény (ZoMBORI 1979), Balatongyörök: Bélap-völgy, Balatongyörök: Mogyorós út, Szőlő-hegyek, Cserszegtomaj: Büdöskúti út, Cserszegtomaj: Dobogó, Cserszegtomaj: Fagyos-kereszt, Várvölgy: Bándi-mező, Vállus: Kis-Láz-völgy (HaRIs 2019), Hárskút: Esztergáli-völgy, Királyszállás: Barok-völgy, Pénzesgyőr: Szömörke-völgy, Tihany: tájvédelmi örház, Veszprém: Alsóerdő. Zirc: Arborétum. Frequent. Host plants: Fragaria and Geum spp. 
Empria parvula (Konow, 1892): Bakony: Cuha-völgy, [Hárskút:] Esztergáli-völgy, Hévíz (Zombori 1979), Balatongyörök: Bélap-völgy (HARIs 2019). Sporadic. Host plant unknown.

Empria pumila (Konow, 1896): Tihany (Roller and Haris 2008). Sporadic. Host plant unknown.

Empria sexpunctata (Serville, 1823) (=Empria klugi Steph.): Bakony: Cuha-völgy, [Hárskút:] Esztergáli-völgy, Tés (Zombori 1979), Fenyőfö, Porva: Pálihálás, Vállus (Roller and HARIS 2008), Balatongyörök: Bélap-völgy, Cserszegtomaj: Büdöskúti út (Haris 2019). Frequent. Larva on Geum spp.

Empria tridens (Konow, 1896): Bakony: Cuha-völgy, [Eplény:] Malomréti-völgy, Pula (Zombori 1979), Balatongyörök: Bélap-völgy, Cserszegtomaj: Dobogó (HARIS 2019), Bakonybél: Gerence-völgy, Fenyőfő: Pisztrángos-tó, Hárskút: Esztergáli-völgy. Frequent. Host plants: Geum spp. and Rubus idaeus.

Eriocampa ovata (Linné, 1760): Pálihálás (Zombori 1979), Devecser: Széki-erdő, Zirc: Szarvaskút. Frequent. Larva on Alnus spp.

Harpiphorus lepidus (Klug, 1818): Badacsony (ZomBORI 1982a). Sporadic. Larva on Quercus.

Monsoma pulveratum (Retzius, 1783): Lesenceistvánd (ZOMBORI 1979). Sporadic. Larva on Alnus spp.

Monostegia abdominalis (Fabricius, 1798): Bakony: Cuha-völgy, Bakonyszücs: Somberek, Balatonalmádi: Csacsi-rét, Nagyvázsony, Nemesvámos: Tekeres-völgy, Somberek (Zombori 1979), Németbánya, Városlőd (Roller and HARIs 2008). Frequent. Recorded on Glaux maritima, Lysimachia numularia and L. vulgaris.

Monostegia analis (Konow, 1887): [Zirc:] Pintér-hegy, Borzavár, Zalaszántó: Tátikaerdö. Rare. New record for the Carpathian Basin.

Monostegia nigra (Konow, 1896): Eplény: Malomréti-völgy, Vállus: Büdöskút, Zalaszántó: Kovácsi-hegy. Sporadic. Host plant unknown.

Taxonus agrorum (Fallén, 1808): Bakonybél, Fenyőfö, [Csesznek:] Gézaháza, Németbánya, Vörösberény (ZoMBori 1979), Köveskál (HARIs 1998), Balatongyörök: Bélap-völgy (HaRIs 2019) Eplény: Malomréti-völgy. Frequent. Host plants: Rubus idaeus and $R$. caesius.

Taxonus sticticus (Klug, 1817): Bakony: Cuha-völgy, [Csesznek:] Gézaháza, Kapolcs, Királyszállás, Ugod, Vállus (Zombori 1979), Kapolcs (Haris 1998). Sporadic. Host plant unknown.

\section{Blennocampinae}

Blennocampa phyllocolpa Viitasaari et Vikberg, 1985: Tihany (Ambrus 1964b), Zirc (Ambrus 1964c), Bakony (Ambrus 1978), Fenyőfő: Kisszépalma, [Bakony:] Gerencevölgy, [Csesznek:] Gézaháza, Hajmáspuszta, Iharkút, Királyszállás, [Csesznek:] Kö-árok, Városlőd, Zirc (Zombori 1979), Eplény: Malomréti-völgy, Hárskút: Esztergáli-völgy, Zirc: Kardosrét. Frequent. Larva rolls the leaves of Rosa spp.

Claremontia alternipes (Klug, 1816): Kardosrét, Farkasgyepü, Hévíz (ZoMBORI 1979), Bakony: Cuha-völgy (Roller and HARIs 2008), Balatongyörök: Bélap-völgy, Vállus: Kis-Láz-völgy (HARIs 2019), Bakonybél: Gerence-völgy, Eplény: Malomréti-völgy, [Csesznek:] Gézaháza: Ördög-árok, Királyszállás: Barok-völgy, Tihany: Kiserdő, Kúpierdő, Zirc: Arborétum, Zirc: Pintér-hegy. Sporadic. Host plant: Rubus idaeus.

Claremontia brevicornis (Brischke, 1883): Bakonyszentlászló (RoLlER and HARIS 2008), Balatongyörök: Bélap-völgy, Cserszegtomaj: Fagyos-kereszt, Várvölgy: Bándimező, Zalaszántó: Alsó-nyíres (HaRIs 2019), Bakonybél: Gerence-völgy, Eplény: Malomréti-völgy. Frequent. Host plants: Fragaria spp., Sanguisorba spp. and Potentilla reptans. 
Claremontia puncticeps (Konow, 1889): Bakony (AmBrus 1978), Királyszállás: Barok-völgy. Rather rare. Host plant: Sanguisorba minor.

Claremontia tenuicornis (Klug, 1816): Gyulafirátót, Tapolcafö, Tés, Veszprém (Zombori 1979), Porva: Pálihálás (Roller and HARIS 2008). Sporadic. Larva on Filipendula ulmaria.

Claremontia uncta (Klug, 1816): Fenyőfö, Királyszállás: Barok-völgy: Pinus sylvestris and Juniper vegetation. Rare. Host plants: Alchemilla spp.

Claremontia waldheimii (Gimmerthal, 1847): Bakonybél, [Bakonyszentlászló:] Hódos-ér, Márkó, Vinyesándormajor (ZoMBORI 1979) Balatoncsicsó, Tihany (RoLLER and Haris 2008), Balatongyörök: Bélap-völgy, Balatongyörök: Mogyorós út: Szőlöhegyek (HARIs 2019), Balatonfüred: Száka-hegy, Bakonybél: Gerence-völgy, Olaszfalu: Alsópere, Olaszfalu: Alsópere, [Fenyőfö:] Kék-hegy, Királyszállás: Barok-völgy, Tihany: tájvédelmi őrház. Frequent. Host plant: Geum urbanum.

Eutomostethus luteiventris (Klug, 1816): Felsőörs, Bakonybél, Balatonakarattya, Padragkút, Zalaszántó (ZomBori 1979). Frequent. Larva on Juncus effusus.

Eutomostethus ephippium (Panzer, 1798): Bakony: Cuha-völgy, Bakonybél, Bakonykoppány, Bakonypölöske, Bakonyszentlászló, Bakonyszücs, Balatonalmádi, Balatonfüred, Bodajk, Csetény, [Bakony:] Gerence-völgy, Eplény, [Csesznek:] Gézaháza, Gyulafirátót, Hajmáspuszta, Iharkút, Isztimér, [Pápa:] Kéttornyúlak, Királyszállás, [Bakonybél:] Kőris-hegy, Nemesvámos, Németbánya, Olaszfalu, Padragkút, Tapolcafö, Tés, Tihany, Ugod, Uzsa, Vinyesándormajor, [Bakonybél:] Vörös János-séd, Zalaszántó (Zombori 1979), Balatonalmádi, Cserszegtomaj, Keszthelyi-hgys., Nemesvita, Németbánya, Pálihálás, Pápa (Roller and Haris 2008), Cserszegtomaj: Várvölgyi út: Pörkölt-hegy, Vonyarcvashegy: Láprét, Zalaszántó: Alsó-nyíres, (HARIS 2019), Bakonybél: Gerence-völgy, Bakonybél: Hódosér-völgye, Balatonalmádi, Balatonfüred, Borzavár, Eplény: Malomréti-völgy, Fenyőfő: Pisztrángos-tó, Kővágóörs: Kornyi-tó, Olaszfalu: Malom-völgy, Ugod: Szár-hegy, Zirc: Arborétum, Zirc: Pintér-hegy, PorvaCsesznek, Zirc: Szarvaskút, Common, larva on Poaceae.

Eutomostethus gagathinus (Klug, 1816): [Csesznek:] Gézaháza, Gyulafirátót, Kapolcs, Nyirád, Tihany, [Bakonybél:] Vörös János-séd, (ZoмBORI 1979), Cserszegtomaj (Roller and HARIS 2008), Vonyarcvashegy: láprét (HARIs 2019). Sporadic. Host plant: Carex paniculata.

Eutomostethus luteiventris (Klug, 1816): Balatongyörök: Bélap-völgy (HARIs 2019). Sporadic, locally frequent. Larva on Juncus effusus.

Halidamia affinis (Fallén, 1807): Bakony: Cuha-völgy, Bakonybél, Felsőörs, Fenyőfö, [Csesznek:] Gézaháza, Kardosrét, Királyszállás, [Gézaháza] Mogyorós-kert, Tihany, Zalaszántó, Zirc (ZomBori 1979), Tihany: Kiserdő, Tihany: tájvédelmi őrház, Csabrendek: Rendeki-hegy. Frequent. Host plants: Galium aparine and G. molugo.

Hoplocampoides xylostei (Vallot, 1836): Bakony (AMBRUs 1978), Bakonybél (ZomBORI 1979). Produce galls on Lonicera xylosteum, ocasionally on L. coerulea and L. nigra. Rare.

Monophadnoides rubi (Harris, 1845): [Bakony:] Gerence-völgy (ZoMBORI 1979), Bakonygyepes, Hárskút (RoLler and HARIs 2008), Rezi: Gyöngyösi csárda, Zalaszántó: Alsó-nyíres (HaRIs 2019). Generally frequent. Host plants: Filipendula ulmaria, Geum spp. and Rubus spp.

Monophadnoides ruficruris (Brullé, 1832): Bakony: Gerence-völgy (ZoMBORI 1979). Frequent. Host plant: Rubus fructicosus.

Monophadnus monticola (Hartig, 1837): Bakony. Cuha-völgy (Roller and HARIS 2008). All other M. monticola published by ZoMBORI, 1979 are proved to be M. pallescens. Sporadic. Larva on Helleborus spp. 


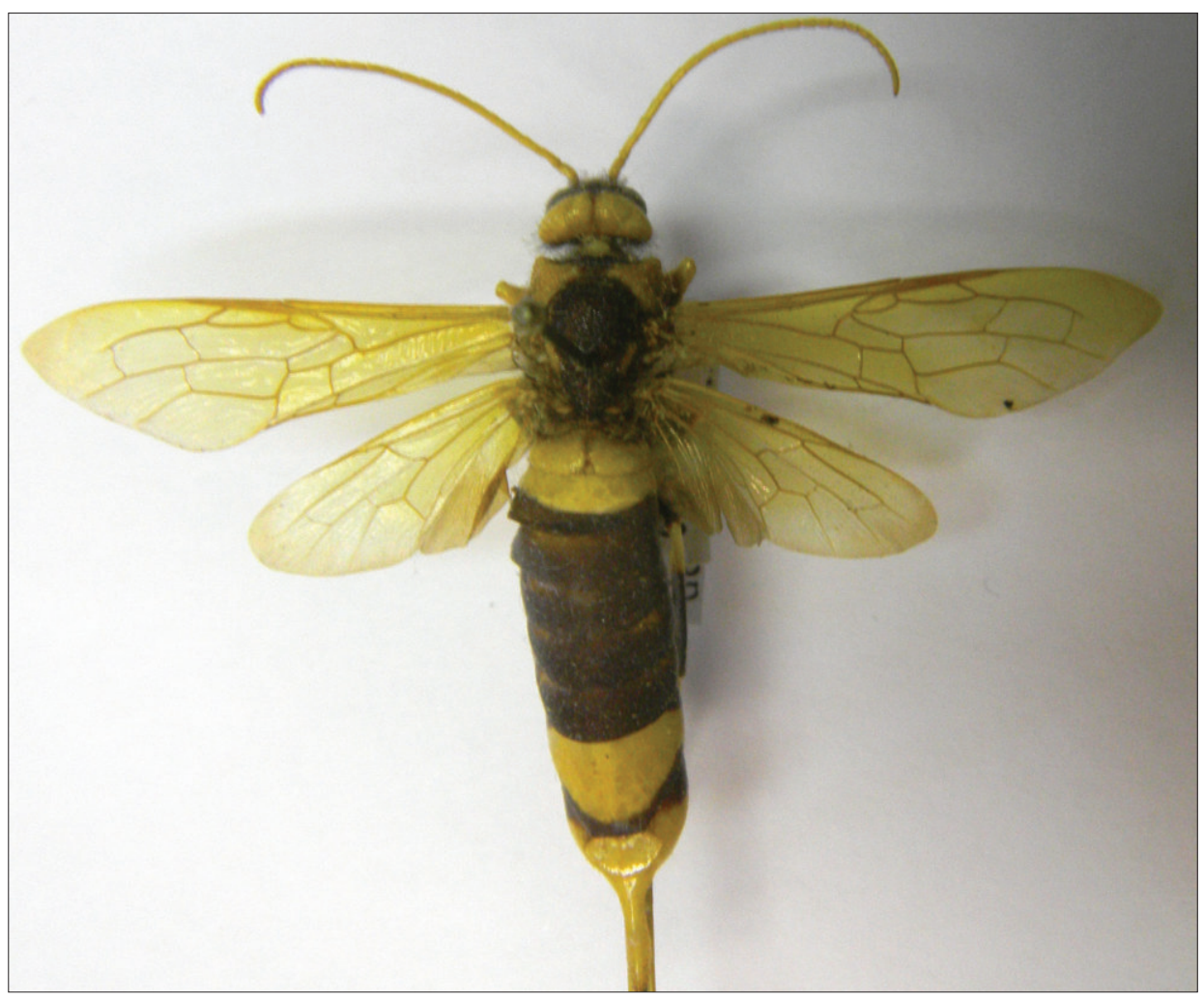

Fig. 10: Urocerus augur (Klug, 1803) (photo: Attila Haris)

Monophadnus pallescens (Gmelin, 1790): Bakony: Cuha-völgy, Bakonybél, Eplény, Farkasgyepü, [Csesznek:] Gézaháza, [Csesznek: Cuha:] Káró, [Csesznek:] Kö-árok, Németbánya, Padragkút, Sáska, Zalaszántó (ZomвORI 1979), Balatongyörök, Fenyőfö (Roller and HARIS 2008), Balatongyörök: Bélap-völgy, Balatongyörök: Mogyorós út: Szőlö-hegyek, Cserszegtomaj: Dobogó, Cserszegtomaj: Várvölgyi út: Pörkölt-hegy, Rezi: Gyöngyösi csárda, (HaRIs 2019), Bakonybél: Gerence-völgy, Eplény: Malomrétivölgy, Fenyőfö, [Csesznek:] Gézaháza, Királyszállás: Barok-völgy, Kardos-rét, Lesenceistvánd, Padragkút, Zirc: Pintér-hegy: Pinus sylvestris and Juniper vegetation. Common. Host plants: Ranunculus acris, $R$. repens, $R$. lanuginosus and Anemone nemorosa.

Monophadnus spinolae (Klug, 1816): Ajka, Bakony: Cuha-völgy, Bakonybél, Csesznek, Eplény, Felsőörs, Halimba, Köveskál, Monostorapáti, Pula, Tihany, Urkút Vállus, Veszprém, (Zombori 1979), Balatongyörök, Tihany, (Roller and HARIs 2008), Balatongyörök: Bélap-völgy, Vállus: Láz-tető (HARIs 2019), Balatonkenese: Tátorjános, Csabrendek: Rendeki-hegy. Sporadic. Host plants: Clematis vitalba and C. flammula.

Pareophora pruni (Linné, 1758): Tihany (ZomBori 1979), Porva: Pálihálás (RoLleR andHARIs 2008), Cserszegtomaj: Dobogó, Cserszegtomaj:Fagyos-kereszt, Balatongyörök: Bélap-völgy, Balatongyörök: Mogyorós út: Szőlő-hegyek (Haris 2019), Tihany: Csúcshegy, Tihany: tájvédelmi örház. Frequent. Larva on Prunus spinosa.

Periclista (Periclista) albiventris (Klug, 1816): Mindszentkálla (RoLler and HARIS 2008), Balatongyörök: Bélap-völgy (HARIs 2019). Sporadic. Host plant unknown. 


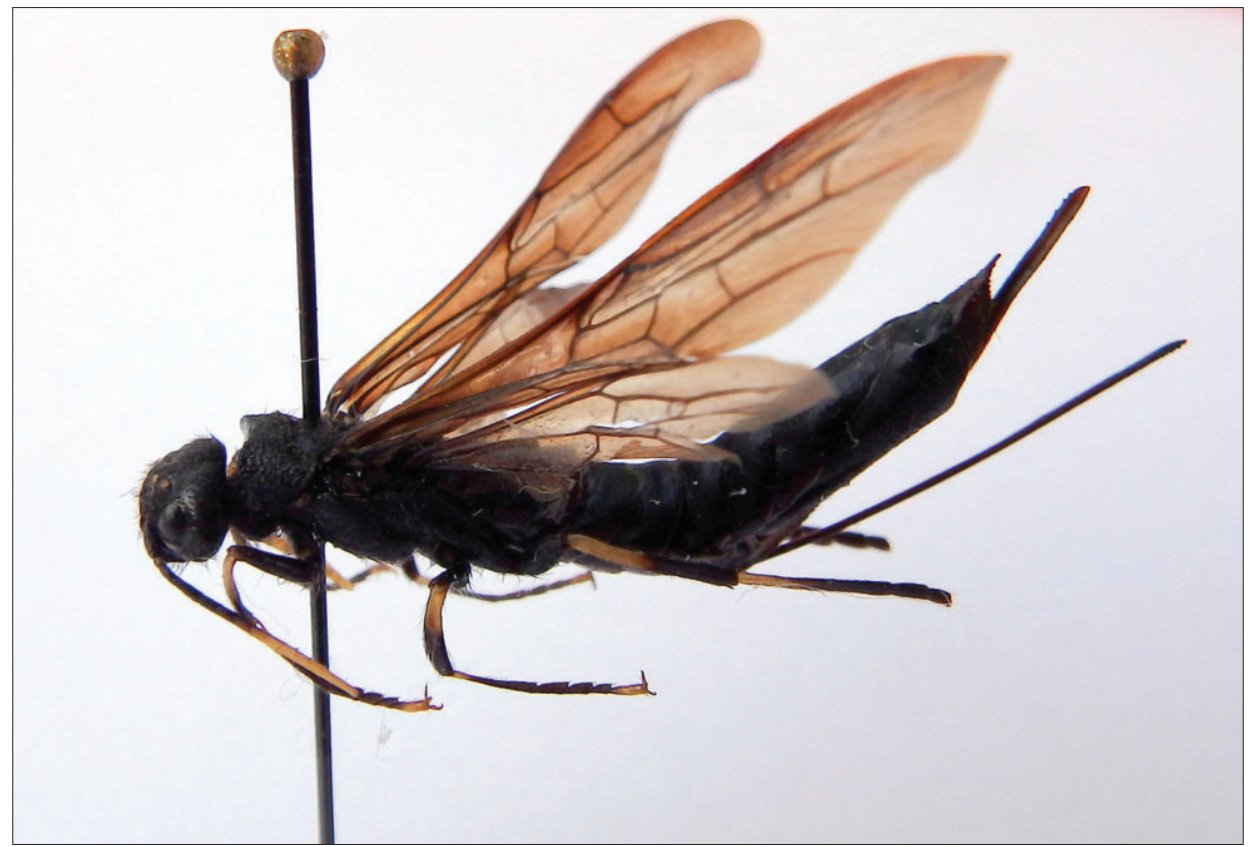

Fig. 11: Tremex alchymista Mocsáry, 1886 (photo: Csaba Kutasi)

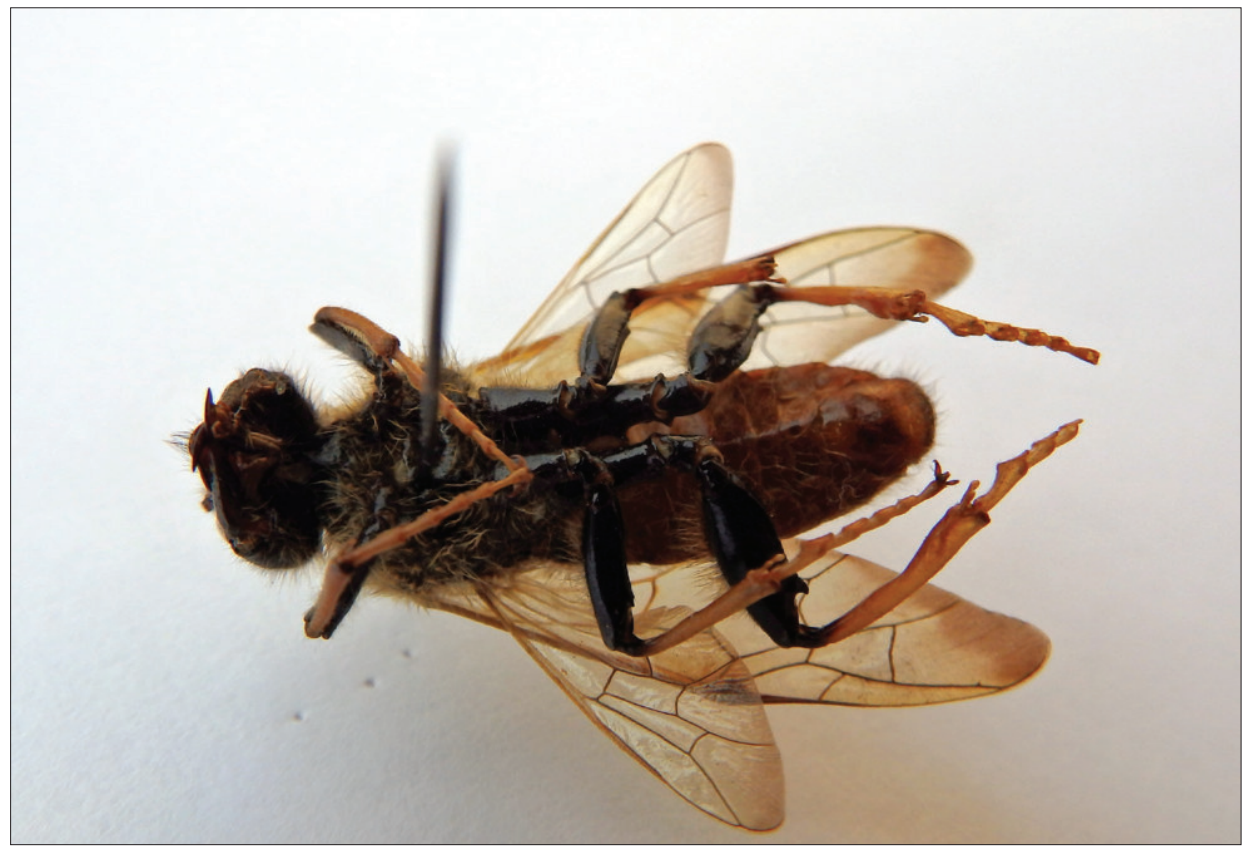

Fig. 12: Trichiosoma vitellina (Linné, 1760) (photo: Csaba Kutasi) 
Periclista (Periclista) lineolata (Klug, 1816): Zirc (Zombori 1979). Rare. Larva on Quercus spp. like Quercus rubra.

Phymatocera aterrima (Klug, 1816): [Királyszállás:] Barok-völgy, [Hárskút:] Esztergáli-völgy, Farkasgyepü, Káptalanfüred, Olaszfalu, Tapolcafő, Vinyesándormajor, Vörösberény (Zombori 1979), Badacsony, Balatoncsicsó (Roller and Haris 2008), Fenyőfő: Pisztrángos-tó, Kővágóörs, Tapolca: Szent György-hegy, Tihany: Sajkod, Tihany: tájvédelmi őrház. Host plants: Polygonatum spp. Frequent.

Rhadinoceraea (Rhadinoceraea) reitteri Konow, 1890: Tihany: Csúcs-hegy, Tihany:

Kiserdö. Sporadic. Larva on Iris pumila, I. germanica and I. sambucina.

Stethomosthus fuliginosus (Schrank, 1781): Bakonybél, Bakonykoppány, Bakonynána, Balatoncsicsó, Balatonfüred, [Királyszállás:] Barok-völgy, Eplény, Farkasgyepü, Iharkút, Lesenceistvánd, Németbánya, Öcs, Porva-Csesznek, Tapolcafó, Tihany, Veszprém, Vinyesándormajor (Zombori 1979), Bakony: Cuha-völgy (Roller and Haris 2008), Zalaszántó: Alsó-nyíres (HARIs 2019), Bakonybél: Gerence-völgy, Balatonfüred: Koloska-völgy, Eplény: Malomréti-völgy, Fenyőfő: Pisztrángos-tó, [Csesznek:] Gézaháza, [Bakonyszentlászló:] Hódosér-völgy, Németbánya: Pisztrángos-tó, Tihany: Bozsai-öböl, Zirc: Arborétum, Zirc: Szarvaskút. Frequent. Larva on Ranunculus acris, $R$. repens and $R$. sceleratus.

Stethomostus funereus (Klug, 1816): Kiliántelep: Balatonpart. Rare. Host plant unknown.

Tomostethus nigritus (Fabricius, 1804): [Királyszállás:] Barok-völgy, [Fenyőfö:] Kisszépalma, [Csesznek:] Kö-árok, Márkó, (Zombori 1979), Fenyőfő (RoLler and HARIS 2008). Sporadic. Host plant: Fraxinus excelsior.

\section{Heterarthrinae}

Caliroa cerasi (Linné, 1758): Hárskút: Köris-hegy (Roller and HaRIS 2008). Frequent. Larva on Pyrus, Malus, Prunus, Crataegus, Sorbus, Rosa, Cydonia, Mespilus, Rubus, Amygdalus, Cerasus, Amelanchier, Pyracantha, Cotoneaster rarely Quercus, Salix spp.

Endelomyia aethiops (Gmelin, 1790): Bakonybél, Gyenesdiás, Tés (ZomBori 1979), Balatonfüred, Porva: Pálihálás (RoLler and HARIs 2008), Balatongyörök: Bélap-völgy (HARIs 2019), Szentgál: Mecsek-hegy. Sporadic. Larva on Rosa spp.

Fenella nigrita Westwood, 1839: Fenyőfö, [Isztimér:] Menyeke, Németbánya (Zombori 1979), Balatonszéplak, Márkó (Zombori 1990), Bakony: Gerence-patak (Roller and Haris 2008), Fenyőfö, Ösfenyves. Sporadic. Host plants: Potentila reptans and Agrimonia eupatoria.

Fenusa dohrnii (Tischbein, 1846): Gyulafirátót, [Ugod:] Somberek, (ZoMBORI 1979). Sporadic. Host plant: Alnus spp.

Hinatara nigripes (Konow, 1907): Balatongyörök: Bélap-völgy, Cserszegtomaj: Fagyos-kereszt (Haris 2019). Sporadic. Host plant: Acer campestre.

Heterarthrus microcephalus (Klug, 1818): Fenyöfő (ZombORI 1979). Host plants: Salix caprea and Salix starkeana. Sporadic.

Metallus albipes (Cameron, 1875): Tihany: Csúcs-hegy (Zombori 1990). Rare. Larva on Rubus idaeus.

Metallus lanceolatus (C. G. Thomson, 1870): Hétházpuszta, Olaszfalu: Alsópere: Szederkény (Zombori 1976). Rare. Host plant: Geum urbanum.

Metallus pumilus (Klug, 1816): Monostorapáti (ZOMBORI 1979), Balatonfüred: camping. Frequent. Larva on Rubus spp. 
Profenusa pygmaea (Klug, 1816): Bakony: [Gézaháza] Mogyorós, Márkó: Menyeke, Sümeg: Sarvaly (Zombori 1975a), [Csesznek:] Gézaháza, Márkó, Sümeg (Zombori 1979), Fenyőfö. Sporadic. Larva on Quercus spp.

Profenusa thomsoni (Konow, 1886): Csesznek (Zombori 1990). Rare. Larva makes mines inside the leaves of Betula pubescens and B. verrucosa.

\section{Tenthredininae}

Aglaostigma (Astochus) aucupariae (Klug, 1817): [Zirc:] Aklipuszta, Hárskút: Esztergáli-völgy, Bakony: Northern part of Cuha-völgy Bakonybél, Eplény, [Csesznek:] Gézaháza, [Csehbánya] Hajag, Hajmáskér, Herend, [Bakonyszentlászló:] Hódos-ér, Lesenceistvánd, Márkó, Pápa, Pápasalom, Sáska, Tés, Tihany, Városlőd, Veszprém, Vörösberény, Zirc (Zombori 1980), Berhida, Porva: Pálihálás (Roller and HARIS 2008), Balatongyörök: Bélap-völgy, Balatongyörök: Mogyorósút: Szőlő-hegyek, Cserszegtomaj: Pilikáni dolomitbánya, Cserszegtomaj: Várvölgyi út: Pörkölt-hegy, Vállus: Szarvaskotrás, Vállus: Kis-Láz-völgy, Várvölgy: Bándi-mezö, Várvölgy: Zsidi-rét, Zalaszántó: Alsó-nyíres (HARIs 2019), [Zirc:]Aklipuszta: Gerence-völgy, Bakonybél, Bakonybél: Gerence-völgy, Csehbánya: Középső-Hajag, Eplény: Malomréti-völgy, Hárskút: Esztergáli-völgy, [Vonyarcvashegy:] Petö-hegy, Pénzesgyör: Szömörke-völgy, Tihany: Csúcs-hegy, Tihany: Gejzír-mező, Tapolca: Tapolca-patak, Tihany: Kiserdő-tető, Ugod: Szár-hegy, Várpalota: Királyszállás, Zirc: Arborétum. Common. Larva on Galium mollugo and $G$. boreale.

Aglaostigma (Astochus) fulvipes (Scopoli, 1763): Bakonybél, Bakony: Cuha-völgy, Dudar, Eplény, [Hárskút:] Esztergáli-völgy, Fenyőfö, [Bakony:] Gerence-völgy, [Csesznek:] Gézaháza, Gyulafirátót, [Bakonyszentlászló:] Hódos-ér, Huszárokelőpuszta, Királyszállás, Lesenceistvánd, Lókút, Márkó, [Gézaháza] Mogyorós, [Csesznek:] Ördög-árok, Pénzesgyőr, Sáska, [Pénzesgyőr:] Szömörke-völgy, Tés, Tihany, Városlőd, Veszprém, Zalaszántó, Zirc (ZoMBORI 1980), Kapolcs (HARIS 1998), Balatongyörök: Bece-hegy, Porva: Pálihálás (RoLler and Haris 2008), Balatongyörök: Bélap-völgy, Balatongyörök: Mogyorós út: Szőlő-hegyek, Cserszegtomaj: Fagyos-kereszt, Gyenesdiás: Lötér, Rezi: Gyöngyösi csárda, Várvölgy: Zsidi-rét (HaRIs 2019), Csehbánya: KözépsőHajag, Eplény: Malomréti-völgy, Fenyőfő: Pisztrángos-tó, Tihany: Kis-erdő, Tihany: Külső-tó, Tihany: tájvédelmi őrház. Common. Larva on Galium mollugo and $G$. verum.

Aglaostigma (Aglaostigma) lichtwardti (Konow, 1892): [Bakonyszentlászló:] Hódosér, Bakonybél, Porva (Zombori 1980). Sporadic. Larva on Petasites spp.

Macrophya (Macrophya) albicincta (Schrank, 1776): Bakony: Cuha-völgy Bakonybél, Bakonyszúcs, [Királyszállás:] Barok-völgy, Csetény, Eplény, [Bakony:] Gerence-völgy, Isztimér, [Bakonybél:] Köris-hegy, Pápa, Porva, [Pénzesgyőr:] Szömörke-völgy, Tés, Zalaszántó (Zombori 1980), Balatoncsicsó, Porva: Pálihálás, Salföld, Tapolca: Szent György-hegy, Tihany, Vászoly (RoLLER and HaRIs 2008), Balatongyörök: Bélap-völgy, Balatongyörök: Mogyorós út: Szőlö-hegyek, Cserszegtomaj: Fagyos-kereszt, Rezi: Gyöngyösi csárda, Vonyarcvashegy: láprét (HARIS 2019), Ajka: Köleskepe, [Zirc:] Aklipuszta: Gerence-patak, Bakony: Cuha-völgy, Bakonybél: Arborétum, Bakonybél: Gerence-völgy, Bakonybél: Szömörkés, Bakonypölöske: Kúpi-erdő, Bakonyszentkirály, Balatonalmádi: Tulipán u. 15, Balatonfökajár: Somló-hegy, Balatonfüred: Koloskavölgy, Bodajk, Bodajk: Zseriszállás, Csehbánya, Dudar: Ördög-árok, Eplény: Malomrétivölgy, Fenyőfö, Fenyőfő: Halastó, Fenyőfő: Pisztrángos-tó, Fenyőfő: Kisszépalma, [Bakony:] Gerence-völgy, [Csesznek:] Gézaháza: Ördög-árok, Gyulafirátót, Hajmás, Hajmáspuszta, [Bakonyszentkirály:] Hajmáspuszta: Halastavak, Hárskút: Esztergálivölgy, Hárskút: Molnár-tanya, Herend: Aranyos, Herend: Somod, Hétházpuszta, 
[Huszárokelőpuszta] Huszárokelő-patak, Iharkút, Kapolcs: Egervíz, Királyszállás: Barok-völgy, Köveskál: Fekete-hegy, Márkó, Márkó: Séd-patak, Mogyorós-domb, Monostorapáti: Doma-hegy, Németbánya, Padragkút: Hajagos, Pénzesgyőr, Pénzesgyőr: Gerence-völgy, Pénzesgyőr: Kerteskő, Sáska: Bükkös-tető, Somlóvásárhely: Somló, Sümeg, Szentkirályszabadja: Kö-hegy, Tapolca: Mogyoró-domb, Tapolca: Tapolcapatak, Tés, Tés: Sötéthorog-völgy, Tihany: Kis-erdö,Tihany: Szabadstrand, Tihany: Külső-tó, Tihany: Sajkod, Tihany: tájvédelmi őrház, Városlőd: Torna-mente, Vállus: Barbacs, Vörösberény: Malom-völgy, Zalaszántó: Kovácsi-hegy, Zirc: Szarvaskút, Zirc: Arborétum, Zirc: Cigány-domb, Zirc: Cuha-patak, Zirc: Pintér-hegy. Common. Host plants: Sambucus ebulus, S. nigra, S. racemosa, Valeriana officinalis and Viburnum opalus.

Macrophya (Macrophya) annulata (Geoffroy, 1785): Balatonkenese, Bakonybél, Bakonykoppány, Bakonypölöske, Bakonyszücs, [Bakony:] Gerence-völgy, Gyepűkaján, Gyulafirátót, Halimba, Isztimér, Kapolcs, [Bakonybél:] Köris-hegy, Márkó, Németbánya, Tapolcafö, Tihany, Ugod, Uzsa, Városlőd, Várpalota, Zirc (ZomBORI 1980), Badacsony, Bakonybél, Balatonalmádi, Balatonfüred, Cserszegtomaj: Kö-hát (RoLler and HARIS 2008), Cserszegtomaj: Dobogó, Cserszegtomaj: Fagyos-kereszt, Balatongyörök: Bélapvölgy, Balatongyörök: Mogyorós út: Szőlő-hegyek (Haris 2019), Ajka, Aszófö, Bakonybél: Gerence-patak, Bakonybél: Szömörkés-völgy, Bakonyszentlászló: Vinye, Bakonyszücs: Gerence-völgy, Csopak: Nosztori-völgy, Eplény: Malomréti-völgy, Felsőörs, Fenyőfő: Pisztrángos-tó, Gyenesdiás: Szék-tető, Gyulafirátót, Gyulafirátót: Miklád, Hárskút: Esztergáli-völgy, Németbánya: Vadászház, Porva-Csesznek, Sáska: Szár-hegy, Sümeg: Mogyorósd [Mogyorós-domb], Sümeg: Sarvaly, Tapolca: Szent György-hegy, Tapolca: Tapolca-patak, Tés: Kis-Futóné, Tihany: Akasztó-domb, Tihany: Bozsai-öböl, Tihany: Kis-erdő, Tihany: Külső-tó, Vállus: Büdöskút: Fekete-hegy, Várpalota: Cseri-erdö, Zirc, Zirc: Arborétum, Zirc: Pintér-hegy, Zirc: Szarvaskút. Frequent. Larva on Potentilla reptans, Origanum vulgare, Euphorbia, Rosa, Rubus and Sambucus spp.

Macrophya (Macrophya) blanda (Fabricius, 1775): Ajka, Bakonypölöske, Balatonalmádi, Balatonfüred, Bodajk, [Csesznek:] Gézaháza, Köveskál, Németbánya, Tapolcafö, Tihany (Zombori 1980), Balatonfüred: Koloska-völgy, Bodajk: Zseriszállás, Borzavár, Felsőörs, Gyenesdiás: Szék-tető, Iharkút, Királyszállás: Barok-völgy, Németbánya: Vadászház, Vállus: Láz-tető, Zirc: Cuha-völgy. Frequent. Host plant unknown.

Macrophya (Macrophya) carinthiaca (Klug, 1817): Porva: Páskom. Rare in Hungary. Larva on Geranium sylvaticum and G. sanguineum.

Macrophya (Macrophya) chrysura (Klug, 1817): Balatonalmádi, Veszprém (ZoMBORI 1980), Balatonfüred, Balatongyörök, Veszprém, (RoLler and HARIs 2008), Vászoly: Öreg-hegy. Sporadic. Host plant Daucus carota.

Macrophya (Macrophya) crassula (Klug, 1817): Tapolca (MocsáRY 1900), Isztimér, Halimba, Úrkút (Zombori 1980), Cserszegtomaj: Dobogó (HaRIs 2019), Ajka: Köleskepe, Bodajk, Eplény: Malomréti-völgy, Hétházpuszta, Iharkút: Láposak, Németbánya: Pisztrángos-tó, Sáska: Bükkös-tető, Somlóvásárhely: Somló, Tapolca: Szent Györgyhegy, Várpalota: Várvölgy, Zirc: Szarvaskút. Sporadic. Host plant: Sambucus ebulus.

Macrophya (Macrophya) diversipes (Schrank, 1782): Bakonybél, Balatonalmádi, Köveskál, Tapolcafö, Tihany, Városlőd (Zombori 1980), Hidegkút (RoLler and Haris 2008), Csehbánya: Középső-Hajag, Tihany: Gejzír-mező, Tés: Kis-Futóné. Frequent. Host plant unknown.

Macrophya (Macrophya) duodecimpunctata (Linné, 1758): Bakonybél, Balatonfüred, Nagyvázsony, Németbánya, Veszprém, (ZombORi 1980), Cserszegtomaj (Roller and 
Haris 2008), Balatongyörök: Mogyorós út: Szőlö-hegyek (HARIS 2019), Fenyőfö: Kisszépalma, Fenyőfő: Ösfenyves, Gyulafirátót: Halastó, [Bakonyszentkirály:] Hajmáspuszta: Halastavak, Hárskút: Esztergáli-völgy, Herend: Aranyos, Kapolcs: Bondoró-hegy, Kapolcs: “Kálomis”, Németbánya: Vadászház, Öcs: Nagy-tó, Tapolcafö: Mogyorós-domb, Tapolcafő: Kalapács-ér, Tihany: Bozsai-öböl, Zirc: Pintér-hegy, Uzsa, Várpalota: Loncsos, Vállus: Büdöskút, Veszprém: Tekeres-völgy, [Bakonybél:] Vörös János-séd, Felsőörs, Tihany: Kiserdő-tető. Common. Host plants: Graminae, Cyperaceae and Carex spp.

Macrophya (Macrophya) erythrocnema A. Costa, 1859: Márkó, Tapolcafő (ZoMBORI 1980), Cserszegtomaj: Dobogó (HARIs 2019), Csesznek: Várbükk. Sporadic. Host plant: Knautia arvensis.

Macrophya (Macrophya) militaris (Klug, 1817): Tapolca (MocsÁRY 1900), Ácsteszér, Bodajk, Fenyőfö, Hajmáspuszta, Úrkút (ZOMBORI 1980), Balatongyörök (RoLLER and HARIS 2008), Bakonybél: Gerence-patak völgy, Bakonyszentkirály: Újmajor, Eplény: Malomréti-völgy, Sümeg: Sarvaly, Uzsa, Várpalota: Cseri-erdő, Zirc, Zirc: Szarvaskút. Sporadic. Host plant: Rubus caesius.

Macrophya (Macrophya) montana ssp. montana (Scopoli, 1763): Bakony: Cuhavölgy, Bakonyszücs, Bakonybél, Balatonalmádi, Balatonfüred, Balatonkenese, Csehbánya, Fenyőfö, Észak Cuha-völgy, Halimba, Herend, Hétházpuszta, Kapolcs, [Ugod:] Királykapu, Királyszállás, Szentgál, Porva, Porva-Csesznek, Tapolcafö, Ugod, Városlőd, Várpalota, Veszprém, Zalaszántó, Zirc (ZoMBORI 1980), Badacsony, Balatongyörök, Hidegkút, Kékkút, Szarvaskút, (RoLlER and Haris 2008), Balatongyörök: Bélap-völgy, Cserszegtomaj: Dobogó, Cserszegtomaj: Várvölgyi út: Pörkölt-hegy (HARIs 2019), Bakonybél: Gerence-patak, Bakonykoppány: Huszárokelö-patak, Bakonyszombathely: Feketevíz-patak, Balatonalmádi: Budatava, Balatonkenese: Tátorjános, Bodajk: Zseriszállás, Csopak: Nosztori-völgy, Eplény Malomréti-völgy, Fenyőfő: Halastó, Fenyőfő: Ösfenyves, Herend: Rakottyás, Hárskút: Esztergáli-völgy, Hétházpuszta, [Ugod:] Királykapu, Királyszállás: Barok-völgy, Németbánya: Vadászház, [Csopak:] Nosztori-völgy, Öcs: Nagy-tó, Pénzesgyőr, Porva-Csesznek, Sümeg: Kopaszdomb, Szentgál: Mecsek-hegy, Tapolcafö: below Mogyorós-domb, Tapolca: Tapolcapatak, Tihany: Bozsai-öböl, Tihany: Gejzír-mező, Tihany: Kis-erdő, Tihany: Külső-tó, Tihany: Szabadstrand, Uzsa, Vállus: Láz-tető, Zirc: Cuha-völgy, Zirc: Pintér-hegy, Zirc: Szarvaskút. Common. Host plant: Rubus caesius.

Macrophya (Macrophya) postica Brullé, 1832: Tapolca (MocsáRY 1900), Csetény, Herend, Köveskál, Sáska, Tihany, Úrkút, Veszprém, (ZOMBORI 1980), Kemenesszentpéter (HARIS 1998) Balatonkenese (Roller and HARIs 2008), Balatongyörök: Bélap-völgy (Haris 2019), Ajka, Herend: Somod, Tihany: Gejzír-mező, Tapolca: Szent György-hegy. Frequent. Host plant unknown.

Macrophya (Pseudomacrophya) punctumalbum (Linné, 1767): Tapolca (MocsÁRY 1900), Bakonyszücs, Eplény, Fenyőfő, Hajmáspuszta, Pula, Tihany, Ugod (ZomBori 1980), Balatongyörök: Bece-hegy (RoLler and HARIS 2008), Bakonyszombathely: Feketevíz-patak, Káptalanfa, Vállus: Büdöskút. Sporadic. Host plants: Fraxinus spp. and Ligustrum spp.

Macrophya (Macrophya) recognata Zombori, 1979: Bakonyszücs, [Pénzesgyőr:] Szömörke-völgy, Zirc (ZomBori 1980), Csesznek: Cuha-völgy, [Bakonyszentkirály:] Hajmáspuszta: Halastavak, Királyszállás: Barok-völgy, Márkó: Séd-patak völgye, Németbánya, Németbánya: Vadászház, Porva, Rezi, Zirc: erdő. Sporadic. Host plant unknown.

Macrophya (Macrophya) ribis (Schrank, 1781): Bakony: Cuha-völgy, Ugod, Zalaszántó (Zombori 1980), Balatonhenye, Bakonyszücs, Csabrendek: Tüskés-puszta, Fenyőfö: 


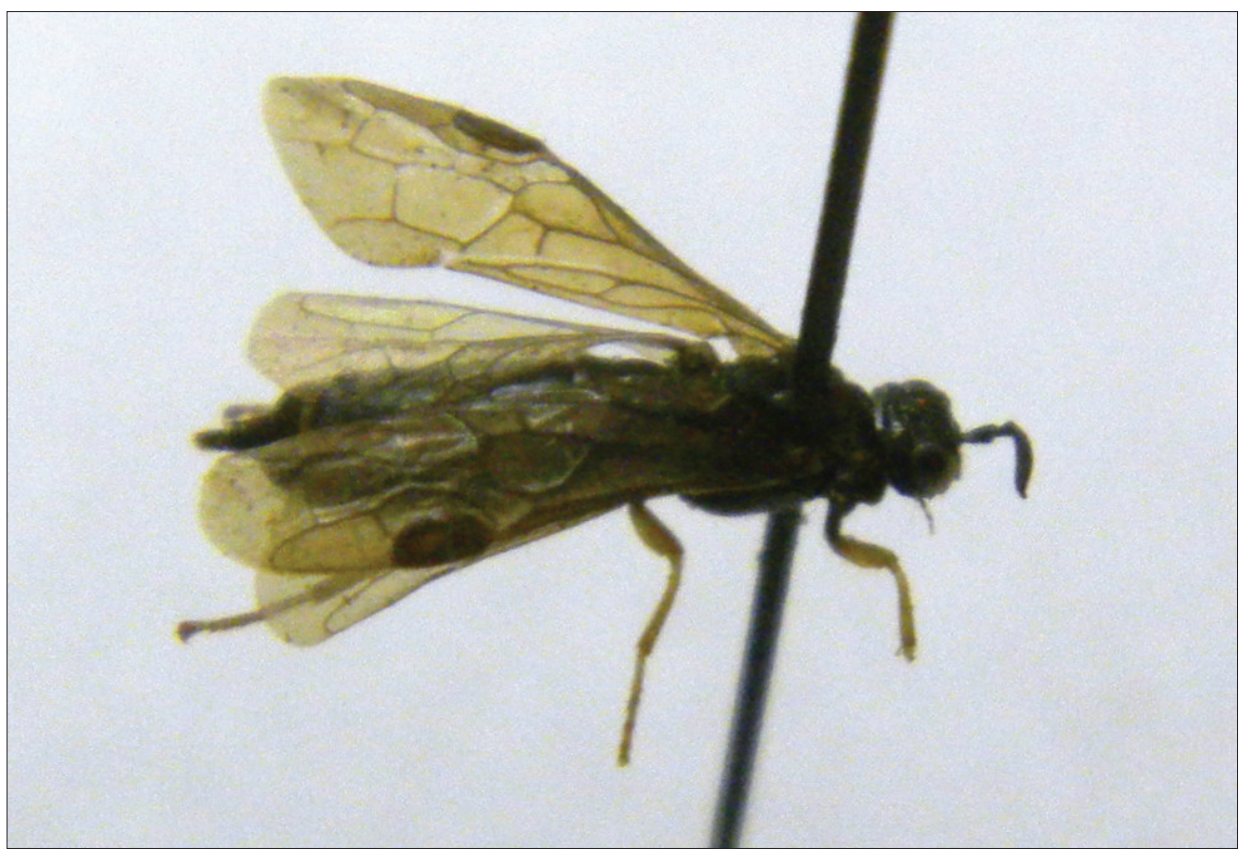

Fig. 14: Blasticotoma filiceti Klug, 1834 (photo: Attila Haris)

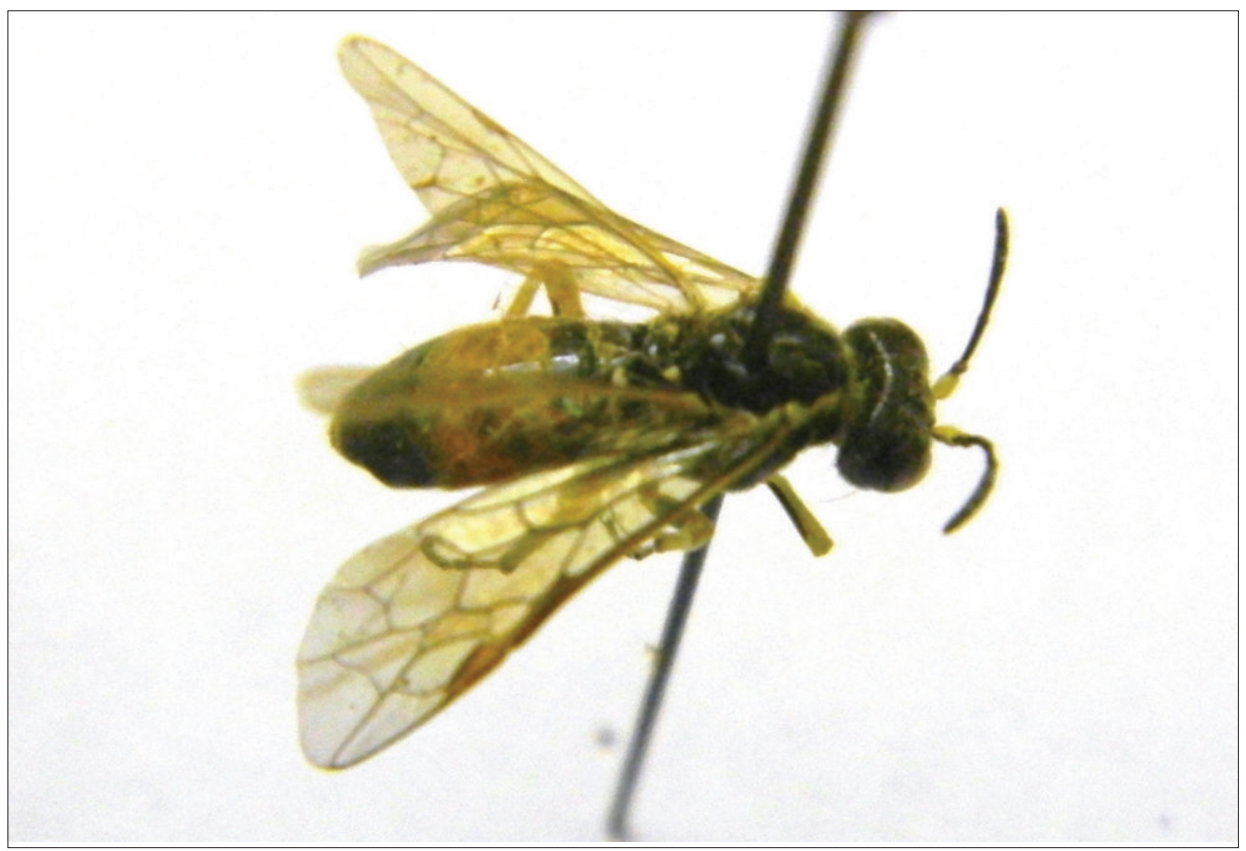

Fig. 15: Tenthredo sabariensis (Mocsáry, 1880) (photo: Attila Haris) 
Pisztrángos-tó, Herend: Aranyos, Kapolcs: Egervíz, Városlőd: Torna-mente, Zalaszántó: Kovácsi-hegy, Zirc: Arborétum, Zirc: erdő, Zirc: Szarvaskút. Frequent. Larva on Sambucus nigra.

Macrophya (Macrophya) rufipes (Linné, 1758): Bakonybél, Herend, Hétházpuszta, Isztimér, Tapolcafö, Tihany, Városlőd, Várpalota, Zirc, (ZoMBORI 1980), Tapolca (HARIS 1998), Cserszegtomaj: Dobogó, Várvölgy: Bándi-mező (Haris 2019), Eplény: Malomrétivölgy, Szentgál: Somod, Kővágóörs: Kornyi-tó, , Tihany: Gejzír-mező, Tihany: Külsőtó. Frequent. Larva on Agrimonia eupatoria.

Macrophya (Macrophya) sanguinolenta (Gmelin, 1790): Balatonfüred, Fenyőfö, [Csesznek:] Gézaháza, Hárskút, Királyszálllás, [Herend] Mogyorós-domb, [Csesznek:] Zörög-tető (ZoMBORI 1980), Bakony: Cuha-völgy, Porva: Pálihálás (RoLLeR and HaRIS 2008), Ajka, Bakonybél: Gerence-völgy, Bazsi, Eplény: Malomréti-völgy, Hárskút: Esztergáli-völgy, Németbánya, Pénzesgyőr: Gerence-völgy, Porva-Csesznek, Ugod: Vörös János-séd, Tihany: Kis erdő-tető, Vállus: Láz-tető, Sümeg: Mogyorós-domb. Sporadic. Larva on Galeopsis spp., Senecio spp. and Veronica spp.

Macrophya (Macrophya) teutona (Panzer, 1799): [Csesznek:] Gézaháza, Szentgál (Zombori 1980). Sporadic. Larva on Euphorbia spp.

Pachyprotasis antennata ssp. antennata (Klug, 1817): Bakony: Northern part of Cuhavölgy, Bakonyszücs: Márvány-árok, Németbánya, Porva: erdő (ZoMBoRI 1980). Sporadic. Larva on Filipendula ulmaria, Hypericum spp. and Fraxinus spp.

Pachyprotasis rapae (Linné, 1767): Bakony: Cuha-völgy, [Királyszállás:] Barokvölgy, Bakonybél, Bakonygyepes, Csesznek, Dudar, Eplény, [Hárskút:] Esztergálivölgy, Farkasgyepü, Fenyőfő, [Bakony:] Gerence-völgy, [Csesznek:] Gézaháza, Hévíz, [Bakonyszentlászló:] Hódos-ér, Huszárokelőpuszta, Iharkút, Kapolcs, Királyszállás, [Csesznek:] Kö-árok, [Bakonybél:] Köris-hegy, Lesenceistvánd, Márkó, Nagyvázsony, Németbánya, Olaszfalu, Padragkút, Pénzesgyőr, Porva, [Ugod:] Somberek, [Pénzesgyőr:] Szömörke-völgy, Tés, Ugod, Úrkút, Várpalota, Zalaszántó, Zirc (ZoMBORI 1980), Fenyőfö, Porva: Pálihálás, Vállus, (RoLler and Haris 2008), Bakonyszentlászló: Hódos-ér, Eplény: Malomréti-völgy, Fenyőfő: Ösfenyves, Hárskút: Esztergáli-völgy, Zirc: Arborétum. Frequent. Host plants: Solanum tuberosum, Pedicularis palustris, Angelica sylvestris, Veronica beccabunga, Betonica officinalis, Corylus avellana, Salix caprea, Fraxinus excelsior, Tussilago farfara, Symphoricarpos albus, Scrophularia, Solidago, Verbascum, Origanum, Atropa, Sarothamnus, Senecio, Polygonum, Aspidium, Epilobium, Hypericum, Galeopsis, Mentha, Polystichum, Plantago, Quercus and Stachys spp.

Pachyprotasis simulans (Klug, 1817): Fenyőfö: Pisztrángos-tó. Sporadic. Host plants: Scrophularia, Senecio and Solidago spp.

Pachyprotasis variegata (Fallén, 1808): [Csesznek:] Gézaháza, [Csesznek:] Kö-árok, Pénzesgyőr, Porva, Zirc (Zombori 1980). Host plants: Solanum tuberosum, Leontodom hispidus, Leucanthemum vulgare, Pyrethrum corymbosum, Valeriana officinalis and Digitalis spp. Sporadic.

Perineura rubi (Panzer, 1803): Bakony: Northern part of Cuha-völgy (ZoMBORI 1980). Sporadic. Host plant unknown. Adults associated with Rubus spp.

Rhogogaster (Rhogogaster) chlorosoma (Benson, 1943): Bakonybél, Eplény, [Csesznek:] Gézaháza, Halimba, Pénzesgyőr, Ugod, [Bakonybél:] Vörös János-séd, (ZOMBORI 1980), Gyenesdiás (Roller and Haris 2008), Gyenesdiás: Kőbánya (HaRIS 2019) Felsőörs, Tihany: Gejzír-mező, Tapolca: Tapolca-patak, Vállus. Frequent. Host plants: Pteridium aquilinum, Alnus glutinosa, Circaea spp., Prunus spp., Ranunculus spp., Rosa spp., Salix alba, S. purpurea, Stellaria spp., Filipendula ulmaria, Populus tremula, Padus spp., Betula spp., Corylus avellana and Sorbus spp. 
Rhogogaster (Cytisogaster) picta (Klug, 1817): Fenyőfö, Gyulafirátót, [Csesznek:] Kö-árok, Márkó, [Gézaháza] Mogyorókert, Tapolca, Zirc (Zombori 1980), Bakony: [Gézaháza]Gézahegy, Veszprém (Roller and HARIS 2008), Balatongyörök: Mogyorós út: Szőlöhegyek (HARIs 2019), Hárskút: Esztergáli-völgy. Sporadic. Cytisus scoparius, C. nigricans, Genista germanica and G. tinctoria.

Rhogogaster (Rhogogaster) punctulata (Klug, 1817): Pénzesgyőr (ZoMBORI 1980). Host plants: Salix, Sorbus, Rosa, Betula, Alnus, Fraxinus, Prunus and Corylus spp. Sporadic in the Carpathian Basin, in Hungary rare.

Rhogogaster (Rhogogaster) scalaris (Klug, 1817): Bakony: Cuha-völgy, Csehbánya, [Csesznek:] Gézaháza, Felsőörs, Fenyőfö, Gyulafirátót, Királyszállás, Németbánya, (Zombori 1980), Csesznek: Gézaháza, Vinye: Hódos-ér. Frequent. Chamnaerion angustifolium, Salix spp., Populus spp., Alnus spp., Quercus spp., Filipendula spp., Stellaria spp. and Circaea spp.

Sciapteryx consobrina (Klug, 1816): Bakony: Cuha-völgy, [Királyszállás:] Barokvölgy, Balatoncsicsó, [Hárskút:] Esztergáli-völgy, Fenyőfő, Hárskút, Márkó, Pápasalamon, Porva, [Pénzesgyőr:] Szömörke-völgy, Tés, Veszprém, Zalaszántó, Zirc (ZoMBORI 1980), Balatongyörök: Bélap-völgy, Cserszegtomaj: Büdöskúti út (HARIs 2019), [Bakonybél:] Borostyánkút, Eplény: Malomréti-völgy, Hárskút: Esztergáli-völgy, Vállus, Várpalota: Vár-völgy. Frequent. Larval hosts: Adoxa spp., Anemone spp., Ranunculus acris and Ranunculus ficaria.

Sciapteryx costalis (Fabricius, 1775): Márkó, Porva, Tés, Szentbékkálla, (ZomBori 1980), Cserszegtomaj: Büdöskútiút,Zalaszántó:Alsó-nyíres(HARIs 2019), Balatonalmádi. Frequent. Host plant: Ranunculuis acris.

Siobla sturmii (Klug, 1817): Bakonybél, Porva-Csesznek, [Ugod:] Somberek, Várpalota (ZOMBORI 1980). Larva on Impatiens nolitangere. Sporadic.

Tenthredo (Zonuledo) amoena (Gravenhorst, 1807): Bakonybél, Bakonyszombathely, Bodajk, Borzavár, Csesznek, Dudar, Fenyőfö, [Bakonybél:] Köris-hegy, Olaszfalu, Pálihálás, [Zirc:] Pintér-hegy, Porva, Porva-Csesznek, Pula, Szentgál, Úrkút, Zirc (Zombori 1980), Balatoncsicsó (Roller and Haris 2008), Cserszegtomaj: Csóka-kő (HARIs 2019), Adásztevel, Bakonybél: Barátok útja, Bakonybél: Gerence-völgy, Bakonybél: Száraz-Gerence, Bakonynána, Bazsi, Farkasgyepü, Fenyőfő: Ösfenyves, Királyszállás: Barok-völgy, [Bakonybél:] Top of Köris-hegy, Zirc: Három-hegy. Frequent. Larva on Hypericum maculatum and $H$. perforatum.

Tenthredo (Tenthredella) atra Linné, 1758: Bakonycsernye, Balinka, Fenyőfö, [Csesznek:] Gézaháza, Királyszállás, Márkó, [Gézaháza] Mogyoróskert, Olaszfalu, Szentgál,[Pénzesgyőr:] Szömörke-völgy, Pálihálás, Porva, Tapolcafő, Tés, Zalaszántó, Zirc (Zombori 1980), Zalaszántó: Kovácsi-hegy (HaRIs 2019), Tihany: Bozsai-öböl, Tihany: Kis-erdő. Frequent. Larval hosts: Lamium, Mentha, Plantago, Vicia, Ranunculus, Scabiosa, Brassica and Solanum spp.

Tenthredo (Cephaledo) bifasciata ssp. rossii (Panzer, 1803): Ajka, Balatonfüred, Csesznek, Eplény, [Csesznek:] Gézaháza, Isztimér, Kapolcs, Monostorapáti, Pápateszér, Pénzesgyőr, Pétfürdő, Somlóvásárhely, Szentkirályszabadja, Tihany: Külső-tó, Úrkút, Veszprémfajsz (Zombori 1980), Badacsony, Bakonybél (Roller and Haris 2008), Fehérvárcsurgó, Hétházpuszta, Tihany: Külső-tó. Frequent. Host plants: Scrophularia and Verbascum spp.

Tenthredo (Cephaledo) bifasciata ssp. violacea (Andre, 1881): Tihany: Akasztó-domb (Roller and Haris 2008), Bakony: Cuha-völgy, Fehérvárcsurgó, Hétházpuszta, Németbánya, Öcs: Nagy-tó, Tihany: Gejzír-mező, Tihany: Külső-tó, Tihany: Óvár, Veszprém: Jutas. Frequent. Host plant unknown. 
Tenthredo (Tenthredella) bipunctula Klug, 1817: Németbánya (ZoMBORI 1980). Larva on Senecio finschii. Rare in Hungary.

Tenthredo (Tenthredo) brevicornis (Konow, 1886): Bakonybél, Fenyőfö, Kovácsdomb, [Bakonybél:] Köris-hegy, Németbánya, Pénzesgyőr, [Ugod:] Somberek, Tihany: Külsö-tó, Zalaszántó, Zirc (ZomBORI 1980), Zalaszántó: Kovácsi-hegy (HARIS 2019), Farkasgyepü, Csesznek. Frequent. Host plant: Lotus corniculatus.

Tenthredo (Endotethryx) campestris Linné, 1758: Bakonybél: Barátok útja, Bakonybél: Köris-hegy, Bakonybél: Tevelvár, Bazsi, Csehbánya, [Bakony:] Gerence-völgy, [Nagyvázsony:] Kab-hegy, Németbánya, Kapolcs: Eger-víz, Királyszállás, Királyszállás: Barok-völgy, Németbánya, Sáska: Szár-hegy, [Ugod:] Somberek, Zalaszántó: Tátika, Zirc: Arborétum. Frequent. Host plant: Aegopodium podagraria.

Tenthredo (Tenthredella) colon Klug, 1817: [Nagyvázsony:] Kab-hegy, Németbánya, Zirc (Zombori 1980), Bakonybél: Barátok útja. Host plants: polyphagous: Salix, Epilobium, Pteridium, Circaea, Fuschia spp. and Chamaenerion angustifolium. Sporadic.

Tenthredo (Cephaledo) costata Klug, 1817: Fenyőfö, Isztimér, [Gézaháza] Mogyorós, Uzsa, Veszprém (Zombori 1980), Hidegkút (Roller and HARIs 2008). Frequent. Host plant unknown.

Tenthredo (Elinora) dahlii Klug, 1817: Tapolca (MocsáRY 1900), Szentbékála, Tihany (Roller and Haris 2008), Sóly, Vászoly. Sporadic. Host plant unknown.,

Tenthredo (Zonuledo) distinguenda (Stein, 1885): Balatonakali, Dudar, [Csesznek:] Gézaháza, Herend, Hétházpuszta, Padragkút, Pénzesgyőr, (ZoMBori 1980), Tihany: Hosszú-hegy (RoLler and HARIs 2008), Balatongyörök: Bélap-völgy, Várvölgy: Bándimező (Haris 2019), Csehbánya: Középső-Hajag, Olaszfalu: Malom-völgy, Szentgál: Mecsek-hegy, Tés: Kis-Futóné, Zirc, Zirc: Cigány-domb, Zirc: Szarvaskút. Frequent. Host plant unknown.

Tenthredo (Cephaledo) excellens (Konow, 1886): Badacsony, Cserszeg (RoLler and HARIS 2008), Balatongyörök: Bélap-völgy (HARIS 2019), Eplény: Malomréti-völgy, Hétházpuszta, Tihany: Kis-erdő, Sporadic. Host plant unknown.

Tenthredo (Tenthredella) ferruginea Schrank, 1776: Bakonybél: Hubertlak. Polyphagous: Alnus, Salix, Filipendula, Rubus, Prunus, Aspidium, Pteridium, Atropa and Sorbus spp. Sporadic in the Carpathian Basin, in Hungary rare.

Tenthredo (Elinora) flaveola Gmelin, 1790: Balatonalmádi, Tihany (ZomBori 1980), [Bakonybél:] Köris-hegy (Roller and Haris 2008), Veszprém. Sporadic. Brassica oleracea, B. nigra, Sinapis arvensis, S. alba, Raphanus raphanistrum and Isatis tinctoria.

Tenthredo (Tenthredella) livida Linné, 1758: Ajka, Bakony: Northern part of Cuhavölgy, Bakonybél, Bakonyszücs, [Királyszállás:] Barok-völgy, Borzavár, Csőszpuszta, Eplény, Felsőörs, Hárskút, Királyszállás, [Bakonyszücs:] Márvány-árok, Németbánya, Pénzesgyőr, Sümeg, Tapolcafö, Ugod, Uzsa, Veszprém, Zirc (Zombori 1980), Tapolca: Szent György-hegy (RoLler and HARIS 2008). Sporadic, locally frequent. Larva on Salix spp., Corylus avellana; Epilobium spp.; Lonicera spp.; Pteridium aquilinum; Rosa spp., Sorbus aucuparia, Symphoricarpos albus, Viburnum opulus, Arctium lappa and Athyrium filix-femina.

Tenthredo (Maculedo) maculata Geoffroy, 1785: [Királyszállás:] Barok-völgy, Bodajk, Eplény, Fenyőfö, Herend, Királyszállás, Németbánya, Padragkút, Ugod, Vállus (ZoMBORI 1980), Hidegkút (Roller and Haris 2008), Vállus: Láz-tető (HARIS 2019), Hárskút: Esztergáli-völgy. Sporadic. Host plants: Brachypodium spp. and Dactylis spp.

Tenthredo (Tenthredella) mandibularis Fabricius, 1804: Eplény, Szentgál, Vinye (ZomBori 1980), Bakonynána, Eplény: Malomréti-völgy, [Bakonybél:] Kőris-hegy, 
Németbánya, Somlóvásárhely: Somló, Tihany: Külső-tó, Zirc: Pintér-hegy, Zirc: Szarvaskút. Larva on Petasites and Tussilago spp. Sporadic.,

Tenthredo (Tenthredo) marginella Fabricius, 1793: Vinye (ZOMBORI 1980), other published specimens by ZoMORI proved to be Tenthredo thomsoni Curtis. Zalaszántó: Tátika-erdő (HARIs 2019), Zirc, Felsőörs: Királykúti-völgy, Zirc, Farkasgyepü. Sporadic. Host plants: Mentha and Ocimum spp.

Tenthredo (Eurogaster) mesomela Linné, 1758: [Zirc:] Aklipuszta, Bakony: Northern part of Cuha-völgy, Bakonybél, Bakonykoppány, Bakonyszúcs, Balatonfüred, Bodajk, Borzavár, Csehbánya, Eplény, Felsőörs, Fenyőfö, Gyepúkaján, [Bakony:] Gerencevölgy, [Csesznek:] Gézaháza, Hajmáspuszta, Halimba, Hárskút, Herend, Hétházpuszta, Homokbödöge, Iharkút, [Nagyvázsony:] Kab-hegy, Kapolcs, Kardosrét, Királyszállás, Kúp, [Bakonyszücs:] Márvány-árok, Pénzesgyőr, Nagyvázsony, Németbánya, PorvaCsesznek, Porva, [Ugod:] Somberek, Tapolcafő, Tés, Ugod, Úrkút, Vállus, Városlőd, Veszprém, Vinye, Zirc (Zombori 1980), [Zirc:] Akli: Gerence-völgy, Bakonyszombathely: Feketevíz-patak, Eplény: Malomréti-völgy, Hárskút: Esztergáli-völgy, Pénzesgyőr: Gerence-völgy, Porva: Páskom, Zirc: Hármaskút, Zirc: Szarvaskút. Frequent. Larval hosts: Polygonum persicaria, Arctium lappa, Heracleum spp., Ranunculus spp., Epilobium spp., Rumex spp, Salix spp., Veronica spp., Tussilago spp., Petasites spp., Senecio spp., Solidago spp., and Stachys spp.

Tenthredo (Tenthredella) moniliata Klug, 1817: Hidegkút (ROLLER and HARIS 2008). Larva on Menyanthes trifoliata and Origanum spp. Rare in Hungary.

Tenthredo (Cephaledo) neobesa Zombori, 1980: [Ajka:] Jókai-bánya, Rezi (ZomBori 1980), Ajka, Szigliget (Roller and Haris 2008), Vállus: Láz-tető (HARIs 2019). Rare. Host plant unknown.

Tenthredo (Tenthredo) notha Klug, 1817: Nagyvázsony: Kab-hegy (RoLLER and HaRIS 2008), Zalaszántó: Kovácsi-hegy, Zalaszántó: Tátika-erdő (HARIS 2019), Bakonybél: Csesznek, Eplény: Malomréti-völgy, Fenyőfő: Ösfenyves, Farkasgyepü, [Bakonyszentlászló:] Hódos-ér, [Bakonybél:] Kőris-hegy (top), Németbánya, Pénzesgyőr, Porva, Somhegy, Várvölgy, Zalaszentlászló: Hidegkút, Zirc, Zirc: Három-hegy, Zirc: Tündérmajor. Frequent. Host plants: Trifolium repens and Vicia cracca.

Tenthredo (Tenthredo) omissa (Förster, 1844): Bakony: Cuha-völgy, Bakonybél, Gyulafirátót, Porva, Szentgál (Zombori 1980), Tapolca (Haris 1998), Sümeg, Vállus, Várvölgy (Roller and HARIs 2008). Frequent. Host plants: Plantago media and P. lanceolata.

Tenthredo (Tenthredella) procera Klug, 1817: Bakonybél: Szömörkés-völgy, [Bakonyszentkirály:] Hajmáspuszta: Halastavak, Pénzesgyőr, Zirc: Arborétum, Zirc: Szarvaskút. Host plants: Symphytum officinale and Petasites spp. Sporadic.

Tenthredo (Elinora) sabariensis (Mocsáry, 1880): Tapolca: Szent György-hegy (Roller and Haris 2008), Tihany. Rare. Host plant unknown.

Tenthredo (Tenthredo) schaefferi Klug, 1817: Nagyvázsony: Kab-hegy (RoLleR and HARIS 2008), Bakonybél: Hideg-hegy, [Ugod:] Somberek,. Sporadic. Larva on Vicia cracca.

Tenthredo (Tenthredella) solitaria Scopoli, 1763: Eplény, [Hárskút:] Esztergáli-völgy, Királyszállás, Márkó, Pénzesgyőr, Tapolcafö, Vállus, Várpalota, Zirc (ZoMBORI 1980), Vállus: Láz-tető (HARIS 2019), Eplény: Malomréti-völgy, Hárskút: Esztergáli-völgy, Olaszfalu: Malom-völgy, Szentgál: Mecsek-hegy, Zirc: Pintér-hegy. Sporadic in Hungary. Larva on Euphorbia cyparissius.

Tenthredo (Tenthredo) scrophulariae Linné, 1758: Ajka, Bakonybél, Csőszpuszta, [Hárskút:] Esztergáli-völgy, Gyulafirátót, Kardosrét, Porva-Csesznek, Sáska, Zalaszántó (Zombori 1980), Bakonybél: Barátok útja, Bakonybél: Gerence-völgy, Bakonybél: 
"Hides"-hegy, Bakonybél: Száraz-Gerence, Borzavár, Felsőörs: Királykúti-völgy, Fenyőfő: Farkasgyepü, Hárskút: Esztergáli-völgy, Káptalanfa: Sárosfőpuszta, Németbánya, Somhegy. Sporadic. Larva on Scrophularia spp., Buddleja alternifolia, Buddleja davidi and Verbascum spp.

Tenthredo (Temuledo) temula Scopoli, 1763: Pénzesgyőr, Tés, Bakonybél, Balatonfüred, Bodajk, Csehbánya, Bakony: Cuha-völgy, Dörgicse, Fenyőfö, [Bakony:] Gerence-völgy, Halimba, Herend, Királyszállás, Márkó, Nagyvázsony, Németbánya, Úrkút, Vállus, Városlöd, Várpalota (ZomBori 1980), Balatongyörök, Hidegkút, Tapolca: Szent Györgyhegy, Tihany: Hosszú-hegy (RoLler and Haris 2008), Balatongyörök: Bélap-völgy (HARIs 2019), [Zirc:] Akli: Gerence-völgy, Balatonalmádi, Bánd: Vár-hegy, Eplény: Malomréti-völgy, Hárskút: Esztergáli-völgy, Királyszállás: Barok-völgy, [Csopak:] Nosztori-völgy, Tapolca: Fenyős-domb, Tihany: Kis-erdö, Zirc: Arborétum. Frequent, locally common. Larva on Ligustrum and Origanum spp.

Tenthredo (Tenthredo) thompsoni (Curtis, 1839): Badacsony (Roller and HARIS 2008), Bakonybél, Bakonybél: Barátok útja, Bakonynána, Bakonyszombathely, Bodajk, Farkasgyepü, Fenyőfö, Fenyőfö: Ösfenyves, Csesznek, Csesznek: Várbükk, Csőszpuszta, Németbánya, Odvaskői-barlang, Pálihálás, Porva, Szentgál, [Ugod:] Somberek, [Pénzesgyőr:] Szömörke-völgy, Tapolcafö, Úrkút, Vinye, Zalaszántó, Zirc. Frequent. Host plant: Pimpinella major.

Tenthredo (Maculedo) trabeata Klug, 1817: Bakony: Cuha-völgy, Porva-Csesznek (ZOMBORI 1980). Host plants: Cicerbita alpina, Cichorium intybus, Crepis biennis, Lapsana communis, Prenanthes purpurea, Senecio ovatus and Petasites hybridus. Sporadic.

Tenthredo (Tenthredo) vespa Retzius, 1783: Ajka, Bakonybél, Bakonynána, Bakonyszentlászló, Fenyőfö, Olaszfalu, Pálihálás, Pápa, Pápateszér, [Bakonyszücs:] Rókapuszta, Tapolcafó, Úrkút, Zalaszántó (ZOMBORI 1980), Balatonfüred (RoLLER and HARIS 2008), Zalaszántó: Kovácsi-hegy, Zalaszántó: Tátika-erdő (HARIs 2019), Bakony: Cuha-völgy, Bakonynána, Cserszegtomaj: Csókakő, Farkasgyepü, Fenyőfö: Osfenyves, Felsőörs: Királykúti-völgy, [Bakonybél:] Köris-hegy (top), Németbánya. Frequent. Host plants: Lonicera caprifolium, Syringa vulgaris, Viburnum opulus, Fraxinus excelsior, Jasminum officinale, Rosa, Spiraea, Acer platanoides, Ligustrum vulgare, Symphoricarpos albus, S. alba.

Tenthredo (Maculedo) vespiformis Schrank, 1781: Balatonfüred, Csesznek, Isztimér, Vállus (Zombori 1980), Vállus: Láz-tető (Haris 2019), Tihany: Kis erdő-tető. Sporadic in Hungary. Host plant unknown.

Tenthredo (Tenthredo) zona Klug, 1817: Csopak, Herend, Vállus (ZomBori 1980), Cserszegtomaj (Roller and HARIS 2008), Vállus: Láz-tető (HARIS 2019) Tihany: tanösvény, Zirc: Pintér-hegy. Sporadic. Host plant: Hypericum perforatum.

Tenthredo (Zonuledo) zonula Klug, 1817: Ajka, [Zirc:] Aklipuszta, [Csesznek:] Gézaháza, [Ugod:] Királykapu, Szentgál, Vinye, Bakonybél, Bakonyszombathely, Bakonyszücs, Balatonfüred, Fenyőfö, Herend, Isztimér, Kapolcs, Kardosrét, Olaszfalu, Padragkút, Pénzesgyőr, Somlóvásárhely, Tés, Tihany, Úrkút, Uzsa, Városlőd, Veszprém, Veszprémfajsz, Zirc (ZoMBori 1980), Várpalota, Fenyőfö (HARIs 1998), Balatonalmádi, Hidegkút (RoLler and Haris 2008), Balatongyörök: Bélap-völgy, Cserszegtomaj: Dobogó, Várvölgy: Bándi-mező (Haris 2019), Eplény: Malomréti-völgy, Csabrendek: Tüskés-puszta, [Csesznek:] Gézaháza, Gyulafirátót, [Csopak:] Nosztori-völgy, Porva: Páskom, Szentgál: Somod, Szentgál: Mecsek-hegy, Tapolca: Fenyős-domb, Tés: KisFutóné, Tihany: Kis erdő-tető, Ugod, Zirc: Cigány-domb.Common. Host plant: Hypericum perforatum. 
Tenthredopsis friesei (Konow, 1884): Bakony: Gerence-völgy, Bakony: Hajmáspuszta, [Csesznek:] Gézaháza, [Nagyvázsony:] Kab-hegy, Bakonybél: Hideghegyi-dülő, Bakonybél: Kőris-hegy, Bakonyszücs: Bécsi-árok, Gyulafirátót: Halastó, Hajmás, Hárskút: Esztergáli-völgy, Hárskút: Ödön-hegy, Hegyhátszentjakab, Hidegkút, [Bakonyjákó:] Iharkút: Tisztavíz, Irsa-patak, Pénzesgyőr, Sáska: Szár-hegy (HARIS and Gyurkovics 2014) Gyenesdiás (Roller and Haris 2008), Eplény: Malomréti-völgy, Gyulafirátót: Kálvária-domb, Fenyőfö: Ösfenyves. Frequent. Host plants: Holcus mollis and other Poaceae.

Tenthredopsis lactiflua (Klug, 1817): Fenyőfö: Kisszépalma, Kapolcs: Bondoró-hegy, Somlóvásárhely: Somló, Zirc: Cigány-domb (HARIs and GyURKovics 2014), Balatonkenese, Balatonszőlös, Kövágóörs (ROLLER and HARIS 2008), Balatongyörök: Bélap-völgy (HaRIs 2019). Sporadic. Host plant unknown.

Tenthredopsis litterata (Geoffroy, 1785): Tapolca (MocsÁRY 1900), Badacsony, Bakony: Cuha-völgy, Bakony: Gézaháza: Mogyorós, Bakonykoppány: Somberekséd, Balatonakali, Balatonfüred, Balatonfüred: Koloska-völgy, Gyenesdiás, Gyenesdiás: Ló-hegy, Eplény: Malomréti-völgy, Márkó: Menyeke, Pénzesgyőr: Kerteskő, Porva, Szigliget: Antal-hegy, Tapolcafö, Tés: Hegyes-berek, Tihany: Sajkod, Ugod: Durrogóstető, Vállus: Büdös-kút, Vállus: Láz-tető, Várpalota: Barok-völgy, Zirc: Pintér-hegy (HARIs and Gyurkovics 2014), Mindszentkálla: Öreg-hegy (Roller and Haris 2008), Cserszegtomaj: Dobogó (HaRIs 2019), [Zirc:] Akli, Bánd: Vár-hegy, [Csesznek:] Gézaháza, Várpalota, [Csopak:] Nosztori-völgy, Tihany: Gejzír-mezö, Tihany: Kis erdőtetö, Tihany: Külső-tó, Zirc: Cigány-domb. Frequent. Larva on Agrostis, Dactylis and Calamagrostis spp.

Tenthredopsis nassata (Linné, 1767): Badacsony, Balatonfüred, Cserszegtomaj, Felsőörs, Hárskút: Lazsnak úti dülő, Nagyvázsony (HARIs and GyURKovics 2014), Balatonfüred, Gyenesdiás, Hárskút (ROLLER and HARIS 2008), Bakonyszentlászló: Vinye: Fenyőfö, Balatonkenese: Tátorjános, Csehbánya: Középső-Hajag, [Csopak:] Nosztori-völgy, Tihany: Gejzír-mező, Zirc: Cigány-domb. Frequent. Host plants: Dactylis glomerata, Deschampsia caespitosa, D. calmagrostis, Flexuosa spp., Holcus spp., Lolium perenne, Agropyron spp., Carex spp., Anthriscus silvestris and Artemisia spp.

Tenthredopsis ornata (Serville, 1823): Bakony: Cuha-völgy, Bakony: Gézaháza: Mogyorós, Bakony: [Gézaháza] Géza-hegy, [Nagyvázsony:] Kab-hegy, [Csesznek:] Bakony: Kö-árok, Bakony: Séd-völgye, [Ugod:] Bakony: Somberek, Bakonyszentlászló, Balatonfüred: Koloska-völgy, Balatonalmádi: Öreg-hegy, Balatonudvari, Fenyőfő: Kisszépalma, Iharkút, Márkó: Menyeke, Nemesvámos: Tekeres-völgy, Németbánya: Laposak, Porva, Tapolcafö: Kalapácsér, Zirc: Botanic garden, Zirc: Cuha-völgy (HaRIS and Gyurkovics 2014), Mindszentkálla (Roller and Haris 2008), Cserszegtomaj: Dobogó (HARIs 2019), Bánd: Vár-hegy, Csehbánya: Középső-Hajag, Dudar, Olaszfalu: Malom-völgy. Frequent. Larva on Brachypodium sylvaticum.

Tenthredopsis scutellaris (Fabricius, 1804): Bakonybél: Tevelvár, Bakonykoppány: Somberekséd, Sümeg: Sarvaly, Ugod: Durrogós-tető, Ugod: Somberek: Hubertlak (Haris and Gyurkovics 2014), Csehbánya: Középső-Hajag. Sporadic. Larva on Poa pratense, Festuca elatior, Dactylis glomerata and Elytrigia repens.

Tenthredopsis sordida (Klug, 1817): Tapolca (MocsáRY 1900), Bakony: Cuha-völgy, Bakony: Farkasgyepü, Bakony: Hétházpuszta, [Ugod:] Bakony: Királykapu, [Csesznek:] Bakony: Kö-árok, Bakony: Lókút, Bakony: [Gézaháza] Mogyorós, Bakonybél: Hubertlak, Bakonykoppány: Somberekséd, Balatoncsicsó, Eplény: Álmos-hegy, Eplény: Malomréti-völgy, [Csesznek:] Gézaháza, Lesenceistvánd, Márkó, Olaszfalu, Tapolcafő: Kalapács-ér, Tapolca: Szent György-hegy, Tihany, Ugod: Durrogós-tető, Úrkút: Bocskor- 
hegy, Vállus: Láz-tető, Városlőd: Torna-patak, Zirc: Botanic garden, Zirc: Cigány-domb, Zirc: Cuha-völgy, Zirc: Pintér-hegy (HARIs and Gyurkovics 2014), Pénzesgyör, Porva: Pálihálás (RoLler and HARIS 2008), Balatongyörök: Bélap-völgy (HARIS 2019), Csehbánya: Középső-Hajag, Eplény: Malomréti-völgy, Olaszfalu: Malom-völgy, Tihany: Bozsai-öböl, Tihany: Kis-erdö. Frequent. Larva on Arrhenatherum elatius, Lolium perenne, Carex spp., Calamagrostis spp. and Dactylis glomerata.

Tenthredopsis stigma (Fabricius, 1798): Tapolca (MocsÁry 1900), Bakony: Cuhavölgy, Bakony: Gézaháza: Mogyorós, Bakony: Lókút, Balatonfüred: Tamás-hegy, Balatonudvari, Kardosrét: Cuha-völgy, Felsőörs, Fenyőfö, Fenyőfő: Kisszépalma, Gyenesdiás: Ló-hegy, Hárskút: Molnár-tanya, Herend: Incsekfa, Herend: Rakottyás, Hidegkút, Kapolcs, Padragkút: Hajagos, Padragkút: Sárcsikút, Somlóvásárhely: Somló, Szentbékkálla, Tapolcafö: Mogyorós-domb alja, Tihany: Barátlakások, Tihany: Hosszúhegy, Zirc, Zirc: Cuha-völgy (Haris and GyUrkovics 2014), Kapolcs (Haris 1998), Balatonfüred, Balatonudvari, Hidegkút, Szentbékkálla, Tihany, Vászoly: Nagyvár-hegy, (Roller and HARIS 2008), Balatongyörök: Bélap-völgy, Cserszegtomaj: Dobogó, Várvölgy: Bándi-mező (HaRIs 2019), Balatonfüred: Nagymező, Eplény: Malomrétivölgy, Olaszfalu: Malom-völgy, Tihany: Gejzír-mezö, Tihany: Kis-erdő, Vászoly: Öreghegy, Veszprém: around Bakony Mủvek, Veszprém: Gulya-domb, Zirc: Három-hegy. Frequent. Host plant: Triticum intermedium.

Tenthredopsis tarsata (Fabricius, 1804): Bakony: Cuha-völgy, Bakony: [Gézaháza] Géza-hegy, Bakony: Farkasgyepü, Bakony: Gerence-völgy, [Csesznek:] Bakony: Kö-árok, [Ugod:] Bakony: Somberek-völgy, Bakonybél: Hubertlak, Balatonfüred: Koloska-völgy, Csehbánya, Csesznek, Dörgicse: Kö-hegy, Eplény: Malomréti-völgy, Felsőörs, Fenyőfő: Kisszépalma, [Csesznek:] Gézaháza, Hajagos, [Bakonyszentlászló:] Hódosér-völgye, Iharkút, Királyszállás: Barok-völgy, Olaszfalu, Óbarok, Padragkút, Padragkút: Sarckút, Pénzesgyőr, Porva-Csesznek, Somlóvásárhely: Somló, Szentkirályszabadja, Szigliget: Antal-hegy, [Pénzesgyőr:] Szömörke-völgy, Tihany, Tihany: Southern beach, Vörösberény: Malom-völgy, Zalaszántó: Kovácsi-hegy, Zirc: Bocskor-hegy, Zirc: botanic garden, Zirc: Pintér-hegy (HARIs and GYURKovics 2014), Keszthelyi-hgys. (Haris 1998) Badacsony, Tihany (Roller and Haris, 2008), Cserszegtomaj: Keszthelyi-hgys. (Haris 2019), Csehbánya: Középső-Hajag, Eplény: Malomréti-völgy, [Csesznek:] Gézaháza, Hárskút: Esztergáli-völgy, Olaszfalu: Malomvölgy, Tihany: tájvédelmi őrház, Tihany: Kis-erdő, Vászoly: Öreg-hegy, Zirc: Arborétum, Zirc: Pintér-hegy. Frequent. Host plants: Poaceae, particularly Brachypodium silvaticum.

Tenthredopsis tesselata (Klug, 1817): Bakony: Cuha-völgy, Bakony: Farkasgyepü, Bakony: Gerence-völgy, Bakony: Gézaháza: Mogyorós, Balatonalmádi: Tulipán str. 15. Eplény: Malomréti-völgy, Fenyőfő, Hidegkút, Lesenceistvánd, Németbánya: vadászház, Perkupa: Telekes-völgy, Somlóvásárhely: Somló, Zalaszántó: Kovácsi-hegy, Zirc (HARIS and GyURKovics 2014), Cserszegtomaj: Dobogó, Cserszegtomaj: Várvölgyi út: Pörkölthegy (Haris 2019), Dudar, Fenyőfö: Pinus sylvestris and Juniper forest, Németbánya. Sporadic. Larva on Deschampsia, Dactylis, Aira and Lolium spp.

\section{Nematinae}

Anoplonyx destructor Benson, 1952: Zirc (Haris 2001). Larva on Larix spp. Rare. Anoplonyx ovatus (Zaddach, 1883): Bakony: Cuha-völgy (HaRIs 2001). Host plant: Larix europaea. Rare.

Cladius (Priophorus) brullei (Dahlbom, 1835): Csesznek, [Bakonyszentlászló:] Hódos-ér, Tés (Haris 2001), Balatongyörök: Bélap-völgy, Cserszeg (Haris 2019), Tihany: Kis-erdő, Tihany: Ranger's house. Frequent. Larva on Rubus spp. 
Cladius (Priophorus) rufipes Serville, 1823: Szentkirályszabadja, Tihany: Akasztódomb, Sajkod (Haris 2001), Tihany: Kis-erdő. Larva on Ulmus spp. Sporadic.

Cladius (Priophorus) compressicornis (Fabricius, 1804): Fenyőfö, Tihany (HARIS 2001), Eplény: Malomréti-völgy, Csehbánya: Középső-Hajag, Zirc: Három-hegy, [Fenyőfö:] Kék-hegy, Frequent. Host plants: Betula, Cotoneaster, Rubus, Sorbus, Prunus, Crataegus, Corylus, Fragaria and Rosa spp., also Laurus nobilis and Aronia arbutifolia.

Cladius (Cladius) pectinicornis (Geoffroy, 1785): Balatonakarattya, Balatonfüred, Cserszegtomaj, Dörgicse, Eplény, Fenyőfö, Gyenesdiás, Hétházpuszta, Királyszállás, Márkó: Menyeke, Nagymező, Olaszfalu, Öskü, Porva, Porva: Ménesjárás, [Ugod:] Szárhegy, Szentkirályszabadja, Tapolcafő, Tábormező, Tihany, Tüskevár, Ugod, Várpalota, Veszprém, Zirc, (Zombori 1982b), Balatoncsicsó, Cserszegtomaj, Hidegkút, Szentbékkálla, Tihany (RoLler and HARIs 2008), Balatongyörök: Bélap-völgy, Cserszeg, Rezi: Gyöngyösi csárda, Vállus: Kis-Láz-völgy, Zalaszántó: Alsó-nyíres (HaRIs 2019) Balatonfüred: Nagymezö, Balatongyörök: Bélap-völgy, Cserszegtomaj: Csóka-kő, Nagyvázsony: víztározó, Tihany: Bozsai-öböl, Tihany: Kis erdő-tető, Tihany: Külső-tó, Zirc: Szarvaskút. Common. Host plant: Rubus spp.

Cladius (Trichiocampus) ulmi (Linné, 1758): Tihany: Kis-erdő-tető. Rare. Larva on Ulmus spp.

Dineura stilata (Klug, 1816): Bakony: [Gézaháza] Mogyorós-kert, [Bakony:] Gerencevölgy Larva on Crataegus spp. Rare.

Euura atra (Jurine, 1807): Fenyőfő (HARIs 2001), Balatonalmádi (HARIS 2002). Frequent. Salix spp.

Euura fagi (Zaddach, 1876) (= Nematus fagi Zadd.): Cserszegtomaj: Várvölgyi road (Haris 2019). Rare. Larva on Fagus sylvatica.

Euura fallax (Serville, 1823) known as Pachynematus xanthocarpus (Hartig, 1840): Balatongyörök:Bélap-völgy(Haris2019), Eplény:Malomréti-völgy,[Bakonyszentkirály:] Hajmáspuszta: Halastavak, Kövágóörs, Szentbékkálla, Tapolca: Fenyős-domb, Tihany: Belső-tó, Tihany: Kis-erdő. Frequent. Larva on Graminae.

Euura laeta (Brischke, 1883): Bakony (Ambrus 1978). Host plant: Salix viminalis. Rare.

Euura mucronata (Hartig, 1837): [Csesznek:] Bakony: Kö-árok, [Csesznek:] Gézaháza (HARIs 2001). Host plants: Salix spp. Rare.

Euura testaceipes (Brischke, 1883): Tihany (Ambrus 1964b), Bakony (Ambrus 1978). Galls on stem of leaves of Salix alba and S. fragilis. Frequent.

Euura venusta (Brischke, 1883): Fenyőfö, Zirc: Szarvaskút (HARIs 2001). Galls on Salix aurita, $S$. caprea and $S$. cinerea. Rare.

Euura viridis (Stephens, 1835) (= Nematus viridis Steph.): Nagyesztergál: Veimpuszta (Zombori 1982). Mentioned as Nematus prasina Hartig, 1835. Now, it is synonyme of E. viridis. The voucher specimen wasn't found. Sporadic.

Euura bergmanni (Dahlbom, 1835) (= Nematus bergmanni Dhlb.): Bakonygyepes, Balatonalmádi, Eplény (Zombori 1982b), Gyenesdiás, Németbánya: Jáger-hegy (RoLLER and Haris 2008), Tihany: Bozsai-öböl. Frequent. Host plant: Salix spp.

Euura hypoxantha (Förster, 1854) ) (= Nemtaus hypoxanthus Först.): Badacsony, [Balatonalmádi] Buda-tava, Bakony: Cuha-völgy, (Haris 2001). Larva on Salix spp. Sporadic.

Euura incompleta (Förster, 1854) ) (= Nematus incompletus Först.): Bakonybél, Felsöörs (HARIS 2001). Larva on Lathyrus vernus and L. pratensis. Frequent.

Euura tibialis (Newman, 1837) (= Nematus tibialis New.): Badacsony, Bakonynána, Bodajk, Csesznek, Farkasgyepü, Hajmáspuszta, Porva, Ugod, Várvölgy (ZoMBORI 1982b), Fenyőfő (Roller and Haris 2008), Bakonykút. Frequent. Larva on Robinia 
pseudacacia and also on Robinia viscosa, R. hispida and Gleditsia triacanthos.

Euura myosotidis (Fabricius, 1804) (=Nematus myosotidis F.): Ajka, Bakony: Cuhavölgy, Bakonybél, Bakonykoppány, Csehbánya, Csesznek, Dudar, Eplény, [Hárskút:] Esztergáli-völgy, Farkasgyepü, Felsőörs, [Csesznek:] Gézaháza, Gyulafirátót, Hétházpuszta, Kapolcs, Kardosrét, [Gézaháza] Mogyorós, [Gyulafirátót:] Miklád, Pannonhalma, Porva, Szentgál, Tapolcafő, Tés, Tihany, Ugod: Somberek, [Pénzesgyőr:] Szömörke-völgy, Vonyarcvashegy, [Bakonybél:] Vörös János-séd, Zalaszántó (ZoMBORI 1982b), Gyenesdiás, Keszthelyi-hgs. (RoLler and Haris 2008), Balatongyörök: Bélapvölgy, Balatongyörök: Mogyorós út: Szőlö-hegyek, Cserszegtomaj: Dobogó, Cserszegtomaj: Fagyos-kereszt, Zalaszántó: Alsó-nyíres (HARIs 2019), Bakonybél: Gerence-völgy, Eplény: Malomréti-völgy, Sáska: Agár-tetö, Tihany: Bozsai-öböl, Tihany: Kiserdő-tetö, Tihany: Külső-tó. Common. Larval hosts: Onobrychis and Trifolium spp.

Euura pavida (Serville, 1823) (= Nematus pavidus Serv.): Bakony: Cuha-völgy, [Csesznek:] Gézaháza Németbánya, Zirc (Haris 2001). Larva on Salix spp. and Populus tremula. Frequent.

Euura ribesii (Scopoli, 1763) (= Nematus ribesii Scop.): Olaszfalu (HaRIS 2001). Larva mostly on Ribes uva-crispa, sometimes on other Ribes $\operatorname{spp}(R$. nigrum or $R$. rubrum). Sporadic.

Euura salicis (Linné, 1758)(=Nematus salicis L.): Bakonybél (HARIs 2001). Larva on Salix alba, S. fragilis and $S$. vitellina. Sporadic.

Euura trautmanni (Enslin, 1919) (=Amauronematus trautmanni Ensl.): [Csesznek:] Bakony: Kö-árok, Németbánya (HaRIs 2001). Larva on Salix atrocinerea. Rare.

Euura vicina (Serville, 1823) (=Nematus vicinus Serv.): Eplény, Hétházpuszta, Királyszállás, (Haris 2001). Larva on Betula, Populus, Salix and Rumex. Sporadic.

Euura viridissima (Möller, 1882) (=Nematus viridissimus Möll.): Bakony: Szarvaskút, Zirc (HARIs 2001). Larva on Alnus. Sporadic.

Euura clitellata (Serville, 1823) (=Pachynematus clitellatus Serv.): Bakonyszentlászló, Fenyőfő, Keszthelyi-hgys., Vállus, Városlőd (RoLler and Haris 2008), Cserszegtomaj: Dobogó (HaRis 2009), Hajmáskér, [Gézaháza] Mogyorós, Tihany: Kis-erdő. Frequent. Larval hosts: Graminae, Carex and Juncus spp.

Euura imperfecta (Zaddach, 1876)(=Pachynematus imperfectus Zadd.): Zirc (HARIS 2001). Rare. Larva on Larix spp.

Euura obducta (Hartig, 1837) (=Pachynematus obductus Htg.): Bakony: Cuha-völgy (Haris 2001), Padragkút: Nyíri-tó. Sporadic. Larva on Gramineae (Poa, Festuca spp.) and Carex spp.

Euura vaga (Fabricius, 1781) (=Pachynematus vagus F.): Bakonybél, Fenyőfö (Haris 2001), Felsöörs. Larva on Carex spp. Frequent.

Euura leucapsis (Tischbein, 1846) (=Phyllocolpa leucaspis Tischb.): Tihany (AmBRUS 1964b), Bakony (Ambrus 1978). Frequent. Larval hosts: Salix phylicifolia, S. aurita, S. caprea and $S$. cinerea.

Euura leucosticta (Hartig, 1837) (=Phyllocolpa leucosticta Htg.): [Csesznek:] Bakony: Kö-árok (Ambrus 1978). Frequent. Salix aurita, S. caprea, S. atrocinerea and S. cinerea.

Euura oblita (Serville, 1823) (=Phyllocolpa oblita Serv.): Gyenesdiás (AmBrus 1964a), Bakony (Ambrus 1978). Rare. Galls on Salix alba, S. fragilis, S. triandra and S. rubens.

Euura albipennis (Hartig, 1837) (=Polynematus albipennis Htg.): Tihany (HARIS 2001). Rare. Larva on Polygonum persicaria. 
Euura annulata (Gimmerthal, 1834) (=Polynematus annulatus Gimm.): Bakonybél, Zirc (Haris 2001), Hétházpuszta, Szarvaskút, Vinye. Larva on Rumex spp. Frequent.

Euura bridgmanii (Cameron, 1883) (=Pontania bridgmanii Cam.): Bakony (AmBrus 1978). Sporadic. Larva on Salix caprea, S. aurita and S. cinerea.

Euura kriechbaumeri (Konow, 1901) (=Pontania kriechbaumeri Knw.): Bakony (Ambrus 1978). Galls on Salix eleagnos. Rare.

Euura proxima (Serville, 1823) (=Pontania proxima Serv.): Bakony (AmBrus 1978), Balatonalmádi, Balatonfüzfö, [Csesznek:] Bakony: Kö-árok (HaRIS 2001), Porva: Pálihálás (Roller and Haris 2008). Frequent, larva on Salix fragilis and S. alba.

Euura vesicator (Bremi-Wolf, 1849) (=Pontania vesicator Bremi-Wolf): Gyenesdiás (Ambrus 1964a), Bakony (Ambrus 1978). Frequent. Galls on Salix purpurea.

Euura viminalis (Linné, 1758) (=Pontania viminalis L.): Gyenesdiás (AmBrus 1964a), Tihany (Ambrus 1964b), Bakony (AmBrus 1978), Vonyarcvashegy: Láprét (HARIS 2019). Frequent. Larva on Salix purpurea.

Hoplocampa chrysorrhoea (Klug, 1816): Veszprémfajsz (ZoMBORI 1977), Hidegkút. Host plant: Prunus spinosa. Sporadic.

Hoplocampa crataegi (Klug, 1816): Bakony: Cuha-völgy, Herend, Kapolcs, (ZomBorI 1979). Frequent. Larva on Crataegus spp.

Hoplocampa flava (Linné, 1760): Tés (Zombori 1979). Frequent. Larva on Prunus domestica and Prunus spinosa.

Hoplocampa fulvicornis (Panzer, 1801): Veszprémfajsz (Zombori 1979). Sporadic. Larva on Prunus spinosa.

Hoplocampa minuta (Christ, 1791) Rezi (HaRIs 1998). Frequent. Larva on Prunus domestica, $P$. armeniaca, $P$. instita, $P$. avium and $P$. spinosa.

Mesoneura opaca (Fabricius, 1775): [Fenyőfö:] Bakony: Kék-hegy (ZomBori 1979). Frequent. Larva on Quercus for instance: Quercus rubra and Quercus robur.

Nematinus fuscipennis (Serville, 1823): Fenyőfö, Zirc (HARIS 2001) Larva on Alnus spp. and Carpinus betulus. Sporadic.

Nematinus bilineatus (Klug, 1819): Bakony: Szarvaskút, Bakonykoppány: Gerencevölgy, Fenyőfö, Tapolcafö, Zirc. Sporadic. Larva on Alnus spp.

Nematinus steini Blank, 1998: Eplény: Álmos-hegy. Frequent. Larva on Alnus spp.

Nematus alniastri (Scharfenberg, 1805) (=Craesus alniastri Scharf.): Bakonybél: Gerence-völgy (Haris 2001), Csesznek. Larva on Alnus spp. Sporadic.

Nematus brischkei Zaddach, 1876 (=Craesus brischkei Zadd.): Eplény (HaRIs 2001). Larva feeds on Corylus and Carpinus spp. Rare.

Nematus lucidus (Panzer, 1801): Balatongyörök: Bélap-völgy (HARIS 2019), Balatonalmádi, Eplény: Malomréti-völgy, Fenyőfő: Pisztrángos-tó, Tihany: Kis erdőtetö. Frequent. Larva on Crataegus and Prunus spinosa.

Platycampus luridiventris (Fallén, 1808): Fenyőfö, Tapocafö (HaRIs 2001), Fenyőfö: Kisszépalma. Larva on Alnus glutionosa and A. incana. Sporadic.

Pristiphora albitibia (Costa, 1859): Balatongyörök: Mogyorós út: Szőlö-hegyek (HARIs 2019), Mogyorós, Tihany: Kis erdő-tető. Rare. Host plant: Vicia cracca, V. hirsuta, $V$. tetrasperma, $V$. baicalensis and $V$. unijuga.

Pristiphora aphantoneura (Förster, 1854): Nagyvázsony (HARIs 2001), Balatongyörök: Bélap-völgy (HaRIs 2019), Bakonybél, Nyárád: Bitva-rétek. Frequent. Host plants: Salix spp. and Lathyrus pratensis.

Pristiphora appendiculata (Hartig, 1837): [Gézaháza] Mogyorós. Frequent. Host plants: Ribes spp.: Ribes alpinum, $R$. rubrum, $R$. uva-crispa, $R$. aureum, $R$. sanguineum, $R$. nigrum and R. spicatum. 
Pristiphora armata (C. G. Thomson, 1863): [Csesznek:] Bakony: Kő-árok, Eplény, Iharkút, Tihany, Köveskál, Zalaszántó, Zirc (HARIs 2001), [Zirc:] Akli, Balatonalmádi, Balinka, Csetény, Fenyőfő: Kisszépalma, Hajmáskér: Tabán-hegy, Királyszállás: Barokvölgy, Öskü: Sötét Horog-völgy, Porva: erdészház, Tihany: Akasztó-domb, Ugod: Szárhegy, Várvölgy: Nagyláz-tető, Vinye, Zalaszántó: Tátika-erdő, Zirc: Pintér-hegy. Frequent. Larva on Crataegus spp.

Pristiphora biscalis (Förster, 1854): Márkó: Menyeke, Tapolca: Szent György-hegy. Rare in Hungary. Host plant: Prunus spinosa.

Pristiphora cincta Newman, 1837: Bakony: Cuha-völgy. New record for Hungary. Larva on Betula pubescens, Salix spp., Vaccinium myrtillus, V. uliginosum, V. myrtilloides, $V$. angustifolium and $V$. macrocarpon.

Pristiphora confusa Lindqvist, 1955: Balatoncsicsó (HARIs 2001). Host plants: Salix caprea, Salix fragilis and S. phylicifolia. Sporadic.

Pristiphora fausta (Hartig, 1837): Balatongyörök: Bélap-völgy (HARIS 2017). Rare. Larva on Quercus robur.

Pristiphora insularis Rohwer, 1910: Hárskút (HARIS 2001). Sporadic. Larva on Amelanchier asiatica, Chaenomeles japonica, Rosa spp., Rosa majalis, Rosa pimpinellifolia and Rosa onoei.

Pristiphora laricis (Hartig, 1837): Balatongyörök: Bélap-völgy, Vonyarcvashegy: Láprét (Haris 2019), Bakony: Cuha: Káró, [Csesznek:] Kö-árok. Sporadic. Host plants: Larix spp.: Larix decidua, L. kaempferi, L. sibirica, L. gmelinii, L. laricina, L. occidentalis and Larix $\times$ eurolepis.

Pristiphora maesta (Zaddach, 1876): Bakony: Northern part of Cuha-völgy (HARIS 2001). Larva on Malus spp.: Malus sylvestris and M. domestica. In interesting way, this species is considered of insect pest of apple orchards, however, it is rarely captured in Hungary. It is only known from the Northern valley of Cuha brook in the Bakony Mountains, the other recorded place of capture is in Bátorliget (NE Hungary).

Pristiphora melanocarpa (Hartig, 1840): Németbánya (HARIs 2001). Larva on Betula spp.: Betula pendula, B. pubescens and B. nana. Sporadic.

Pristiphora monogyniae (Hartig, 1840): Balatoncsicsó, Balatonudvari, Fenyőfö, Tihany (HARIs 2001), Balatongyörök: Bélap-völgy (HARIs 2019). Frequent. Larva on Prunus spinosa, ocasionally on $P$. domestica.

Pristiphora pallidiventris (Fallén, 1808): Bakonybél, Felsőörs, [Bakonyszentlászló:] Hódosér-völgy, Királyszállás, Lesenceistvánd, Tihany (HARIs 2001), Balatonalmádi, Farkasgyepü, Iharkút, Tihany: Kis-erdő. Frequent. Larva on Geum, Potentilla, Rubus and Filipendula spp. Filipendula ulmaria, Geum urbanum, G. rivale, Rubus chamaemorus, $R$. idaeus, R. fruticosus and $R$. ulmifolius.

Pristiphora punctifrons (Thomson, 1871): Bakony: [Gézaháza] Mogyorós (ZoMBORI 1982b, HARIs 2001). Rare. Larva on Rosa canina and Rosa majalis.

Pristiphora rufipes Serville, 1823: Bakonyszentlászló (HARIs 2001). Host plants: Aquilegia vulgaris, A. chrysantha, A. caerulea, A. canadensis, A. flabellata, A. olympica, Ribes uva-crispa and R. rubrum. Sporadic.

Pristiphora subbifida (C. G. Thomson, 1871): Eplény, Királyszállás (HARIs 2001), Balatongyörök: Bélap-völgy (HARIs 2019), Bakonybél: Gerence-völgy, Fenyőfő: Kisszépalma, Hajmáspuszta. Sporadic. Host plants: Acer campestre, sometimes A. pseudoplatanus and A. orientale.

Pristiphora thalictri (Kriechbaumer, 1884): Várpalota: Vár-völgy. Rare. Host plants: Thalictrum aquilegiifolium and T. minus.

Pseudodineura parvula (Klug, 1816): Lesenceistvánd (ZoMBORI 1976). Larva on Pulsatilla vulgaris, $P$. grandis, and $P$. patens. Sporadic. 
Stauronematus platycerus (Hartig, 1840): Németbánya (HARIs 2001). Host plants: Populus tremula and Salix spp. The only European sawfly, whose larva erects a palisade of dried saliva around its feeding place. Frequent.

\section{Cephoidea}

Calameuta (Calameuta) filiformis (Eversmann, 1847): Bakony: Northern part of Cuha-völgy, Bakonybél, Bakonyszücs, Fenyőfö, [Csesznek:] Gézaháza Hárskút, [Nagyvázsony:] Kab-hegy, [Isztimér:] Menyeke, Németbánya, Nyirád, Padragkút, Pétfürdő, Szentgál, Városlőd, (ZoMBORI 1973), Balatonalmádi, Balatongyörök, Gyenesdiás, Keszthelyi-hgys. (Roller and Haris 2008), Várvölgy: Zsidi-rét (HARIS 2019), Balatonfüred: Koloska-völgy, Balatonkenese: Tátorjános, Bakonybél, Bakonyszombathely: Feketevíz-patak, Cuha-völgy: Kardosrét, Eplény: Malomrétivölgy, Fenyőfő: Pisztrángos-tó, [Bakonyszentkirály:] Hajmáspuszta: Halastavak, Hétházpuszta, Újszépalma, Tihany: Bozsai-öböl, Várpalota, Zirc: Pintér-hegy. Frequent species. Larva lives in stems of Arrhenaterum elatius, Phalaris arundinacea, Calamagrostis epigeios, Elytrigia repens and Phragmites communis.

Calameuta (Calameuta) haemorrhoidalis (Fabricius, 1781): [Csesznek:] Gézaháza Kö-hegy, Kapolcs, Németbánya, Nyirád, Sümeg, Vállus (Zombori 1973), Szentbékálla (Roller and Haris 2008), Vállus: Barbacs (HARIs 2019), Bakonygyepes: láprét. Frequent. Host plant unknown.

Calameuta (Calameuta) pallipes (Klug, 1803): Bakony: Cuha-völgy, Bakonybél, Gézaháza: Mogyorós-kert, Tés, Vállus, Zalaszántó, Zirc (ZoMBori 1973), Bakonyszentlászló, Porva: Pálihálás (RoLler and HARIs 2008), Vállus: Láz-tető, Zalaszántó: Kovácsi-hegy, (HARIS 2019), Eplény: Malomréti-völgy, Balatonfüred: Nagymező, Királyszállás: Barok-völgy, Tihany: Csúcs-hegy. Frequent on diverse Poaceae.

Cephus brachycercus C. G. Thomson, 1871: Bakonybél, Bakonykoppány, Vállus (ZoMBORI 1973), Balatongyörök: Bélap-völgy (HaRIs 2019), Balatonfüred: Nagymezö, Tihany: Kis-erdő. Widely distributed, sporadic species. Host plant unknown.

Cephus infuscatus C. G. Thomson, 1871: Ábrahámhegy (Roller and Haris 2008). Host plant: Phalaris arundinacea. Rare.

Cephus nigrinus C. G. Thomson, 1871: [Fenyőfö:] Kisszépalma, Zirc (Zombori 1973), [Csesznek:] Gézaháza, Királyszállás: Barok-völgy, Lesenceistvánd, Tihany: Kiserdő, Zirc. Frequent species. Host plants: Milium effusum and Poa pratens.

Cephus pygmaeus (Linné, 1767): Bakonybél, Bakonykoppány, Bakonypölöske, Csehbánya, Csopak, Dörgicse, Fenyőfö: Kisszépalma, [Bakony:] Gerence-völgy, Herend, Herend: Rakottyás, Pénzesgyőr: Kerteskő, Kapolcs, Márkó: Menyeke, Vinyesándormajor, Nagyvázsony, Sáska, Sümeg, Tapolcafó, Uzsa, Vállus, Városlőd: Csóványos, (Zombori 1973), Balatongyörök, Hidegkút, Sümeg, Tihany (Roller and HARIS 2008), Balatongyörök: Mogyorós út: Szőlő-hegyek, Cserszegtomaj: Dobogó (HARIS 2019), Balatonfüred: Balaton-part, Bakonybél, Eplény: Malomréti-völgy, Hétházpuszta, [Ugod:] Királykapu, Szentgál: Somod, Tihany: Kis erdő-tető, Ugod: Szőlö-hegy,Vászoly: Öreg-hegy. Common. Insect pest of cereals and Gramineae.

Cephus runcator Konow, 1896: Bakonyszombathely: Feketevíz-patak, Tihany: Külsőtó. Sporadic. Host plant unknown.

Cephus spinipes (Panzer, 1800): Bakonypölöske, Iharkút, Királyszállás: Barok-völgy, [Bakonybél:] Köris-hegy, [Isztimér:] Menyeke, Nyirád, Sümeg, Tihany, Vállus, Városlőd (Zombori 1973), Balatonalmádi, Balatongyörök (Roller and HARIS 2008), Balatongyörök: Bélap-völgy, Cserszegtomaj: Várvölgyi út: Pörkölt-hegy, Cserszegtomaj: Dobogó (Haris 2019), Ácsteszér, Balatonfüred: Balatonpart, Balatonfüred: Camping, 
Eplény: Malomréti-völgy, Fenyőfő: Ösfenyves, Gyulafirátót, Hajmáspuszta, Hajmáspuszta: Halastó, Királyszállás: Barok-völgy, Tapolcafő: Kalapács-ér, Tihany: Gejzír-mező, Tihany: Külső-tó, Tihany: Sajkod, Olaszfalu: Malom-völgy, Zirc: Cigánydomb. Frequent. Host plant: Phleum pratense.

Phylloecus linearis (Schrank, 1781) (= Hartigia linearis Schrk.): [Zirc:] Aklipuszta, Hárskút, Zirc (Zombori 1973), Ajka. Sporadic. Larva feeds on Agrimonia eupatoria.

Phylloecus niger (Harris, 1779) (= Hartigia nigra Harris): Bakony: Cuha-völgy,

Balatoncsicsó, [Csesznek:] Gézaháza, Zalaszántó (ZoMBORI 1973), Balatongyörök:

Bélap-völgy, Zalaszántó: Kovácsi-hegy (HARIS 2019), Eplény: Malomréti-völgy,

Fenyőfö: Pisztrángos-tó, Hárskút: Esztergáli-völgy, Tihany: Kis erdő-tető. Sporadic in Hungary. Host plants: Rosa and Rubus spp.

Janus cynosbati (Linné, 1758) (= Janus femoratus Curtis, 1830): [Csesznek:] Gézaháza (Roller and HARIs 2008), Fenyőfö, Pinus sylvestris and Juniper vegetation. Sporadic. Host plants: Quercus pubescens and Q. robur.

Janus luteipes (Lepeletier, 1823): Németbánya (Zombori 1973). Host plants: Salix, Populus and Viburnum spp. Sporadic.

Trachelus tabidus (Fabricius, 1775): Bakonybél (ZomBori 1973). Larva on Hordeum, Secale and Triticum spp. Rare.

Trachelus troglodyta (Fabricius, 1787): Bakony: Cuha-völgy, Herend, Vállus, (Zombori 1973), Vállus: Büdöskút: Fekete-hegy (Haris 2019), Olaszfalu: Malomvölgy. Sporadic. Host plant: Secale cereale.

\section{Siricidae}

Sirex noctilio Fabricius, 1793: Tapolca (Mocsáry 1900), Káptalanfüred, Pula, Tés, Várpalota (Zombori 1973), Zirc. In Picea, Larix, Pinus, Abies and Pseudotsuga. Symbiotic fungus: Amylostereum areolatum. Frequent.

Sirex juvencus (Linné, 1758): Balatonalmádi: Öreg-hegy, Ugod. Mainly in Picea spp. but also in Pinus, Abies and Pseudotsuga. Symbiotic fungus: Amylostereum areolatum. Sporadic.

Tremex alchymista Mocsáry, 1886: Várpalota (Zombori 1973), Rezi (Roller and Haris 2018), Rezi: Cseres: Postaút (Haris 2019), Balatonalmádi. Rare. Host plants: Quercus, Acer, Betula, Fagus and Carpinus spp.

Tremex fuscicornis (Fabricius, 1787): Bakonybél, Balatonalmádi, Németbánya, Öcs, Tés, Veszprém (Zombori 1973), Zirc. The most frequent Siricidae. Host plants: Fagus, Acer, Salix, Betula, Populus and Ulmus.

Tremex magus (Fabricius, 1787): Hévíz (HARIs 2019). Rare. Host plants: Betula, Quercus, Carpinus and Populus spp.

Urocerus augur (Klug, 1803): Csopak, Herend: Bányatelep. Rare. Host plants: Abies alba, A. cilicica, A. borisii-regis, A procera, Picea abies and Pinus sylvestris.

Urocerus gigas (Linné, 1758): [Pénzesgyőr:] Szömörke-völgy, Vállus, Veszprém (Zombori 1973), Vállus: Büdös-kút (Haris 2019). Sporadic. Larva lives in Pinus, Picea, Larix and Abies spp.

Xeris spectrum (Linné, 1758): Bakonybél, Németbánya, Veszprém (ZoMBori 1973). Larva lives in Pinus, Picea, Abies, Larix, Pseudotsuga and Chamaecyparis spp. Sporadic.

Xiphydria camelus (Linné, 1758): Bakonykoppány, Káptalanfüred (ZoMBORI 1973). Sporadic. Host plants: Betula and Alnus spp.

Xiphydria longicollis (Geoffroy, 1785): Olaszfalu: Kis Csiga-hegy. Host plants: Acer, Quercus, Pinus and Betula spp. Frequent. 


\section{Orussidae}

Orussus abietinus (Scopoli, 1763): Bakonybél, [Csesznek:] Gézaháza, Gyulafirátót, Németbánya (Zombori 1973), Pápa (Roller and Haris 2008), Cserszegtomaj: Várvölgyi street (HARIS 2019). Sporadic. Parasitoid of Semanotus unduatus L.

Orussus unicolor Latreille, 1812: Vállus (ZOMBORI 1973), Devecser (RoLLER and HARIS 2008). Rare.

\section{Changes in the sawfly fauna of the Bakony Mountains and the Balaton Uplands}

This year, approximately 2000 specimens were identified and the remaining 7000 specimens were checked. Several groups needed total reidentification. One of them is genus Tenthredopsis Costa, 1859, reidentificaiton is based on the work of BLANK and RITZAU (1998); these results were already published in HARIS and GYURKOVICS, 2014 and these data were taken over to this paper, replacing the outdated original identification of ZOMBORI, 1980. The arcuata group of genus Tenthredo was fully reidentified either based on TAEGER, 1988, also the genus Rhogogaster, based on TAEGER, 2015 and the whole subfamily of Nematinae based on ZHELOCHOVTSEV, 1988 (this revision was already published by HARIS, 2001). In this way, from the original 269 names of ZOMBORI, 1973, 1979, 1980 and 1982, 20 names and species were cancelled (some of them were already published in HARIS, 2001). With the new records, the number of species is increased up to 358 species (109 species are newly added).

\section{Evaluation of the sawfly fauna}

\section{Dominant species}

In the Zirc collection, (7075 specimens), 4 species were collected with more than 200 specimens. These are: Athalia rosae (Linné, 1758) (586 specimens), Macrophya montana (Scopoli, 1763) (208 specimens), Tenthredo notha Klug, 1817 (279 specimens) and Macrophya albicincta (Schrank, 1776) (255 specimens). This 4 species amounts 19\% of the total material; $40 \%$ of the total material consists only the 15 most frequent species (collected more than 100 specimens of each). These species are: the four species mentioned above and Eutomostethus ephippium (Panzer, 1798), Athalia ancilla Serville, 1823, Athalia cordata Serville, 1823, Athalia circularis (Klug, 1815), Tenthredopsis tarsata (Fabricius, 1804), Pachyprotasis rapae (Linné, 1767), Aglaostigma aucupariae (Klug, 1817), Aglaostigma fulvipes (Scopoli, 1763), Tenthredo mesomela Linné, 1758, Tenthredo zonula Klug, 1817 and Arge melanochra (Gmelin, 1790).

\section{Rare species}

From the total 358 species, 62 species are rare (rare means: less than 10 specimens were captured in the last 160 years, since the Hymenoptera collecting is intensive in Hungary). It is $17 \%$ of the total number of the species.

Blasticotoma filiceti Klug, 1834: Fenyőfö, around Kisszépalma, 25-31. 05. 1965, 1 female. This was the only specimen in Hungary collected till 2010, when 2 females were captured in Somogy county, in Szenta and Berzence. Other places of capture from the Carpathian Basin: Körmöci hegység (Körmöci Mountains), Királyhágó, Uglya: Kvasznij patak, Tiszaborkút. Host ferns are Athyrium filix-femina, Matteuccia struthiopteris, Dryopteris spp., Polystichium sp., Pteridium aquilinum. Known from Austria, 
Switzerland, Czech Republic, Germany, Denmark, Finland, France, Great Britain, The Netherlands, Poland, Russia, Sweden, Slovakia and Ukraine (Fig. 14).

Aprosthema humeratum (Konow, 1892): Veszprém: 1 female, 23 August 1972. Known from Austria, Croatia, Czech Republic, Hungary, Italy, Slovakia and Spain. From the Carpathian Basin, we have records only from Mecsek: Zobák and Čajkov near Levice (Csejkö), there is also an indefinite record from Croatia.

Aprosthema instratum (Zaddach, 1895): Balatonudvari, 09. 05. 1976, 1 male. In the Carpathian Basin, all places of captures are from Hungary, namely Pécel, Felsőtárkány, Debrecen and Balatonudvari. We have also an indefinite record from Croatia. It occurs only in Germany, Croatia and Hungary.

Aprosthema intermedium (Zaddach, 1864): Occurs only in Debrecen, Felsőtárkány, Pécel and Balatonudvari in Hungary. We have 2 additional records from Transylvania: Bélbor (Bilbor) and Ponoare. It is recorded in Hungary, Romania, Denmark, Germany, Latvia, Lithuania, Russia and Ukraine.

Aprosthema konowi (Mocsáry, 1891): Balatronudvari, 09. 05. 1976, 1 female, Hidegkút, 1 male, no further data. Known from Balatronudvari, Hidegkút Budakeszi, Hüvösvölgy, Buda, and Szigetbecse in Hungary. From the Carpathian Basin, it is also recorded in Székelykeresztúr (Cristuru Secuiesc), Nagyenyed (Aiud) and Szerbkeresztúr (Srpski Krstur). It occurs also in Germany and Italy.

Arge frivaldszkyi (Tischbein, 1852): Tihany: Külső-tó, 07. 05. 1983, 1 female. Out of Tihany, from Hungary, this species is known from Simontornya, Gellérthegy, Sukoró, Martonvásár, Vértes: Gém hegy and Diósd. Few specimens were captured in Slovakia: Štúrovo (Párkány), Kamenica nad Hronom (Garamkövesd) and Fačkovské sedlo (Facskói hágó). It is recorded in Albania, Bulgaria, Greece, Hungary, Macedonia, Romania, Slovakia and Ukraine.

Spinarge metallica (Klug, 1834): Zirc (MocsÁRY 1900). This is the only known record from Hungary. The voucher specimen is lost. From the Carpathian Basin, we have records from Vihorlat-Remet'ské Hámre: 4 males 8 females, 15 July 1969 and one old female from Tusnád (19th century) is deposited in the Budapest collection. Further known localities: Dicsőszentmárton (Tirnaveni), and Korytnica. It occurs in Europe, except Scandinavia.

Neurotoma mandibularis (Zaddach, 1866): Balatonfüred, 19. 04. 1981, 1 female. In Hungary, it is also known from: Simontornya, Egyek, Ohat and Öriszentpéter: Bárkás-tó. Other records from the Carpathian Basin: Kamenica nad Hronom (Garamkövesd) Borosjenő (Ineu) and Hriňová (Herencsvölgy). Rare European species.

Pamphilius marginatus (Serville, 1823): Eplény: Malomréti-völgy, 23. 05. 1978, 1 female. Known distribution in Hungary: Budapest, Aggtelek, Perkupa, Szin, Mecsek hgs.: Takanyó völgy. Rare European species.

Pamphilius pallipes (Zetterstedt, 1838): Ugod, 10. 05. 1973, 1 female. In Hungary, it is captured only in Budapest, Komjáti and Perkupa. Also known from Piesting, Turzovka (Turzófalva), Polonina Rovna, Feketehegy (Cserno Gora) and Rivna. Rare European species. 
Pseudocephaleia praeteritorum (Semenov, 1934) The species is known from Albania, Azerbaijan, China, Croatia, Italy, Romania and Turkey. Only 3 specimens are known from the Carpathian Basin so far, one female from Vászoly (North of Lake Balaton) collected on 23rd April 1984, one female from Borosjenő (Ineu, West Transylvania) collected on 10th April 1921 and 1 female from Jestice (Jeszte): Nagy-Somos, 3rd May 2019.

Trichiosoma latreillii Leach, 1817: Rare Palaearctic species. In the Carpathian Basin, out of Hungary, we have record from Orsova (Orsova: Alion: 7 May 1995), and indefinite record from Slovakia. In Hungary, known from Bakonybél: Hubertlak: 2 males, 11 May 1964, Veszprém: Tekeres-völgy: 1 male, 10 August 1965, and 1 female from Simontornya.

Trichiosoma vitellina (Linné, 1760): The only known specimens from Hungary captured in Bakonybél: Hubertlak: 1 male, 8-10 June 1964. We have further records from Sninský kameň (Szinnaikő): 2 males, (19th c.), Vályalunga: 1 female, Gorgota (Valea Lunga: Gorgota): 1 female, 3rd May 1968, and 1 male from Retyezát (Mt. Retezat) 19th c. Rare Palaearctic species (Fig. 12).

Dolerus (Achaetoprion) pachycerus Hartig, 1837: Tihany: Külső-tó, 09. 05. 1957, 1 male. Only few specimen are known from Hungary: Budapest: Rákos, Simontornya, Kőszeg, Veresegyház, Szentendre and Csepel (part of Budapest). Also known from Humenné (Homonna), Viničky (Szöllőske), Nagyszeben (Sibiu), Cernegura and Cracaoani. It is widely distributed, rare, North and Central European species.

Dolerus (Poodolerus) blanki Liston, 1995: Tapolca, 11. 03. 1990, 1 male. From Hungary, it is reported from Szeged, Fehértó, Kis-Balaton: Zala part, Darány and Kaposvár: Tókaji-parkerdő. Other records from the Carpathian Basin: Humenné (Homonna), Hátszeg (Hateg), Tasnád (Tasnad), Peér (Pir), Nagyszeben (Sibiu), Magura, Vízakna (Ocna Sibiului), Szenterzsébet (Gusterita), Pöltinis (Paltinis), Gyilkos-tó (Lacu Rosu), Fogaras (Mt. Fagaras), Szinája (Sinaia) and Ogulin. Occurrence: temperate and Northern Europe.

Dolerus (Equidolerus) pratensis (Linné, 1758): Bakonybél: Vörös János-séd, 21. 05. 1959, 1 female, Lesenceistvánd, láprét, 04. 05. 1973, 1 male and Tihany, 10. 04. 1987, 1 female. Originally sporadic species. It has not been captured in Hungary in the last 40 years. In this period, hardly any specimens were collected even in the Carpathian Basin, except one, near Bratislava.

Dolerus (Poodolerus) varispinus Hartig, 1837: From Hungary, only known from the Bakony Mountains. Porva: Pálihálás, Kővágóörs and Gyulafirátót: Kálvária-domb. From the Carpathian Basin, we have further records from Devínska Kobyla (Pozsony: Dévény), Rovná hol’a-Luková (Lukó), Trebusafejérpatak (Dilove), Loučka, Palačov and from the Szörényi érchegység (Muntilor Semenic). Central and Northern European species.

Aneugmenus fuerstenbergensis (Konow, 1885): In Hungary, only known from Fenyőfö, 03. 05. 1974, 1 female. Other records from the Carpathian Basin: PoianaTeiului (Piatra Nemat): 1 female, 19 Aug. 1959, Bicaz baraj 19 June 1960, Pingarati, 5 july 1960 and also known from Leithagebirge b. Admont. Rare, Palaearctic species. 
Aneugmenus temporalis (C. G. Thomson, 1871): Uzsa, 02. 09. 1958, 1 female. From Hungary, we have records from the Kőszegi Mts. and Mátra Mts.: Gyepes-völgy. Further records from the Carpathian Basin: Malé Ozorovce (Kisazar), NPR Turková (nat. res. at Feketevág), Nagymuzsaj (Muzhievo), Berlebán (Kosztilevka), Karánsebes (Caransebes): Borló (Borlova) and it is also recorded in NE Croatia.

Strongylogaster macula (Klug, 1817): The only known specimen from Hungary: 1 female, 30. 05. 1974, Zirc: Pintér-hegy. We have further records from the Carpathian Basin from Javorina (Balázsvágás), Mošovce (Mosóc), Rovná hol'a-Luková (Lukó), sedlo Javorie (Jávori-hágó), Görgény (Gheorgheni), Nagyszeben (Sibiu), Fogarasihavasok (Mt. Fagaras), Vöröstornyi-szoros, Tiszabogdány, Brebenyeszkul (Bogdan), Jičina, Tatranská Lomnica (Tátralomnic) - Štart, Sekule (Székelyfalva), Ivó: Ivó-patak (Izovare), Zeteváralja (Sub Cetatea): Szencsed patak and Tusnádfürdő.

Strongylogaster xanthoceros (Stephens, 1835): Fenyöfö, 03. 05. 1974, 1 male and one other male from the same place but on 04. 05. 1974. Also known from Darány and Tarany in Hungary. Further records from the Carpathian Basin: Mošovce (Mosóc), Ihelník, Magura, Nagyszeben (Sibiu) and Bálványosfüred (Baile Bálványos). Rare, Palaearctic species.

Apethymus cereus (Klug, 1818): [Fenyőfö:] Kék-hegy: 1 female and 1 male, collected on 27 October 1985. We have an other specimen from Budapest: Jánoshegy: 20-22 Sept. 1917. Other specimens from the Carpathian Basin: Vinosady (Csukárd-Terlény): 5 males and 2 females, 10 Oct. 1996, Ihelník: 1 male, 1 Nov. 1999, and BratislavaPatrónka (Pozsony: Patrónka): 1 male, 15 October 1999. It is known from Austria, Czech Republic, Germany, Hungary, Italy, The Netherlands, Romania, Slovakia and Sweden (Central and Northern European species).

Athalia paradoxa Konow, 1886: Tihany: 1 female, 9 May 1968. Most of the specimens in the Carpathian Basin, were collected from Hungary. We have also specimens from Budaörs and Zamárdi-Felső. Other records from the Carpathian Basin: Trenčín (Trencsén), Békás (Izvoru Muntelui Mts.) and an indefinite 19th century record from Croatia. It is a rare, Central and South European species.

Empria hungarica (Konow, 1895): One male captured in Köveskál on 05. 05. 1992. Other records from Hungary: Simontornya, Hármashatár-hegy, Budakeszi, Ócsa, Jósvafö, Lébény and Ádánd. Also we have records from Neusiedler See, Štúrovo (Párkány), Devínska Kobyla (Pozsony: Dévény), Mehádia, Arad, Krassó-Szörény (Caras-Severin), Szenterzsébet (Gusterita), Tiszabogdány, Brebenyeszkul (Bogdan), Zeteváralja (Sub Cetatea): Szencsed-patak and Homoródfürdő (Baile Homorod). Rare, European species.

Monostegia analis (Konow, 1887): Zalaszántó: Tátika-erdő, 13. 08. 1966, 3 females; [Zirc:] Pintér-hegy, 04. 08. 1973, 1 female, Borzavár, 03. 08. 1979, 1 female. Collected by Sándor Tóth and László Berczi. New record for the Carpathian Basin. It was described from Croatia. Out of Croatia, it is reported only from Turkey.

Claremontia uncta (Klug, 1816): Királyszállás: Barok-völgy, 07. 05. 1974, 1 female and Fenyőfö, 01. 05. 1983, 1 female. Further Hungarian records available from Aggtelek, Dobogókő and Ócsa. Places of capture in the Carpathian Basin: Hriňová (Herencsvölgy), 
Javorina (Balázsvágás), Limbach (Limpak), Mošovce (Mosóc), Štefanová (Istvánkirályfalva) Ihelník, Lúka (Vágluka), Bystrá (Szentiván)-sedlo Javorie (Jávori hágó), Rovná hol'a, Tiszabogdány, Brebenyeszkul (Bogdan), Trebusafejérpatak (Dilove) Pieniny Mts., Nový Jičín, Tatranská Lomnica (Tátralomnic) - Štart and Retyezát (Mt. Retezat). European species.

Stethomostus funereus (Klug, 1816): Kiliántelep: Balatonpart, 15. 08. 1974, 1 male. We have other records from Hungary from Darány, Aggtelek, Tákos, Fehértó, Látrány, Szeged, Pákozd and from the bank of River Zala. Further records from the Carpathian Basin: Leithagebirge, Číčov (Csicsó), Syarínske lúky (Liptóújvár: Svarín), Nagyszeben (Sibiu) and Mníchova lehota (Barátszabadi).

Hoplocampoides xylostei (Vallot, 1836): Bakonybél: Arborétum, galls were collected on 16. 06. 1964 on Lonicera xylosteum. Other records from the Carpathian Basin: Bystrá (Hegyesbisztra)-sedlo Javorie (Jávori-hágó): old galls, 21 June 2005, Svarínska dolina: old galls, 19 June 2005, Gleboka-Felsztyn: 15 May 1897-98, it is also reported from Dobšiná-l'adová jaskyňa env. and Hargita: Tolvajos patak. Evaluation: Food plants (several Lonicera species) are common in the Carpathian Basin; however distribution of $H$. xylostei is restricted to few submontane or montane localities. Distribution: Europe and Armenia.

Periclista (Periclista) lineolata (Klug, 1816): Zirc: forest, 18. 05. 1972, 1 female. Further records from Hungary: Simontornya, Cekeháza, Balk and Vése: Csöpröndi forest. Occurences in the Carpathian Basin: Ihelník, Ivano-Frankivska obl., Podcetrtek, Bílé Karpaty: National Reseve Čeretoryje, National Reserve Hutě. European species.

Profenusa thomsoni (Konow, 1886): Known from Csesznek: 1 female, 20 Aug. 1976, this is the only Hungarian specimen. Other records from the Carpathian Basin: Jeselnyica (Eselnita), Ogradena, Bezirk, Mehedinc (Mehedinti) and Radziechowy k. Zywca. Holarctic, rare species.

Metallus albipes (Cameron, 1875): Tihany: Csúcs-hegy, 22. 06. 1967, 1 female. Out of this specimen, it was captured only in Budapest: Kamara-erdö, Nagybugac and Kapuvár. Other records from the Carpathian Basin: Trojačka and Tatranska Lomnica (Tátralomnic). Palaearctic species.

Macrophya (Macrophya) carinthiaca (Klug, 1817): Porva: Páskom, 31. 05. 2008, 1 female. Sporadic in the Carpathian Basin, but rare in Hungary. We have records from Budapest, Visegrád, Örszentmiklós, Csepel and Pilisszántó.

Rhogogaster (Rhogogaster) punctulata (Klug, 1817): Pénzesgyőr , 21. 05. 1974, 1 male and 1 female. It isn't rare in the Carpathian Basin, but in Hungary rare. Known places of capture in Hungary: Bükk Mts.: Nagymező, Bélapátfalva and Nagyvisnyó. Palaearctic.

Tenthredo (Tenthredella) bipunctula Klug, 1817: Sporadic in the Carpathian Basin, but rare in Hungary. We have one specimen from Németbánya: Vadászház, 29. 05. - 02. 06. 1967, 1 female. The other specimens from Hungary were collected from the Bükk Mountains: Németbánya, Miskolc, Nagyvisnyó, Szilvásvárad and Szalajka. European species. 
Tenthredo (Tenthredella) ferruginea Schrank, 1776: Bakonybél: Hubertlak, 8-10. 06. 1964, 1 male. Out of this specimen, we have records from Tiszaalpár, Köszegi hgs., Bükk: Moldva-völgy, Nagyvisnyó, Répáshuta and Szögliget. It is rare in Hungary and sporadic in the Carpathian Basin. Palaearctic species.

Tenthredo (Tenthredella) moniliata Klug, 1817: Out of the Bakony Mountains (Hidegkút), we have records from the Bükk Mountains (Miskolc, Nagyvisnyó) and from the Mátra Mountains (Gyöngyös: Kékes-tetö). Sporadic in the Carpathian Basin, but rare in Hungary. Palaearctic species.

Tenthredo (Elinora) sabariensis (Mocsáry, 1880): Szombathely: 1 specimen from the 19th century, Tapolca: Szent György-hegy: 2 females, 10 Aug. 1993 and Tihany, 12. 07. 1978, 1 female. Rare species. So far, only these 3 specimens are known from Hungary. Further records from the Carpathian Basin: Záhorie: 1 female coll. in late 20th c., Zaleszczyki: 1 female, 11 July 1928, Alsókarácsonfalva (Carciunelu de Jos): 1 female, 31 May 1992; also known from Winden a. Neusiedlersee, Zurndorf, Tulcea, Mt. Rarau and Oniscani. Central and South Europaean species (Fig. 15).

Anoplonyx destructor Benson, 1952: Zirc: Pintér-hegy, 1 female, 15.05.1976. This is the only record from Hungary and also from the Carpathian Basin. Rare Palaearctic species. Further records from the Carpathian Basin: PR Vršatské bralá-Vrš. Podhradie (Oroszlánkő): 2 males and 1 female, 19 April- 8 May 2003, Tatranské Zruby (Tátraotthon): 1 male, 15 May 2007.

Anoplonyx ovatus (Zaddach, 1883): The only known Hungarian specimen: Bakony: Cuha-völgy, 1 female, 23.05.1957. Further records from the Carpathian Basin: PR Vršatské bralá-Vrš. Podhradie (Oroszlánkő): 2 males and 1 female, 19 April- 8 May 2003, Tatranské Zruby (Tátraotthon): 1 male, 15 May 2007. Rare, Palaearctic species.

Cladius (Trichiocampus) ulmi (Linné, 1758): Tihany: Kis erdő-tető, 26. 04. 1983, 1 female. From Hungary, it is known from Dunaörs, Simontornya, Lébény and Szigetköz. Other records from the Carpathian Basin: Jakubov (Nagyjakabfalva), Marosgombás (Gimbas), Nagyszeben (Hermannstadt), Sibiu, Mehádia, Nagylankás (LuncavitaCetatuie), Krassó-Szörény (Caras-Severin), Tökös (Tikves), Stolarzówka-Pieniny and Jasenová (Jaszenova-Alsójeszenő). Palaearctic species.

Dineura stilata (Klug, 1816): [Bakony:] Gerence-völgy, 11. 05. 1958, 1 male, Bakony: Mogyorós-kert, 12. 05. 1957, 1 female. Other Hungarian records: Budapest: Hárs-hegy, Nagyvisnyó, Bálvány, Bükk. Also known from Devínska Kobyla (Pozsony: Dévény), Ihelník, Sambor region, Szvidovec hg., Podcetrtek, PR Vršatské bradlá (Oroszlánkő) and Vel'ký Blh (Vámosbalog). It is a rare, European species.

Nematus brischkei Zaddach, 1876 (= Craesus brischkei Zadd.): Eplény: Malomrétivölgy: 1 female, 8 May 1974; it is also reported from Simontornya, Herkulesfürdö and Krassó-Szörény (Caras-Severin). Known from Austria, Belgium, Croatia, Czech Republic, France, Germany, Great Britain, Hungary, Lithuania, Poland, Romania, Russia and Switzerland.

Euura fagi (Zaddach, 1876): Cserszegtomaj: Várvölgyi road, 22. 05. 1991, 1 female (HARIs 2019). From Hungary, this species is known from Ómassa, Börzsöny Mts.: Széna 
patak and Bükk Mts.: Nagyvisnyó. It is also known from Limbach (Limpak), Nagyszeben (Sibiu), from the Ukrainian Carpaths, Nevicke, Mts. Sar: Brezovicza, Loučka, Jičina, NPR Šomoška (Somoska), PR Vršatské bradlá (Oroszlánkő) and Rača (Récse). European species.

Euura laeta (Brischke, 1883): Bakony (AmBrus 1978). Known Hungrian occurences: Sopron: galls, coll. in 1956-57, Bakony: Bakonybél: galls in July (no further data). From the other parts of the Carpathian Basin, it is reported only from Virful Nemira and Hodlsavice. This rare species known only from Austria, Czech Republic, Denmark, Germany, Poland and Russia.

Euura mucronata (Hartig, 1837): [Csesznek:] Bakony: Kö-árok, 1 female, 21. 05. 1957.; [Csesznek:] Gézaháza, 1 specimen, 15. 05. 1976 (HARIs 2001) and we have an additional Hungarian record from Sopron (AmBrus 1958). Rare in Hungary, but we have numerous records from the Carpathian Basin. European species.

Euura venusta (Brischke, 1883): Fenyőfö, 6 males, 25-31. 05.1965 and Zirc: Szarvaskút, 1 female, 06. 06. 1974 (Haris 2001). Out of the Bakony Mountains, only galls were collected in Sopron (AmBrus 1958). Further records from the Carpathian Basin: Kriváň Mt. env.-Jamy Mt., Brassó (Brasov), Zakarpatskaya oblast, Loučka, Bezkyd and Jičina. European species.

Euura trautmanni (Enslin, 1919) (= Amauronematus trautmanni Ensl.): [Csesznek:] Bakony: Kö-árok, 1 female, 21.05.1957.; Németbánya, 1 female, 21.05.1970. Rare in Hungary and also in the Carpathian Basin. Further records from Hungary: Bükk: Kurtabérc and Látrány. We also have some records from the Carpathian Basin, namely from Brebenyeszkul, Karst Mts., Tatranská Lomnica (Tátralomnic) - Štart and Zeteváralja (Sub Cetatea): Szencsed-patak. Central, Western and North European species.

Euura imperfecta (Zaddach, 1876)(=Pachynematus imperfectus Zadd.): Zirc: Pintérhegy, 1 female, 15 May 1976. In Hungary, recently an other sepcimen was also captured: Somogytúr: Túri-erdö, 15. 04. 2018, 1 female. Other records from the Carpathian Basin: Kozí chrbát-Pol'ana Mts (Kecskehát): 1 female, 11 May 1999, Királymező (UstTschorna): 2 females, 4 May 1963. Rare, Palaearctic species, associated with Larix spp.

Euura oblita (Serville, 1823) (= Phyllocolpa oblita Serv.): Rare in Hungary, only galls were collected in the 60's from Gyenesdiás. Other records from the Carpathian Basin: Belušská Slatina-Rohatín Mt., Púchov-Váh env., Porúbka-Turský potok, SoblahovTrenčín (Trencsén), Č́ícov (Csicsó), Demänovská slatina (Demén-völgy), Ukrainian Carpaths, Trojačka, Val. Meziříčí and Csetate Boli. European species.

Euura albipennis (Hartig, 1837) (= Polynematus albipennis (Hartig, 1837)): Records from the Carpathian Basin: Tihany: 3 females, Sept, 1929, Szolnok: Tisza (River Theis) bank: 1 female, 27-29 Aug. 1957, Szinaja (Sinaia): 1 male, 16 July 1963, Nagyenyed (Aiud): 1 male, early 20th c.; also known from Fehér (Alba), Arad, Prahova, Szucsáva (Suceava) counties and Budapest. It wasn't collected in the last 50 years.

Euura kriechbaumeri (Konow, 1901) (= Pontania kriechbaumeri Konow, 1901): We have indefinite records only from the Bakony Mts. (Ambrus 1978). This species was 
also recorded in Tátra-Kotlina: Sutova near river Vág, Piešt’any, Trenčín (Trencsén), Liptovský Ján, Svarínska dolina, Prahova, Polish Tatra, Val. Meziř́íćí and Királymező (Ust-Tschorna). Central and South European species.

Pristiphora biscalis (Förster, 1854): Márkó: Menyeke, 12. 05. 1963, 1 male; Tapolca: Szent György-hegy, 08. 05. 1979, 1 male. In the Carpathian Basin, it is reported from Gánt, Ivanka pri Dunaji (Pozsonyivánka), Devín-NPR Devínska Kobyla (Pozsony: Dévény), Hriňová (Herencsvölgy), Mošovce (Mosóc), Pernek, Sološnica (Széleskút), Štefanová (Istvánkirályfalva), Ihelník, Lúka (Vágluka), Magura (Magura-Sibiu) (Scobiola-Palade, 1968), Szeben (Sibiu), Jičina and Kremnica (Körmöcbánya). We have indefinite record from NE Croatia either.

Pristiphora cincta Newman, 1837: Bakony: Cuha-völgy, 23. 05. 1957, 1 male. Not rare in the Carpathian Basin, but it has never been reported from Hungary. Holarctic species.

Pristiphora punctifrons (Thomson, 1871): Bakony: Mogyorós, 22. 05. 1957, 1 female. We have further 3 specimens from Nagykovácsi and Bélapátfalva. Sporadic in Slovakia and Romania. Holarctic species.

Pristiphora thalictri (Kriechbaumer, 1884): Várpalota: Vár-völgy, 05. 04. 1983, 1 male. Other places of capture in the Carpathian Basin: Javorina: 1 male, 4 June 1992; also known from Hainburg, Simontornya, Munkács (Mukachevo) and Klastromalja. Palaearctic species.

Pristiphora fausta (Hartig, 1837): Balatongyörök: Bélap-völgy, 19. 04. 2019, 1 female; other records from the Carpathian Basin: Jakubov (Nagyjakabfalva): 1 female, 15 May 1994, Malacky (Malacka): 1 female, 15 May 1993, Ihelník: 1 female, 25 Apr.-3 May 1999, Pécel: 1 female, 19th c. and Noszvaj: Síkfőkút: 1 female. 13 May 1980. European species.

Cephus infuscatus C. G. Thomson, 1871: We have records from Ábrahámhegy and further Hungarian data from Jósvafó, Szeged and Inárcs. In the Carpathian Basin, this species occurs in Číčov (Csicsó), Malacky (Malacka), Šúr, NPR Devínska Kobyla (Pozsony: Dévény), PR Ostrov Kopáč, Sekule (Székelyfalva). Central and Southern Palaearctic species.

Trachelus tabidus (Fabricius, 1775): Bakonybél: Hubertlak environment, 8-10. 06. 1964, 1 female. From Hungary, it is also known from Egyek, Kiskundorozsma, Szirmabesenyő and Ohat. We have also records from Devínska Kobyla (Pozsony: Dévény), Piriul Doamnei, Voniesci and Bokroshát (Zlatna Greda). West Palaearctic species, it is also reported from the USA.

Tremex alchymista Mocsáry, 1886: Extremely rare species, known only from Hungary, Austria and Romania. Most of the specimens were collected from Hungary, mainly in the Bakony Mountains. These specimens: Rezi: Cseres: Postaút, 12. 05. 2002, 1 female; Balatonalmádi, 13. 06. 1987, 1 male; Várpalota: Vár-völgy, 06. 08. 1968, 1 female and Várpalota: Barok-völgy, May or June, 1969, 1 male. Other records from Hungary: Budapest, Budakeszi, Irsa and Törökkoppány (Fig. 11). 
Tremex magus (Fabricius, 1787): Hévíz, 28. 05. 1967, 1 male. Other Hungarian records: Leányfalu, Szár, Irsa. Further records from the Carpathian Basin: Laxenburg, Jurský Š́r (Jurský Šur) and Slovenské Nové Mesto (Újhely). Rare Central and Eastern European species.

Urocerus augur (Klug, 1803): Csopak, 22. 07. 1977, 1 female and Herend: Bányatelep, 30. 09. 1973, 1 female. So far, we had only one indefinite record from Hungary, therefore, the above mentioned 2 specimens are the first complete published data. From the Carpathian Basin, it was published from Stiffing NE Graz, Burgenland, Revúca (Nagyrőcze), Hronsek (Garamszeg), Varatec, Máramaros (Maramures), Panaci, Rarai, Lotru, Subcarpathia (Zakarpatie), Fuzine, NE Croatia, Spas and Szczyrzyce (Fig.: 10).

Orussus unicolor Latreille, 1812: Vállus, 28. 05. 1964, 1 female and Devecser: Székierdő, 20. 10. 2001, 1 male. Other places of capture in Hungary: Budakeszi, Fényi-erdö, Budapest, Valkó: Szent Pál-hegy. From the Carpathian Basin, we have records in Zádiel (Szádelő), Kamenica nad Hronom (Garamkövesd), Nagyzsuppány (Jupalnic), Herkulesfürdő (Baile Herculanea), Németbogsán (Bocsa Montana) and Oroszvár (Rusovce). Central and South European species, also reported from Algeria.

\section{Deleted species from the fauna of the Bakony Mountains or from the fauna of Hungary and note on some species}

Megalodontes laticeps Konow, 1897: Following the revisions of TAEGER 1998 and 2002, these specimens (from Balatonalmádi and Szentkirályszabadja) run to Megalodontes plagiocephalus (Fabricius, 1804).

Sterictiphora furcata var. melanocephala Panzer, 1799: Invalid name, published by Zombori 1973. It is deleted from the list. These specimens are Sterictiphora angelicae (Panzer, 1799) following the revision of KocH 1988b.

Gilpinia laricis (Jurine, 1807): HaVAs (1897) reported the outbreak of Gilpina laricis in Sóly causing serious damage on Pinus nigra plantation (young forest). His description of larvae doesn't support the identity of this rare species. Therefore Gilpinia laricis (Jurine, 1807) is cancelled from the fauna of Bakony Mts.

Cimbex femorata var. silvarum Fabricius, 1793: Invalid name, published by ZoMBORI 1973. Deleted from the list. It is a colour variation of Cimbex femoratus (Linné, 1758) and cannot be handled separately as distinctive taxon.

Tenthredo arcuata Förster, 1771: Ajka, Bakony: Cuha-völgy, Fenyőfö, [Ugod:] Somberek, Bakonybél, Pálihálás, Zirc (Zombori 1980). Note: All checked specimens from Hungary proved to be T. notha $\mathrm{Kl}$. or T. brevicornis Knw. These specimens are cancelled from the list and moved to T. notha Kl. or T. brevicornis Knw.

Apethymus cerris (Kollar, 1850): [Fenyőfö:] Kék-hegy (RoLleR and HARIS 2008) It is Apethymus cereus (Klug, 1818). The original identification is based on ZoMBORI 1982a. After the reidentification, based on the revision of $\mathrm{KocH}$ (1988a), this specimen run to A. cereus $\mathrm{Kl}$. 
Monostegia cingulata (Konow, 1891). These specimens proved to be partly Monostegia analis (Konow, 1887) and partly Monostegia nigra (Konow, 1896) after the reidentification by using TAEGER (1987). The key of ZOMBORI shall be corrected according to this revision (TAEGER 1987).

Empria alector Benson, 1938: Veszprém (ZOMBORI 1979). This specimen proved to be Empria liturata (Gmelin, 1790) using the key of Zhelochovtsev 1988 and Prous 2012. The key of Zombori shall be corrected according to the recent revisions.

Cephalcia alpina (Klug, 1808): [Csesznek:] Gézaháza (Zombori 1973). Misidentification by Zombori (Zombori 1973). It is Cephalcia arvensis Panzer, 1803. This species is deleted from the Hungarian fauna either.

Pamphilius aurantiacus (Giraud, 1857): Királyszállás: Barok-völgy, Tés (ZoMBORI 1973). LACOURT revised this species. The specimens deposited in Zirc are all Pamphilius ignymontiensis Lacourt, 1973.

Tenthredo acerrima Benson, 1940: Synonym of Tenthredo (Tenthredo) brevicornis (Konow, 1886). Most of the specimen published by ZoMBORI 1980, proved to be Tenthredo (Tenthredo) notha Klug, 1817. This is the commonest Tenthredo species in Hungary and in the Bakony Mts. Identification follows the revision of TAEGER (1988).

Tenthredo schaefferi Klug, 1817: Valid species, unfortunately all specimen published by ZomвORI (1980), proved to be Tenthredo (Tenthredo) notha Klug, 1817 and Tenthredo (Tenthredo) brevicornis (Konow, 1886).

Cladius difformis (Panzer, 1799): ZoMBORI (1982b) discusses this species separated from Cladius pectinicornis (Geoffroy, 1785), however these 2 species are synonyms therefore Cladius difformis (Panzer, 1799) is deleted from the species list, and the specimens moved to C. pecitnicornis Geoffr.

Priophorus pilicornis (Curtis, 1831): It is a synonym of Cladius (Trichiocampus) ulmi (Linné, 1758), therefore this species is deleted from the list, furthermore, this published P. pilicornis is a Cladius (Priophorus) compressicornis (Fabricius, 1804) (earlier Priophorus pallipes Lep.).

Amauronematus fasciatus Konow, 1897: These 2 specimens published by ZomBori (1982b) proved to be Euura fagi (Zaddach, 1876). A. fasciatus Knw. is cancelled from the list.

Euura testaceipes (Zaddach, 1883): The imagoes published by ZoMBORI (1982b) proved to be Euura proxima (Serville, 1823). Galls were published by AmBRUs 1964b.

Nematinus luteus (Panzer, 1805): All published specimens are Nematinus bilineatus (Klug, 1819). N. luteus is cancelled from the list.

Nematus brevivalvis Thomson, 1871: After revision, the specimen from Szarvaskút published in ZomBori (1982b) proved to be Euura viridissima (Möller, 1882). N. brevivalis Ths. is deleted from the fauna of Bakony Mts. (HaRIs 2001). 
Pachynematus montanus (Zaddach, 1883): The specimen published from North Cuha Valley proved to be Pristiphora maesta (Zaddach, 1876). P. montanus Zad. is deleted from the fauna of Bakony Mountains (HARIs 2001).

Pachynematus kirbyi Dahlbom, 1835: It is synonym of Euura clitellata (Serville, 1823). Zombori (1982) listed P. kirby Dhlb. and E. clitellatus Serv. separately.

Pachynematus truncatus Benson, 1948: It is synonym of Euura clitellata (Serville, 1823). Zombori (1982) listed P. truncatus Bens. and E. clitellata Serv. separately.

Urocerus fantoma Fabricius, 1781: Csopak (HARIS 1998). It is a misidentification, based on MóczÁr and Zombori (1973). After the reideintification of this specimen based on QUINLAN and GAULD (1981), this specimen is Urocerus augur (Klug, 1803). The Hungarian key (MóczÁr and ZOMBORI 1973) shall be corrected according to the latest revision.

\section{Acknowledgement}

Author expresses his grateful thanks to Csaba Kutasi, director of Bakony Natural History Museum in Zirc for loaning the material for identification and to András Zámbó for the donation of his landscape photos. 


\section{References}

AchterberG, C. 2013: Hymenoptera in Fauna Europaea version 2.6.2. - http://www.faunaeur.org. last accessed 20th December 2019.

Achterberg, C. van \& B. van Aartsen 1986: The European Pamphiliidae (Hymenoptera: Symphyta), with special reference to The Netherlands.- Zoologische Verhandelingen Leiden 234: 1-98.

Ambrus, B. 1964a: Adatok a Balatonfelvidék és a Bakony flórája cecidiumainak ismeretéhez I. - Folia entomologica hungarica 17: 7-56.

Ambrus, B. 1964b: Adatok a hazai gubacsfauna ismeretéhez V. Tihanyi félsziget zoocecidiumai. - Folia entomologica hungarica 17: 245-264.

Ambrus, B. 1964c: A Zirci Arborétum cecidiumai. - Botanikai közlemények 51(2-3): 87-94.

Balázs, A. and Haris, A. 2019: Sawflies (Hymenoptera: Symphyta) of Cerová vrchovina Upland (South Slovakia) - Natura Somogyiensis 33: 61-74.

Blank, S. M. and Ritzau, C. 1998: Die Tenthredopsini Deutschlands (Hymenoptera: Tenthredinidae) p. $227-$ 246. - In: Taeger, A., Blank, S.M. (ed): Pflanzenwespen Deutschlands (Hymenoptera, Symphyta). Kommentierte Bestandsaufnahme. Deutsches Entomologisches Institut, Verlag Goecke \& Evers, Keltern.

Chevin, H. and Hamon, J. 2010: Inventaire des Hyménoptères Symphytes du département de Haute-Savoie - Bulletin mensuel de la Société Linnéenne de Lyon. 79(9-10): 275-300.

Haris, A. 1998: A Somogy Megyei Múzeum levéldarázs-gyüjteménye (Hymenoptera, Symphyta). - Somogyi Múzeumok Közleményei 13: 275-285.

HaRIs, A. 2001: Revisional list of the Hungarian Nematinae with the description of three new species (Hymenoptera: Tenthredinidae). - Folia entomologica hungarica 62: 95-114.

Haris, A. 2009: Sawflies of the Zselic Hills, SW Hungary (Hymenoptera: Symphyta), - Natura Somogyiensis 15: $127-158$.

Haris, A. 2010: Sawflies of the Vértes Mountains (Hymenoptera: Symphyta). - Natura Somogyiensis 17: 221250 .

Haris, A. 2011: Sawflies of the Börzsöny Mountains (North Hungary) (Hymenoptera: Symphyta). - Natura Somogyiensis 19: 149-176.

HARIS, A. 2012: Sawflies of Belső-Somogy (Hymenoptera: Symphyta). - Natura Somogyiensis 22: 141-162.

HARIS, A. 2018: Sawflies from Külső-Somogy, South-West Hungary (Hymenoptera: Symphyta). - Natura Somogyiensis 32: 147-164.

Haris, A. 2019: Sawflies of the Keszthely Hills and its surroundings. - Natura Somogyiensis 33:107-128.

Haris, A. and Gyurkovics, H. 2014: The genus Tenthredopsis Costa, 1859 in Hungary (Hymenoptera: Symphyta). - Natura Somogyiensis 24: 99-124.

Havas, Á. 1897: A Lophyrus rufus és Lophyrus laricis elterjedése a Dunántúlon - Erdészeti Lapok. 36: 901907.

KocH, F. 1988a: Die palaearktischen Arten der Gattung Apethymus Benson, 1939 (Hymenoptera, Symphyta, Allantinae). - Mitteilungen der Münchner Entomologischen Gesellschaft, München 78: 155-178.

КосH, F. 1988b: Die Gattung Sterictiphora Billberg (Insecta, Hymenoptera, Symphyta: Argidae). Entomologische Abhandlungen. Staatliches Museum für Tierkunde in Dresden , Leipzig 52(2): 29-61.

Liston, A. 1995: Compendium of European Sawflies. List of species, modern nomenclature, distribution, foodplants, identification literature. Chalastos Forestry, Gottfrieding. 190 pp.

MaceK, J. 2012 Sawflies (Hymenoptera: Symphyta) of the Bílé Karpaty Protected Landscape Area and Biosphere Reserve (Czech Republic) - Acta Musei Moraviae, Scientiae biologicae (Brno) 96(2) 2011: 819-896.

Mocsáry, S. 1900: Ordo Hymenoptera. p. 7-113. In: Paszlavsky, J. (ed.): Fauna Regni Hungariae, Regia Societas Scientiarum Naturalium Hungarica, Budapest.

MóczÁr, L., Zombori, L. 1973: Tenthredinoidea - Levéldarázs-alkatúak I. In: Fauna Hungariae, Akadémiai Kiadó, Budapest, 111, 11(2), 128 p.

Prous, M. 2012: Taxonomy and phylogeny of the sawfly genus Empria (Hymenoptera, Tenthredinidae). Dissertationes Biologicae Universitas Tartuensis. 222. Tartu University Press. 180 pp.

Prous, M., Kramp, K., Vikberg, V. \& Liston, L. 2017: North-Western Palaearctic species of Pristiphora (Hymenoptera, Tenthredinidae). - Journal of Hymenoptera Research 59: 1-190.

Quinlan, J. \& Gauld, I. D. 1981: Symphyta (except Tenthredinidae). Hymenoptera. New edition. Handbooks for the Identification of British Insects, London 6(2a): $67 \mathrm{pp}$. 
Roller, L. 1999: Check list of the sawflies (Hymenoptera: Symphyta) of Slovakia. - Entomological Problems 30(2): 37-48.

Roller, L. 2000: First records of Blasticotomidae, Tenthredinidae, Pamphiliidae (Hymenoptera) from Slovakia. - Biologia, Bratislava 55(5): 561-562.

Roller, L. and Haris, A. 2008: Sawflies of the Carpathian Basin, History and Current Research. - Natura Somogyiensis 11: 1-261.

Roller L., Beneš K., Blank S. M., Holuša J., Jansen E., Jänicke M., Kaluza S., Kehl A., Kehr I., Kraus M., Liston A. D., Nyman T., Nie H., Savina H., Taeger A., Wei M., 2006: Contribution to the knowledge of sawfly fauna (Hymenoptera, Symphyta) of the Low Tatras National Park in Central Slovakia. - Naturae Tutela 10: 57-72.

SchedL, W. 1972: Die Pflanzenwespen (Hymenoptera, Symphyta) des Landes-museums Joanneum in Graz. Teil 1: Megalodontoidea, Siricoidea, Orussoidea und Cephoidea. - Mitteilungen der Abteilung für Zoologie und Botanik am Landesmuseum ,Joanneum‘ in Graz, 1(3): 93-110.

SchedL, W. 1973: Die Pflanzenwespen (Hymenoptera, Symphyta) des Landes-museums Joanneum in Graz. Teil 2: Tenthredinoidea: Familie Argidae, Blasticotomidae und Cimbicidae. - Mitteilungen der Abteilung für Zoologie und Botanik am Landesmuseum ,Joanneum‘ in Graz, 2: 39-54.

SchedL, W. 1975: Die Pflanzenwespen (Hymenoptera, Symphyta) des Landes-museums Joanneum in Graz. Teil 3: Tenthredinoidea: Familie Diprionidae. - Mitteilungen der Abteilung für Zoologie und Botanik am Landesmuseum ,Joanneum‘ in Graz, 4: 203-210.

SCHEDL, W. 1980: Die Pflanzenwespen (Hymenoptera, Symphyta) des Landesmuseums Joanneum in Graz Teil 4: Tenthredinoidea: Familie Tenthredinidae, Unterfamilie Selandriinae. - Mitteilungen der Abteilung für Zoologie und Botanik am Landesmuseum ,Joanneum“ in Graz 9(1): 41-52.

SchedL, W. 1976: Untersuchungen an Pflanzenwespen (Hymenoptera: Symphyta) in der subalpinen bis alpinen Stufe der zentralen Ötztaler Alpen (Tirol, Österreich). - Veröffentlichungen Universität Innsbruck, Alpin-Biologische Studien 8: 1-85.

SchedL, W. 1983: Die Pflanzenwespen (Hymenoptera, Symphyta) des Landesmuseums Joanneum in Graz, Teil 5: Tenthredinoidea: Familie Tenthredinidae, Unterfamilie Blennocampinae. - Mitteilungen der Abteilung für Zoologie und Botanik am Landesmuseum ,Joanneum‘ in Graz 30: 65-78.

SchedL, W. 1987: Die Pflanzenwespen (Hymenoptera, Symphyta) des Landesmuseums Joanneum in Graz, Teil 6: Tenthredinidae, Unterfamilie Tenthrediniae. - Mitteilungen der Abteilung für Zoologie und Botanik am Landesmuseum ,Joanneum' in Graz 40: 1-23.

SchedL, W. 2003: Die Pflanzenwespen (Hymenoptera, Symphyta) des Landesmuseums Joanneum in Graz Teil 7: Tenthredinoidea: Familie Tenthredinidae, Unterfamilie Nematinae. - Joannea Zoologie 5: 11-28.

Shinohara, A. and Zombori L., 1997: New pamphiliid sawfly records in the Carpathian Basin (Hymenoptera: Symphyta). - Folia entomologia hungarica 58: 183-185.

TAEGER, A. 1987: Ergänzungen zur Blattwespenfauna Bulgariens und Bearbeitung der Gattung Monostegia O. Costa (Insecta, Hymenoptera, Symphyta, Tenthredinidae). - Faunistische Abhandlungen Staatliches Museum für Tierkunde Dresden 15(1):1-10.

TAeger, A. 1998: Die Megalodontesidae Europas (Hymenoptera: Symphyta) Pflanzenwespen Deutschlands (Hymenoptera, Symphyta) 175-192. - In: Blank, S. M. and Taeger, A. (eds) Kommentierte Bestandsaufnahme Chapter: Die Megalodontesidae Europas (Hymenoptera: Symphyta) Publisher: Goecke \& Evers, Keltern. Pp. 379.

TAeger, A. 1988: Dritter Beitrag zur Kenntnis der Blattwespengattung Tenthredo L. (Hymenoptera: Symphyta: Tenthredinidae) - Beitrage zur Entomologie , Berlin 38(2): 337-359.

TAeger, A. 2002: The Megalodontesidae of Europe (Hymenoptera, Symphyta). pp. 461-480. - In: VIITASAARI, M. Sawflies (Hymenoptera, Symphyta) I. A review of the suborder, the Western Palaearctic taxa of Xyeloidea and Pamphilioidea. Tremex Press Ltd., Helsinki 1: 1-516.

TAEger, A. 2015: European Rhogogaster s. str., with notes on several Asian species (Hymenoptera: Tenthredinidae). - Zootaxa 4013(3): 369-398.

Zhelochovtsev, A. N. 1988: Otryad Hymenoptera - Pereponchatokrylye, Podotryad Symphyta Sidyachebryukhie, 7-234. - In: Medvedev, K. H. (ed.) Opredelitel nasekomykh evropeiskoi chasti SSSR, Vol. 3 Hymenoptera, Part 6, Nauka, Leningrad.

Zoмвori, L. 1968: Egy rendkivül ritka levéldarázs a Bakonyból (Hym.: Blasticotomidae). - Folia entomologica hungarica 21: 335-337.

Zombori, L. 1973: A Bakonyi Természettudományi Múzeum levéldarázs-gyüjteménye (Hymenoptera: Symphyta) I. - A Veszprém megyei múzeumok közleményei 12: 467-475. 
Zomвori, L. 1976: New sawfly species in the Hungarian fauna (Hymenoptera, Symphyta), II. - Annales historico-naturales Musei Nationalis Hungarici 68: 209-213.

Zombori, L. 1977: New sawfly species in the Hungarian fauna (Hymenoptera, Symphyta), III. - Annales historico-naturales Musei Nationalis Hungarici 69: 191-194.

Zomвori, L. 1978b: A Bakony levéldarázs faunájának kutatottságáról (Hymenoptera: Symphyta). - A Veszprém megyei múzeumok közleményei 13: 57-59.

Zombori, L. 1979: A Bakonyi Természettudományi Múzeum levéldarázs-gyüjteménye (Hymenoptera: Symphyta) II. - A Veszprém megyei múzeumok közleményei 14: 211-220.

Zombori, L. 1980: A Bakonyi Természettudományi Múzeum levéldarázs-gyüjteménye (Hymenoptera: Symphyta) III. - A Veszprém megyei múzeumok közleményei 15: 181-188.

Zombori, L. 1982a: Tenthredinoidea - Levéldarázs-alkatúak II. - In: Fauna Hungariae, Akadémiai Kiadó, Budapest, 153, 11(3/A), 144 p.

Zombori, L. 1982b: A Bakonyi Természettudományi Múzeum levéldarázs-gyüjteménye (Hymenoptera: Symphyta) IV. - Folia Musei Historico- Naturalis Bakonyiensis 1: 165-170.

Zombori, L. 1990: Tenthredinoidea - Levéldarázs-alkatúak III. - In: Fauna Hungariae, Akadémiai Kiadó, Budapest, 165, 11(3/B), 81 pp. 